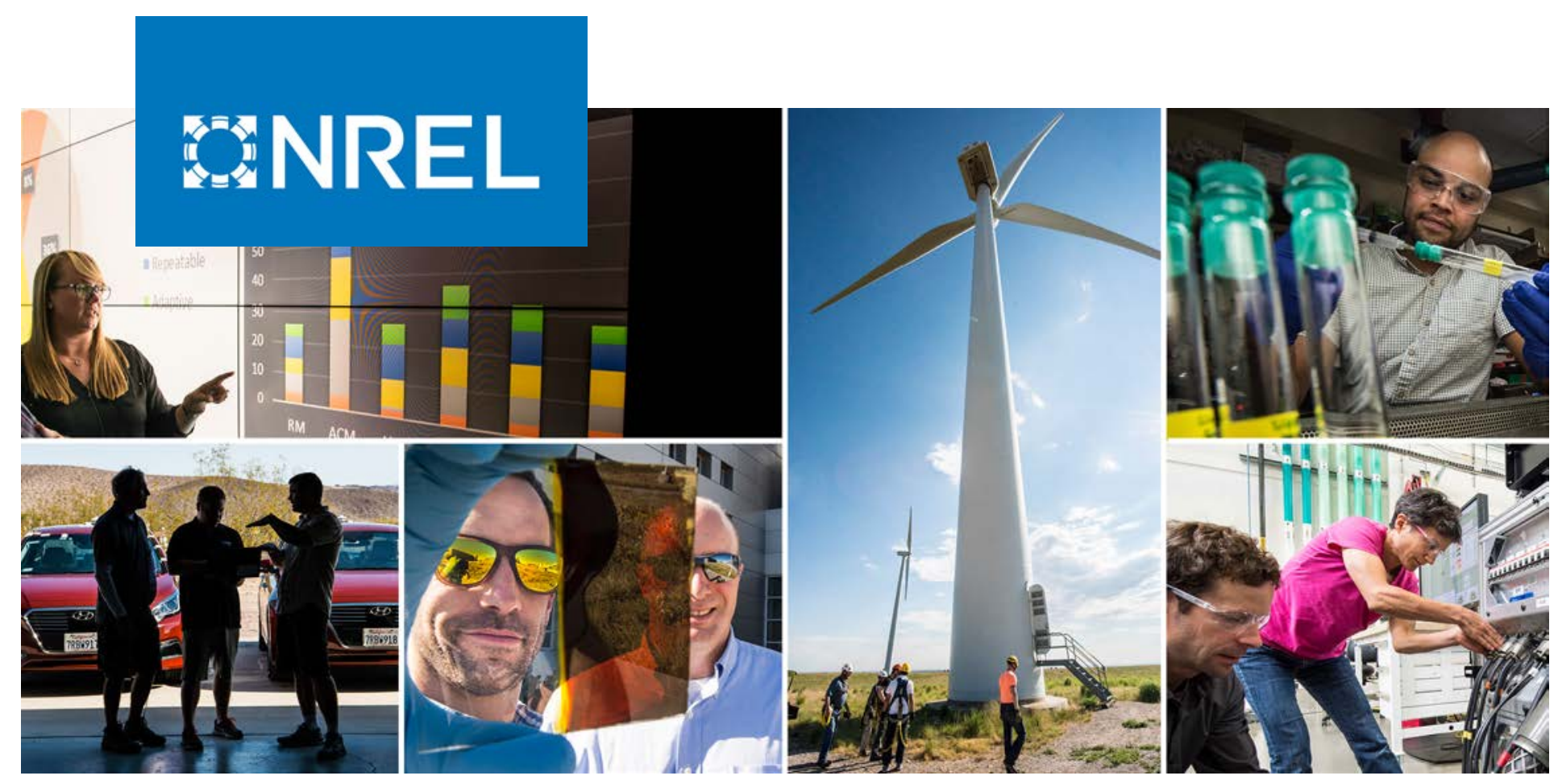

\title{
NREL Pyrheliometer Comparisons: September 24 - October 5, 2018 (NPC-2018)
}

Ibrahim Reda, Mike Dooraghi, Afshin Andreas, and Aron Habte

National Renewable Energy Laboratory

NREL is a national laboratory of the U.S. Department of Energy

Office of Energy Efficiency \& Renewable Energy

Operated by the Alliance for Sustainable Energy, LLC

This report is available at no cost from the National Renewable Energy Laboratory (NREL) at www.nrel.gov/publications.

\section{Technical Report}

NREL/TP-1900-72607

October 2018 


\section{BNREL}

\section{NREL Pyrheliometer Comparisons: September 24 - October 5, 2018 (NPC-2018)}

Ibrahim Reda, Mike Dooraghi, Afshin Andreas, and Aron Habte

National Renewable Energy Laboratory

\section{Suggested Citation}

Ibrahim, Mike Dooraghi, Afshin Andreas, and Aron Habte. 2018. NREL Pyrheliometer Comparisons: September 24 - October 5, 2018 (NPC-2018). Golden, CO: National Renewable Energy Laboratory. NREL/TP-1900-72607.

https://www.nrel.gov/docs/fy19osti/72607.pdf.

NREL is a national laboratory of the U.S. Department of Energy Office of Energy Efficiency \& Renewable Energy Operated by the Alliance for Sustainable Energy, LLC

This report is available at no cost from the National Renewable Energy Laboratory (NREL) at www.nrel.gov/publications.

Contract No. DE-AC36-08GO28308
Technical Report NREL/TP-1900-72607

October 2018

National Renewable Energy Laboratory 15013 Denver West Parkway Golden, CO 80401

303-275-3000 • www.nrel.gov 


\section{NOTICE}

This work was authored by the National Renewable Energy Laboratory, operated by Alliance for Sustainable Energy, LLC, for the U.S. Department of Energy (DOE) under Contract No. DE-AC36-08G028308. Funding provided by U.S. Department of Energy Office of Energy Efficiency and Renewable Energy's Solar Energy Technologies Program and the Atmospheric Radiation Measurement (ARM) Research Facility. The views expressed herein do not necessarily represent the views of the DOE or the U.S. Government.

This report is available at no cost from the National Renewable Energy Laboratory (NREL) at www.nrel.gov/publications.

U.S. Department of Energy (DOE) reports produced after 1991 and a growing number of pre-1991 documents are available free via www.OSTI.gov.

Cover Photos by Dennis Schroeder: (clockwise, left to right) NREL 51934, NREL 45897, NREL 42160, NREL 45891, NREL 48097, NREL 46526.

NREL prints on paper that contains recycled content. 


\section{Acknowledgments}

We sincerely appreciate the support of Solar Radiance Research Laboratory (SRRL) staff and National Renewable Energy Laboratory (NREL) management, the U.S. Department of Energy (DOE) Office of Energy Efficiency and Renewable Energy/Solar Energy Technologies Program, Environmental Research/Atmospheric Radiation Measurement Program, and NREL's Environment, Safety, Health, \& Quality center (ESH\&Q). Our thanks also go to all the participants for their patience and cooperation during this weather-dependent exercise.

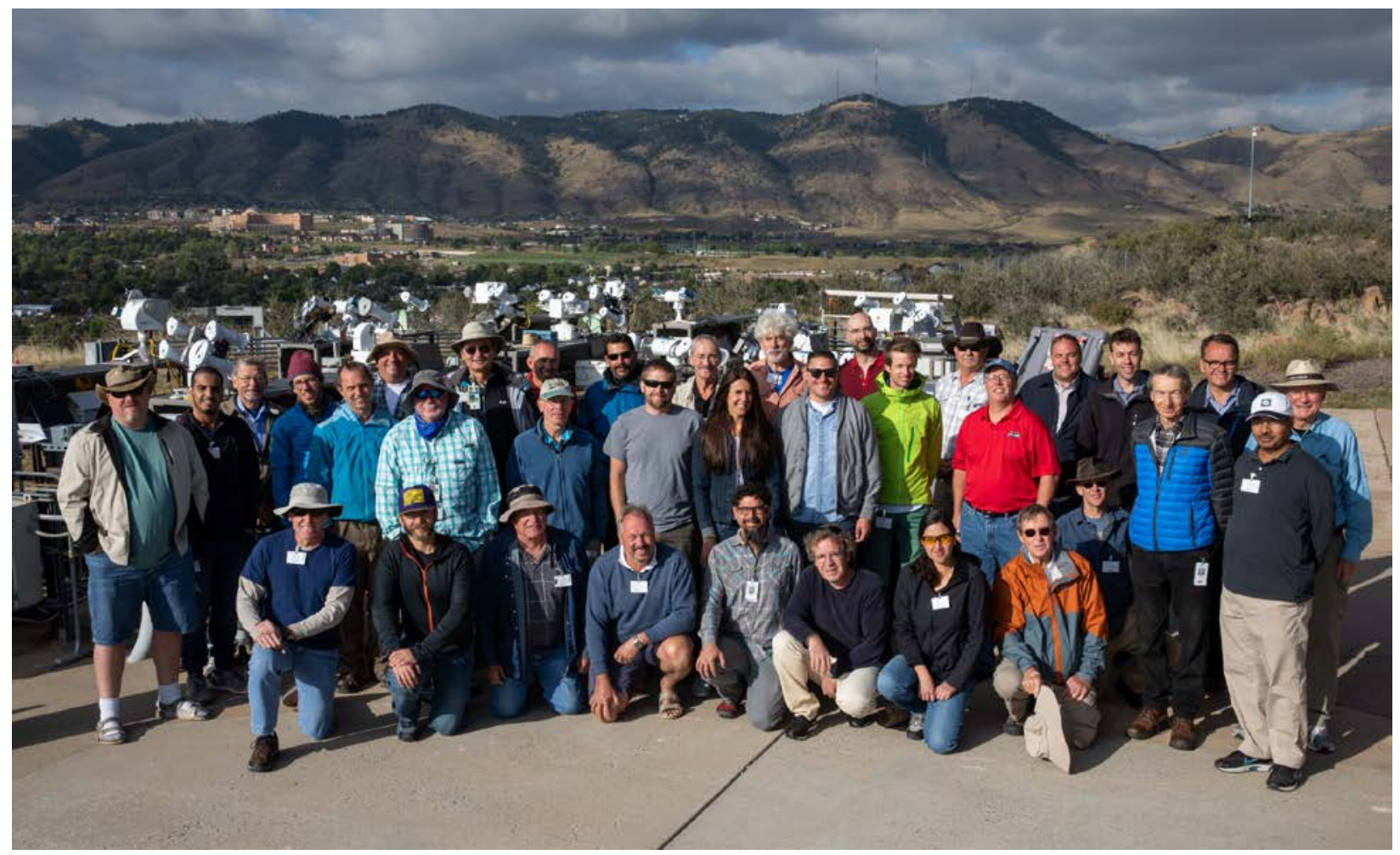

Figure 1. NPC-2018 participants

Photo by Werner Slocum 


\section{List of Acronyms}

\begin{tabular}{|c|c|}
\hline $\mathrm{AHF}$ & Automatic Hickey-Frieden \\
\hline BMS & Baseline Measurement System \\
\hline BORCAL & Broadband Outdoor Radiometer Calibration \\
\hline DOE & U.S. Department of Energy \\
\hline IPC & International Pyrheliometer Comparison \\
\hline IPC-XII & Twelfth International Pyrheliometer Comparisons \\
\hline ISO & International Organization for Standardization \\
\hline MST & Mountain Standard Time \\
\hline NPC & National Renewable Energy Laboratory Pyrheliometer Comparisons \\
\hline NREL & National Renewable Energy Laboratory \\
\hline $\mathrm{PMOD} / \mathrm{WRC}$ & $\begin{array}{l}\text { Physikalisch-Meteorologisches Observatorium Davos-World } \\
\text { Radiation Center }\end{array}$ \\
\hline $\mathrm{SDp}$ & pooled standard deviation \\
\hline SI & International System of Units \\
\hline SRRL & Solar Radiation Research Laboratory \\
\hline TSG & Transfer Standard Group \\
\hline WMO & World Meteorological Organization \\
\hline WRR & World Radiometric Reference \\
\hline WRR-TF & World Radiometric Reference transfer factor \\
\hline WSG & World Standard Group \\
\hline $\mathrm{S} / \mathrm{N}$ & serial number of radiometer \\
\hline$\% \mathrm{uA}$ & Percentage Type-A standard uncertainty \\
\hline NRdg & number of readings \\
\hline $\mathrm{uC}$ & combined standard uncertainty \\
\hline Eff DF & effective degrees of freedom \\
\hline
\end{tabular}




\section{Executive Summary}

Accurate measurements of direct normal (beam) solar irradiance from pyrheliometers ${ }^{1}$ are important for developing and deploying solar energy conversion systems, for improving our understanding of the Earth's energy budget for climate change studies, and for other science and technology applications involving solar flux. These measurements place many demands on the quality system used by operators of commercially available radiometers. Maintaining accurate radiometer calibrations that are traceable to an international standard is the first step in producing research-quality solar irradiance measurements.

In 1977, the World Meteorological Organization (WMO) established the World Radiometric Reference (WRR) as the international standard for the measurement of direct normal solar irradiance (Fröhlich 1991). The WRR is an internationally recognized, detector-based measurement standard determined by the collective performance of six electrically selfcalibrated absolute cavity radiometers comprising the World Standard Group (WSG). Various countries, including the United States,${ }^{2}$ have contributed these specialized radiometers to the Physikalisch-Meteorologisches Observatorium Davos-World Radiation Center (PMOD/WRC) to establish the WSG.

As with all measurement systems, Absolute Cavity Radiometers (ASR) are subject to performance changes over time. Therefore, PMOD/WRC in Davos, Switzerland, hosts an International Pyrheliometer Comparison (IPC) for transferring the WRR to participating radiometers quinquennially by invitation. The National Renewable Energy Laboratory (NREL) has represented the U.S. Department of Energy (DOE) in each IPC since 1980. As a result, NREL has developed and maintained a select group of absolute cavity radiometers with direct calibration traceability to the WRR and uses these reference instruments to calibrate pyrheliometers and pyranometers using the International Organization for Standardization (ISO) 17025 accredited Broadband Outdoor Radiometer Calibration (BORCAL) process (Reda et al. 2008).

To fill the gap between each IPC, NREL pyrheliometer comparisons (NPCs) are held annually at the Solar Radiation Research Laboratory (SRRL) in Golden, Colorado. Open to all ACR owners and operators, each NPC provides an opportunity to determine the unique WRR transfer factor (WRR-TF) for each participating pyrheliometer. By adjusting all subsequent pyrheliometer measurements by the appropriate WRR-TF, the solar irradiance data are traceable to the WRR.

NPC-2018 was September 24 through October 5, 2018. Participants operated 43 ACRs to simultaneously measure clear-sky direct normal solar irradiance during this period. The Transfer Standard Group (TSG) of reference radiometers for NPC-2018 consisted of four NREL radiometers with direct traceability to the WRR, having participated in the Twelfth International Pyrheliometer Comparisons (IPC-XII) in the fall of 2015. As a result of NPC-2018, each participating absolute cavity radiometer was assigned a new WRR-TF, computed as the reference irradiance determined by the TSG divided by the observed irradiance from the participating radiometer. The performance of the TSG during NPC-2018 was consistent with previous comparisons, including IPC-XII. The measurement performance of the TSG allowed

\footnotetext{
${ }^{1}$ Pyrheliometers are a type of radiometer used to measure solar irradiance (i.e., radiant flux in Watts per square meter) on a surface normal to the apparent solar disk within a $5.0^{\circ}$ or $5.7^{\circ}$ field of view, depending on the optical design of the instrument. A solar tracker is used to maintain proper alignment of the pyrheliometer with the sun during daylight periods.

${ }^{2}$ The WSG includes radiometers on permanent loan from the Eppley Laboratory, Inc., and NREL.
} 
the transfer of the WRR to each participating radiometer with an estimated uncertainty of \pm $0.36 \%$ with respect to the International System of Units.

The comparison protocol is based on data collection periods called "runs". Each run consists of an electrical self-calibration requiring five minutes for the Automatic Hickey-Frieden (AHF) cavities, a series of 49 solar irradiance measurements at 30 -second intervals, and a postcalibration. More than 2,300 reference irradiance measurements were collected by the TSG during NPC-2018. Clear-sky daily maximum direct normal irradiance level was $1017 \mathrm{Wm}^{-2}$.

Ancillary environmental conditions (e.g., broadband turbidity, ambient temperature, relative humidity, wind speed, precipitable water vapor, and spectral data) collected at SRRL during the comparison are presented in Appendix B to document the environmental test conditions.

NPCs are planned annually at the SRRL to ensure worldwide homogeneity of solar radiation measurements traceable to the WRR. 


\section{Table of Contents}

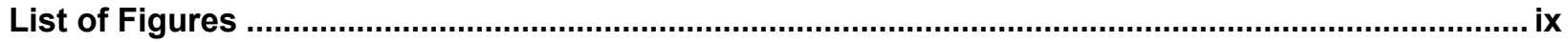

List of Tables

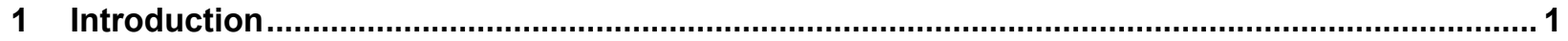

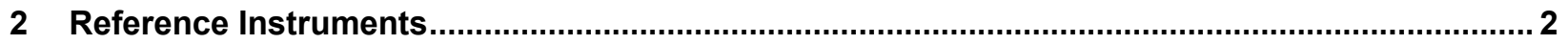

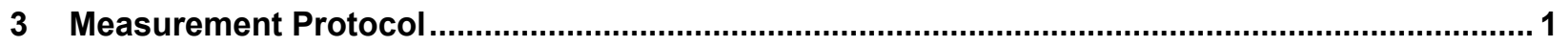

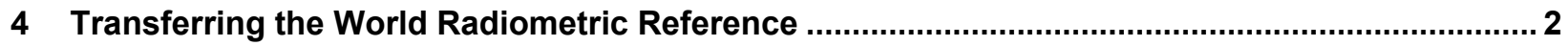

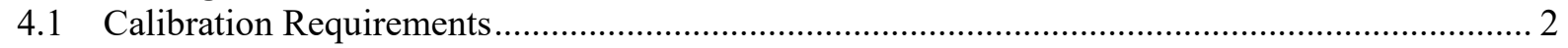

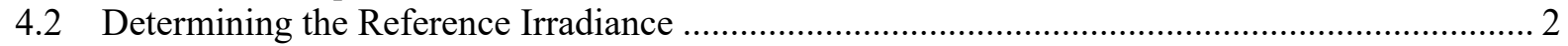

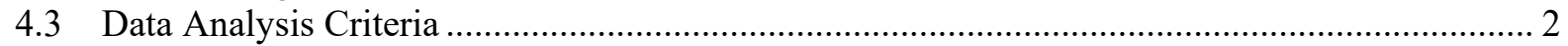

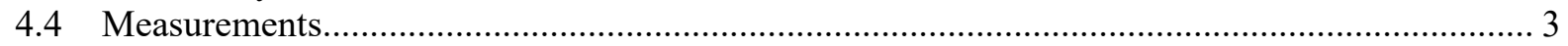

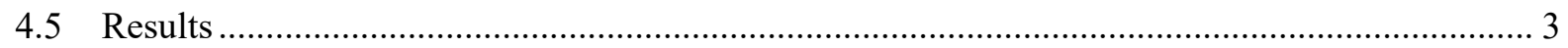

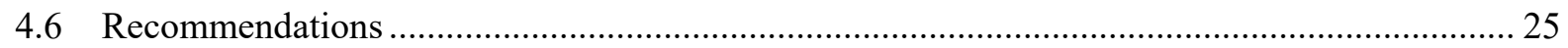

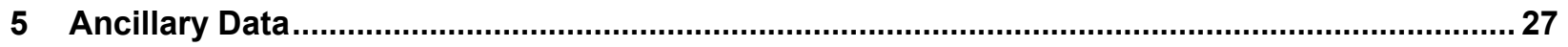

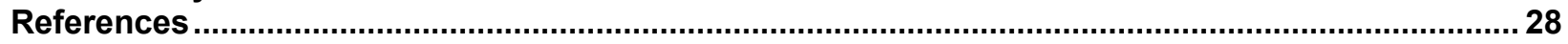

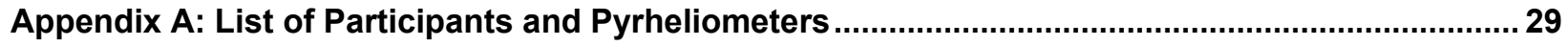

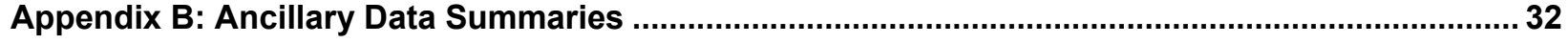




\section{List of Figures}

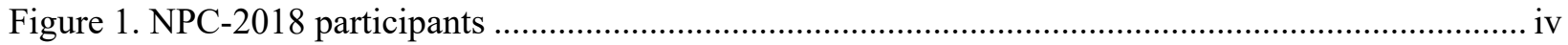

Figure 2. History of WRR reduction factors for NREL reference cavities ............................................ 4

Figure 3. WRR-Transfer Factor vs. Mountain Standard Time (MST) NPC-2018 for AHF 0000 ............... 7

Figure 4. WRR-Transfer Factor vs. MST NPC-2018 for AHF 14915 ................................................. 7

Figure 5. WRR-Transfer Factor vs. MST NPC-2018 for AHF 17142 …............................................ 7

Figure 6. WRR-Transfer Factor vs. MST NPC-2018 for AHF23734 ............................................... 8

Figure 7. WRR-Transfer Factor vs. MST NPC-2018 for AHF 28486 ................................................. 8

Figure 8. WRR-Transfer Factor vs. MST NPC-2018 for AHF28553 …................................................ 9

Figure 9. WRR-Transfer Factor vs. MST NPC-2018 for AHF 28556 .................................................... 9

Figure 10. WRR-Transfer Factor vs. MST NPC-2018 for AHF 28560 …............................................. 10

Figure 11. WRR-Transfer Factor vs. MST NPC-2018 for AHF 29219 - Windowed ................................ 10

Figure 12. WRR-Transfer Factor vs. MST NPC-2018 for AHF 29222 - Windowed ............................... 11

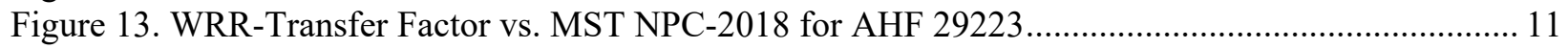

Figure 14. WRR-Transfer Factor vs. MST NPC-2018 for AHF 30110 ............................................ 12

Figure 15. WRR-Transfer Factor vs. MST NPC-2018 for AHF 310495-Window.................................. 12

Figure 16. WRR-Transfer Factor vs. MST NPC-2018 for AHF 31041 .............................................. 13

Figure 17. WRR-Transfer Factor vs. MST NPC-2018 for AHF 31104-Window..................................... 13

Figure 18. WRR-Transfer Factor vs. MST NPC-2018 for AHF 31105 _............................................... 14

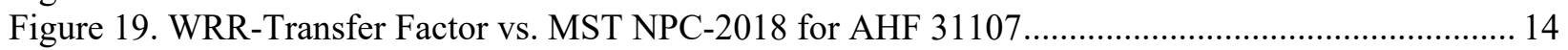

Figure 20. WRR-Transfer Factor vs. MST NPC-2018 for AHF 31108 _............................................... 15

Figure 21. WRR-Transfer Factor vs. MST NPC-2018 for AHF 32452AWX-Window ............................ 15

Figure 22. WRR-Transfer Factor vs. MST NPC-2018 for AHF 31113AWX …..................................... 16

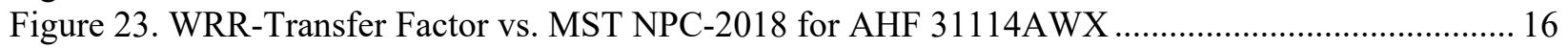

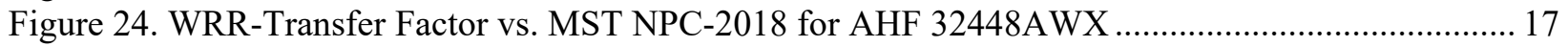

Figure 25. WRR-Transfer Factor vs. MST NPC-2018 for AHF 32455 .............................................. 17

Figure 26. WRR-Transfer Factor vs. MST NPC-2018 for AHF 33392 .............................................. 18

Figure 27. WRR-Transfer Factor vs. MST NPC-2018 for AHF 34926AWX ........................................ 18

Figure 28. WRR-Transfer Factor vs. MST NPC-2018 for AHF 37816 ................................................. 19

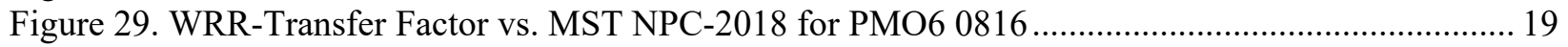

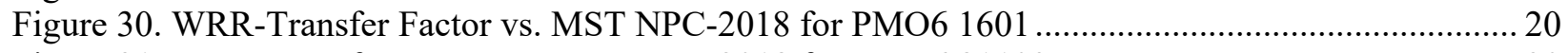

Figure 31. WRR-Transfer Factor vs. MST NPC-2018 for PMO6 81109 ….............................................. 20

Figure 32. WRR-Transfer Factor vs. MST NPC-2018 for PMO6 911204 …......................................... 21

Figure 33. WRR-Transfer Factor vs. MST NPC-2018 for PMO6cc 0103 ............................................. 21

Figure 34. WRR-Transfer Factor vs. MST NPC-2018 for PMO6cc 0401 .............................................. 22

Figure 35. WRR-Transfer Factor vs. MST NPC-2018 for PMO6cc 0803 …......................................... 22

Figure 36. WRR-Transfer Factor vs. MST NPC-2018 for PMO6 1611-Linard-00.................................. 23

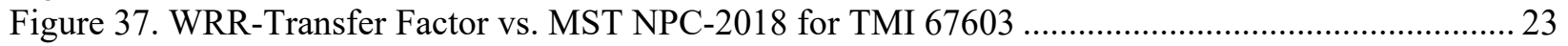

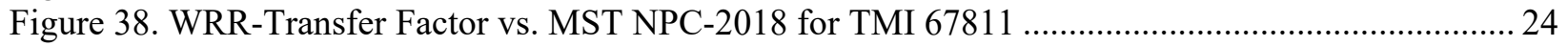

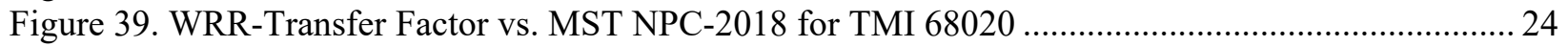

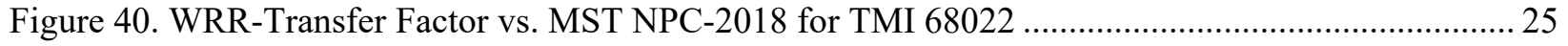

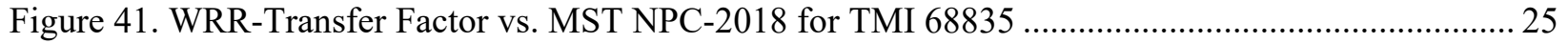

\section{List of Tables}

Table 1. IPC-XII Results Summary for the NPC-2018 TSG ............................................................. 2

Table 2. Summary Results for Proficiency Test During NPC-2018 …................................................... 4

Table 3. Results for Radiometers Participating in NPC-2018 ............................................................. 5 


\section{Introduction}

Accurate measurements of broadband solar irradiance require radiometers with proper design and performance characteristics, correct installation, and documented operation and maintenance procedures, including regular calibration. Calibrations of any measuring device must be traceable to a recognized reference standard. The World Radiometric Reference (WRR) is the internationally recognized measurement standard for direct normal irradiance measurements of broadband solar radiation (Fröhlich 1991).

The WRR was established by the World Meteorological Organization (WMO) in 1977 and has been maintained by the Physikalisch-Meteorologisches Observatorium Davos-World Radiation Center (PMOD/WRC) in Switzerland (www.pmodwrc.ch). This reference is maintained for broadband solar irradiance with an absolute uncertainty of better than $\pm 0.3 \%$ with respect to the International System of Units (SI) (Romero et al. 1996). This standard is widely used to calibrate pyrheliometers and pyranometers with a wavelength response range that is compatible with the solar spectrum wavelengths of 280-3,000 nm. Every five years, the WRR is transferred to WMO regional centers and other participants at International Pyrheliometer Comparisons (IPC) held at the PMOD/WRC. The Twelfth IPC (IPC-XII) was completed in 2015 (Finsterle 2018). At each IPC, instantaneous measurements from the World Standard Group (WSG) are compared at 90-second intervals with the data from participating radiometers recorded under clear-sky conditions. A new WRR transfer factor (WRR-TF) is calculated for each participating radiometer based on the mean WRR of the WSG radiometers for each IPC. Multiplying the irradiance reading of each radiometer by its assigned WRR-TF will result in measurements that are traceable to SI units through WRR and therefore consistent with the international reference of solar radiation measurement.

In compliance with Organization for Standardization (ISO) 17025 accreditation requirements for demonstrating interlaboratory proficiency, the National Renewable Energy Laboratory (NREL) hosts annual pyrheliometer comparisons at the Solar Radiation Research Laboratory (SRRL) in Golden, Colorado, during non-IPC years. The NREL Pyrheliometer Comparisons in 2018 (NPC-2018) was September 24 through October 5, 2018. Participants operated 43 absolute cavity radiometers during the comparisons. See Appendix A for the list of participants and affiliations.

The results presented in this report are based on clear-sky, direct normal solar irradiance data collected during the NPC. See Appendix B for environmental conditions. 


\section{Reference Instruments}

NREL developed the transfer standard group (TSG) of four absolute cavity radiometers to serve as the transfer reference for each NPC. The radiometers comprising the TSG were included in the most recent IPC and maintain the WRR for NREL (see Table 1). Using the method described by Reda (1996), the mean of the TSG measurements was maintained for establishing the reference irradiance data for NPC2018 data reduction. Table 1 provides a list of the TSG absolute cavity radiometers with their WRR-TFs and pooled standard deviation ( $\left.\mathrm{SD}_{\mathrm{p}}\right)$ as determined from the latest IPC in 2015 (Finsterle 2016).

Table 1. IPC-XII Results Summary for the NPC-2018 TSG

\begin{tabular}{|l|l|l|l|}
\hline Serial Number & $\begin{array}{l}\text { WRR Factor } \\
\text { (IPC-XI) }\end{array}$ & $\begin{array}{l}\text { Standard Deviation } \\
(\%)\end{array}$ & $\begin{array}{l}\text { Number of } \\
\text { Readings }\end{array}$ \\
\hline AHF 28968 & 0.99763 & 0.063 & 519 \\
\hline AHF 29220 & 0.99749 & 0.0621 & 523 \\
\hline AHF 30713 & 0.99723 & 0.0639 & 525 \\
\hline ATMI 68018 & 0.99660 & 0.0669 & 522 \\
\hline Mean WRR for the TSG & 0.99724 & SDp for the TSG: $0.06 \%$ \\
\hline
\end{tabular}

The pooled standard deviation, $\mathrm{SD}_{\mathrm{p}}$ for the TSG was computed from the following equation:

$$
S D_{p}=\sqrt{\frac{\sum_{i=1}^{m} n_{i} * S_{i}^{2}}{\sum_{i=1}^{m} n_{i}}}
$$

where,

$\mathrm{i}=\mathrm{i}^{\text {th }}$ cavity

$\mathrm{m}=$ number of reference cavities

$\mathrm{S}_{\mathrm{i}}=$ standard deviation of the $\mathrm{i}^{\text {th }}$ cavity from IPC-XII

$\mathrm{n}_{\mathrm{i}}=$ number of readings of the $\mathrm{i}^{\text {th }}$ cavity from IPC-XII 


\section{Measurement Protocol}

The decision to deploy instruments for a comparison was made daily. Data were collected only during clear-sky conditions, which were determined visually and from the stability of pyrheliometer readings. Simultaneous direct normal solar irradiance measurements were taken by most cavity radiometers in groups of 49 observations at 30-second intervals (PMO6 used 90, 80, or 30-second open/closed-shutter cycles). Each group of observations is called a "run." An electrical self-calibration of each Automatic Hickey-Frieden (AHF) absolute cavity was performed prior to each run. Previous WRR-TFs determined from results of IPCs or NPCs were not applied to the observations. The original manufacturer's calibration factor was used according to the standard operating procedure provided by the manufacturer for each radiometer. A timekeeper announced the beginning of each calibration period and gave a fiveminute countdown prior to the start of each run to facilitate the AHF cavity self-calibrations and the simultaneous start for each participant.

By consensus, at least 300 observations from each radiometer were required to determine the WRR-TF for an NPC. A statistically significant dataset was required to derive the WRR-TF for each pyrheliometer. Data from each pyrheliometer/operator system were emailed at the end of the day. 


\section{Transferring the World Radiometric Reference}

The primary purpose of an NREL pyrheliometer comparison is to transfer the current WRR from the NPC-TSG to each participating absolute cavity pyrheliometer. This requires that the participating pyrheliometers and the TSG collect simultaneous measurements of clear-sky direct normal (beam) solar irradiance. Because the NPC data analysis is intended for absolute cavity pyrheliometers only, users of pyrheliometers other than absolute cavity pyrheliometers might interpret their NPC results differently.

\subsection{Calibration Requirements}

Using WMO guidelines (Romero 1995), the following conditions were required before data collection was accomplished during NPC-2018:

- The radiation source was the sun, with irradiance levels $>700 \mathrm{Wm}^{-2}$.

- A Digital Multimeter with uncertainty $>0.05 \%$ reading or better was used to measure the thermopile signals from each radiometer.

- Solar trackers were aligned within $\pm 0.25^{\circ}$ slope angle.

- Wind speed was low $(<5 \mathrm{~m} / \mathrm{s})$ from the direction of the solar azimuth $\pm 30^{\circ}$.

- Cloud cover was $<1 / 8$ of the sky dome, with an angular distance $>15^{\circ}$ from the sun.

\subsection{Determining the Reference Irradiance}

Four absolute cavity radiometers maintained by NREL and were part of IPC-XII were used as the TSG to transfer the WRR in the comparison. The WRR-TF for each TSG is presented in Table 1 above. The reference irradiance at each reading was calculated using the following steps, as described by Reda (1996):

1. Each irradiance reading of the TSG is divided by the irradiance measured by AHF28968, for its participation in many IPCs.

2. By maintaining the mean of WRR for the TSG, a new WRR-TF for NPC-2018 is recalculated for each of the TSG cavities (see Figure 2).

3. The reference irradiance for each 30-second observation in a run is computed as the mean of the simultaneous reference irradiances measured by the TSG. The reference irradiance reading for each cavity in the TSG is the irradiance reading of the cavity multiplied by its new WRR-TF calculated in Step 2.

\subsection{Data Analysis Criteria}

AHF28968 was used to check irradiance stability at the time of each comparison reading during a run. Stable irradiance readings are defined to within $1.0 \mathrm{Wm}^{-2}$ during an interval of two seconds centered on each reading time (i.e. one second before and one second after the recorded reading). Unstable irradiance readings are marked in the data record and automatically rejected from the data analysis. Historically, this has affected fewer than $10 \%$ of the data collected during an NPC.

Additionally, all calculated ratios of the test instrument irradiance divided by AHF28968 irradiance that deviated from their mean by $0.3 \%$ were rejected (Reda 1996). Typically, data rejected from the analysis in this manner were the result of failed tracker alignment, problems with the pre-calibration, or a similar cause for bias greater than expected from a properly functioning absolute cavity radiometer. 


\subsection{Measurements}

NPC-2018 was completed for most participants on October 4, after more than 2,000 data points were collected by the reference cavities during the requisite clear-sky conditions. The actual number of readings for each participating radiometer compared with the reference irradiance varied according to the data analysis selection criteria described above. Additionally, some instruments experienced minor data loss because a variety of problems occurred with the measurement systems and operations.

\subsection{Results}

The historical results for the TSG are presented in Figure 2. To evaluate the performance of these instruments, the standard deviations of each radiometer were monitored during the comparisons. The results suggest successful performance of the TSG during this NPC:

- For the TSG, the NPC-2018 WRR-TF did not change by more than a fraction of the standard deviation derived during IPC-XII in 2015 (see Figure 2. History of WRR reduction factors for NREL reference cavities).

- For NPC-2018 Proficiency Test, the results of the participating cavities in IPC-XII and NPC-2018 were evaluated using the following equation:

$$
E_{n}=\frac{W R R_{I P C}-W R R_{N P C}}{\sqrt{U 95_{I P C}^{2}+U 95_{N P C}^{2}}}
$$

where En must lie in the interval -1 to +1 .

From Figure 2. History of WRR reduction factors for NREL reference cavities

Table 2, En for all cavities was well within the interval -1 to +1 (i.e., the WRR from NPC-2018 is consistent with the WRR from IPC-XII). 


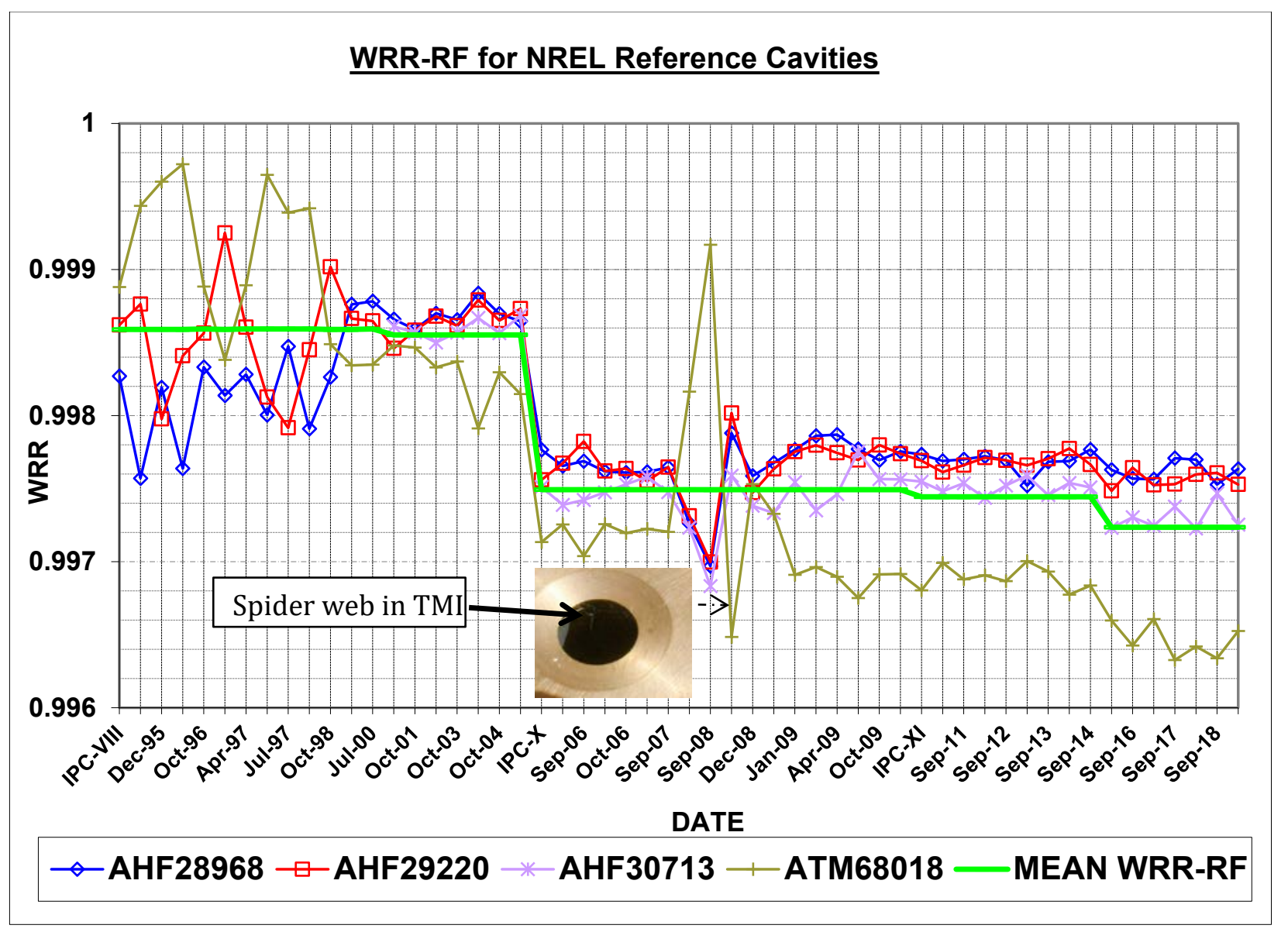

Figure 2. History of WRR reduction factors for NREL reference cavities

Table 2. Summary Results for Proficiency Test During NPC-2018

\begin{tabular}{|c||c|c|c|c|c|}
\hline $\begin{array}{c}\text { Participating } \\
\text { Cavity }\end{array}$ & IPC-XII & \%U95 & NPC-2018 & \%U95 & Red if abs(En) > 1 \\
\hline AHF 0000 & 1.00031 & 0.36 & 1.00275 & 0.39 & -0.46 \\
\hline AHF 14915 & 0.99954 & 0.35 & 0.99954 & 0.38 & 0.00 \\
\hline AHF 17142 & 0.99795 & 0.39 & 0.99828 & 0.38 & -0.06 \\
\hline AHF 23734 & 0.99819 & 0.35 & 0.99830 & 0.37 & -0.02 \\
\hline AHF 28553 & 0.99774 & 0.35 & 0.99781 & 0.37 & -0.01 \\
\hline AHF 28556 & 0.99541 & 0.36 & 0.99056 & 0.42 & 0.89 \\
\hline AHF 31041 & 0.99639 & 0.36 & 0.99663 & 0.38 & -0.05 \\
\hline AHF 31105 & 0.99866 & 0.36 & 0.99861 & 0.38 & 0.01 \\
\hline AHF 31114AWX & 1.00121 & 0.33 & 1.00093 & 0.38 & 0.06 \\
\hline AHF 32448AWX & 0.99999 & 0.35 & 1.00017 & 0.38 & -0.03 \\
\hline AHF 32455 & 1.00138 & 0.33 & 1.00140 & 0.39 & 0.00 \\
\hline AHF 37816 & 0.99959 & 0.33 & 0.99933 & 0.38 & 0.05 \\
\hline PM06 0816 & 0.99984 & 0.45 & 1.00026 & 0.47 & -0.07 \\
\hline PM06 81109 & 0.99832 & 0.32 & 0.99823 & 0.39 & 0.02 \\
\hline PMO6 911204 & 0.99945 & 0.41 & 1.00013 & 0.41 & -0.12 \\
\hline Pmo6cC 0103 & 0.99792 & 0.32 & 0.99911 & 0.39 & -0.24 \\
\hline TMI 68835 & 1.000714 & 0.32 & 0.99983 & 0.41 & 0.17 \\
\hline
\end{tabular}


Table 3. Results for Radiometers Participating in NPC-2018

\begin{tabular}{|c|c|c|c|c|}
\hline$S / N$ & WRR (NPC-2018) & SD & NRDG & $\%$ U95 \\
\hline AHF 0000 & 1.00275 & 0.00073 & 1997 & 0.39 \\
\hline AHF 14915 & 0.99954 & 0.00063 & 1378 & 0.38 \\
\hline AHF 17142 & 0.99828 & 0.00061 & 1441 & 0.38 \\
\hline AHF 23734 & 0.99830 & 0.00038 & 1543 & 0.37 \\
\hline AHF 28486 & 0.99722 & 0.00064 & 1452 & 0.38 \\
\hline AHF 28553 & 0.99781 & 0.00049 & 1431 & 0.37 \\
\hline AHF 28556 & 0.99056 & 0.00103 & 1498 & 0.42 \\
\hline AHF 28560 & 1.00289 & 0.00089 & 1419 & 0.40 \\
\hline AHF 29219-Window & 1.06176 & 0.00069 & 1495 & 0.38 \\
\hline AHF 29222-Window & 1.05900 & 0.00068 & 1965 & 0.38 \\
\hline AHF 29223 & 0.99904 & 0.00072 & 1325 & 0.39 \\
\hline AHF 30110 & 1.06312 & 0.00087 & 968 & 0.40 \\
\hline AHF 30495-Window & 1.05572 & 0.00085 & 1959 & 0.39 \\
\hline AHF 31041 & 0.99663 & 0.00067 & 1169 & 0.38 \\
\hline AHF 31104-Window & 1.03877 & 0.00089 & 1258 & 0.40 \\
\hline AHF 31105 & 0.99861 & 0.00056 & 1183 & 0.38 \\
\hline AHF 31107 & 1.04821 & 0.00121 & 929 & 0.43 \\
\hline AHF 31108 & 0.99684 & 0.00074 & 1498 & 0.39 \\
\hline AHF 32452AWX-Window & 1.03139 & 0.00091 & 1484 & 0.40 \\
\hline AHF 31113AWX-Window & 1.05056 & 0.00075 & 1399 & 0.39 \\
\hline AHF 31114AWX & 1.00093 & 0.00064 & 1407 & 0.38 \\
\hline AHF 32448AWX & 1.00017 & 0.00065 & 1424 & 0.38 \\
\hline AHF 32455 & 1.00140 & 0.00072 & 2278 & 0.39 \\
\hline AHF 33392 & 0.99890 & 0.00058 & 1284 & 0.38 \\
\hline AHF 34926AWX & 1.00117 & 0.00088 & 1408 & 0.40 \\
\hline AHF 37816 & 0.99933 & 0.00067 & 1406 & 0.38 \\
\hline PMO6 0816 & 1.00026 & 0.00155 & 335 & 0.47 \\
\hline PM06 1601 & 1.00310 & 0.00061 & 473 & 0.38 \\
\hline PMO6 81109 & 0.99823 & 0.00073 & 584 & 0.39 \\
\hline PMO6 911204 & 1.00013 & 0.00096 & 593 & 0.41 \\
\hline Pmo6cc 0103 & 0.99911 & 0.00073 & 360 & 0.39 \\
\hline PMO6cc 0401 & 1.02097 & 0.00074 & 374 & 0.39 \\
\hline PMO6cc 0803 & 1.00005 & 0.00078 & 382 & 0.39 \\
\hline PMO6 1611-Linard-00 & 1.00165 & 0.00075 & 1097 & 0.39 \\
\hline TMI 67603 & 0.99993 & 0.00070 & 1488 & 0.39 \\
\hline TMI 67811 & 0.99866 & 0.00104 & 1338 & 0.42 \\
\hline TMI 68020 & 0.99897 & 0.00096 & 1213 & 0.41 \\
\hline TMI 68022 & 0.99996 & 0.00144 & 1327 & 0.46 \\
\hline TMI 68835 & 0.99983 & 0.00099 & 2169 & 0.41 \\
\hline
\end{tabular}


The uncertainty of the WRR-TF associated with each participating radiometer with respect to SI was calculated using the following formula:

$$
U_{95}= \pm 1.96 * \sqrt{u_{A}^{2}+u_{B}^{2}}
$$

where,

$\mathrm{U}_{95}=$ Uncertainty of the WRR-TF (in percent) determined at NPC-2018 with 95\% confidence level $1.96=$ Coverage factor

$\mathrm{u}_{\mathrm{A}}=$ Type A standard uncertainty $=$ standard deviation of each participating radiometer (in \%) determined at NPC-2018

$\mathrm{uB}_{\mathrm{B}}=$ Type B standard uncertainty

$\mathrm{uB}_{\mathrm{B}}= \pm \sqrt{\left(\frac{0.3}{\sqrt{3}}\right)^{2}+0.06^{2}}$

where,

$0.3=$ Estimated expanded uncertainty of the WRR scale with respect to SI, in \%

$\sqrt{3}=$ Coverage factor for rectangular distribution

$0.06=$ Pooled standard deviation of the four reference radiometers (TSG) that participated in IPC-XII (September/October 2015), in \%.

The statistical analyses of WRR-TF for the participating pyrheliometers are presented in the following figures. These graphical summaries indicate the mean, standard deviation, and histograms of the WRR-TF determined during NPC-2018.

WRR-Transfer Factor vs MST NPC-2018

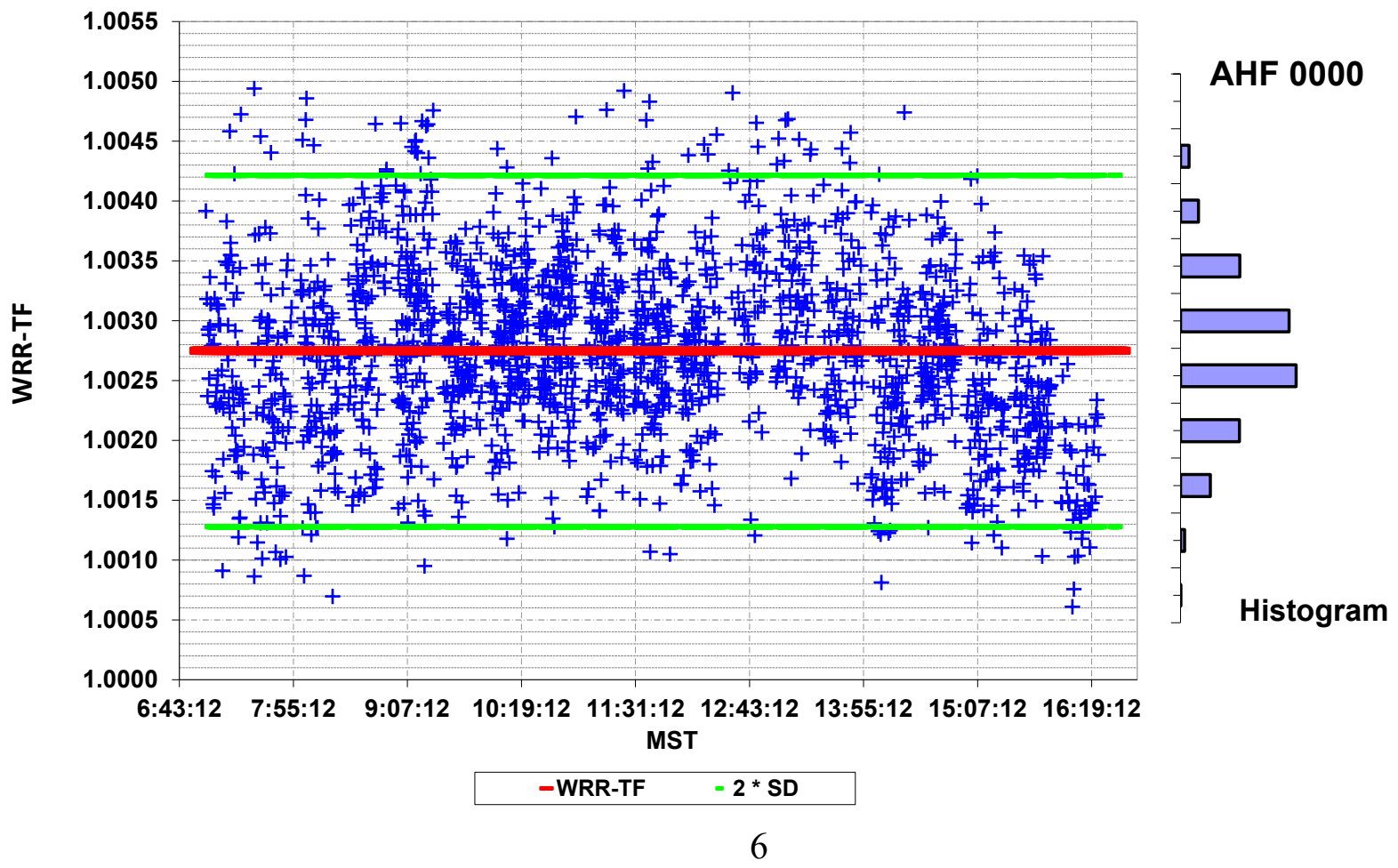


Figure 3. WRR-Transfer Factor vs. Mountain Standard Time (MST) NPC-2018 for AHF 0000

\section{WRR-Transfer Factor vs MST NPC-2018}
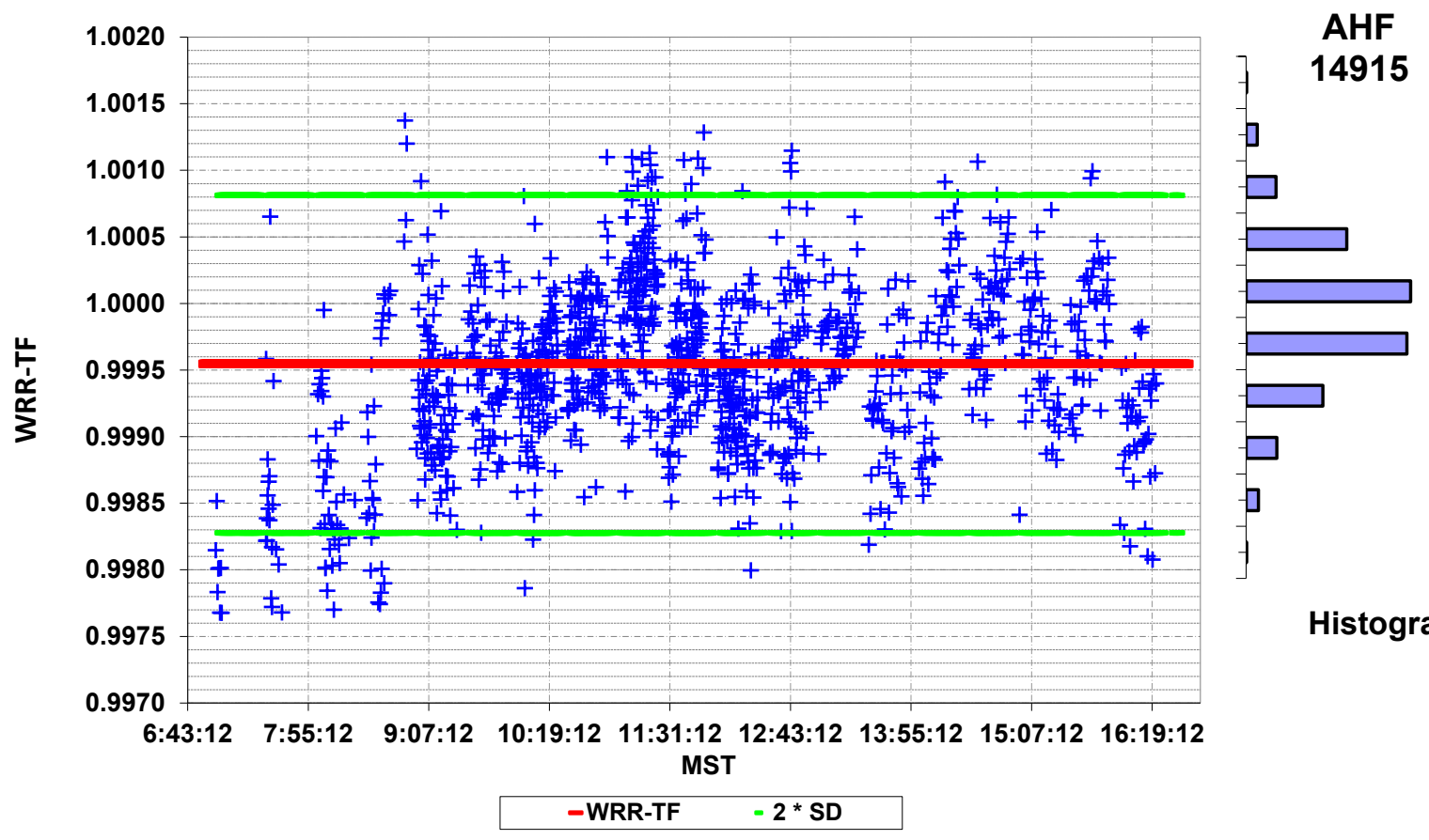

Histogram

Figure 4. WRR-Transfer Factor vs. MST NPC-2018 for AHF 14915

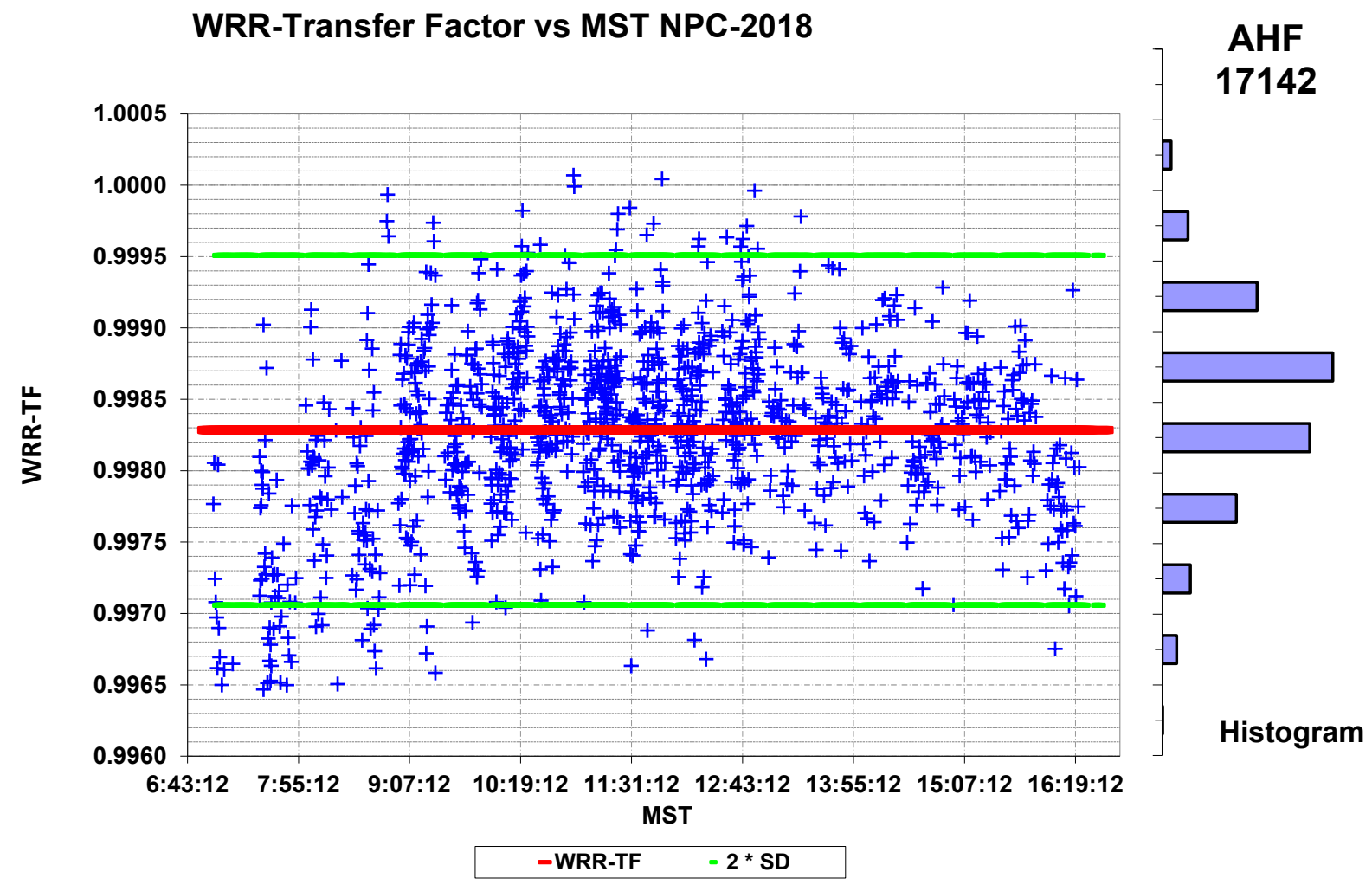

Figure 5. WRR-Transfer Factor vs. MST NPC-2018 for AHF 17142 
WRR-Transfer Factor vs MST NPC-2018

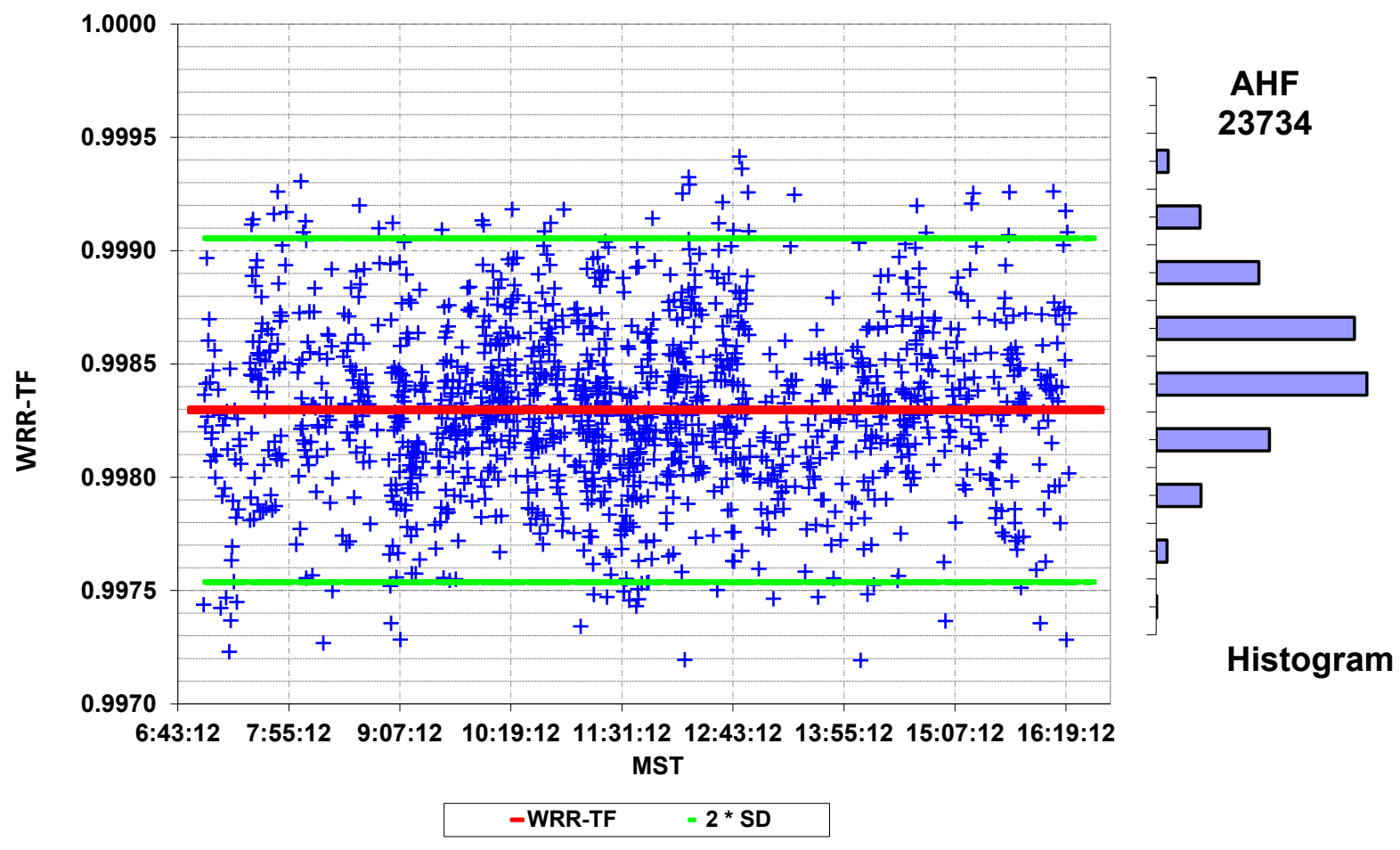

Figure 6. WRR-Transfer Factor vs. MST NPC-2018 for AHF23734

WRR-Transfer Factor vs MST NPC-2018

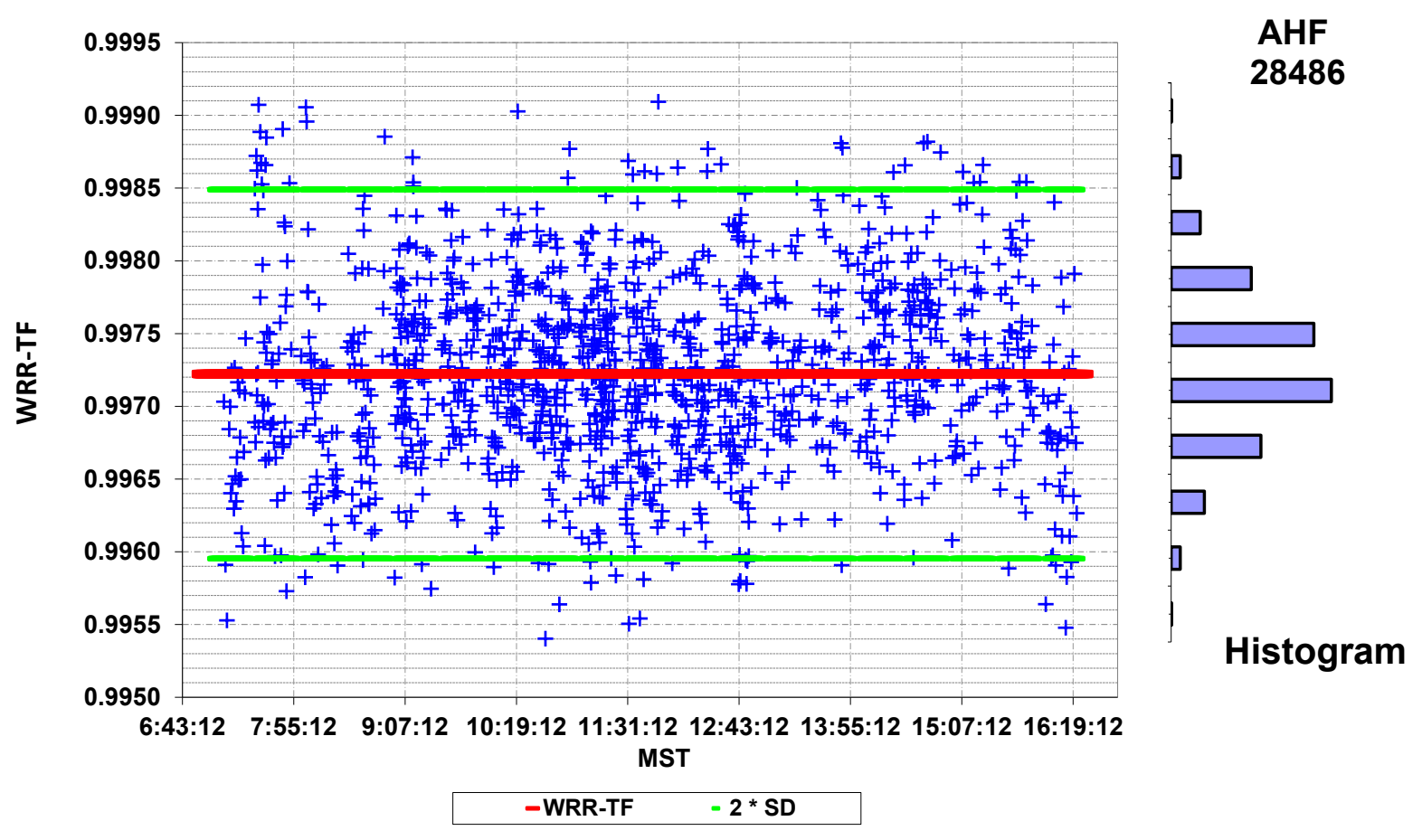

Figure 7. WRR-Transfer Factor vs. MST NPC-2018 for AHF 28486 


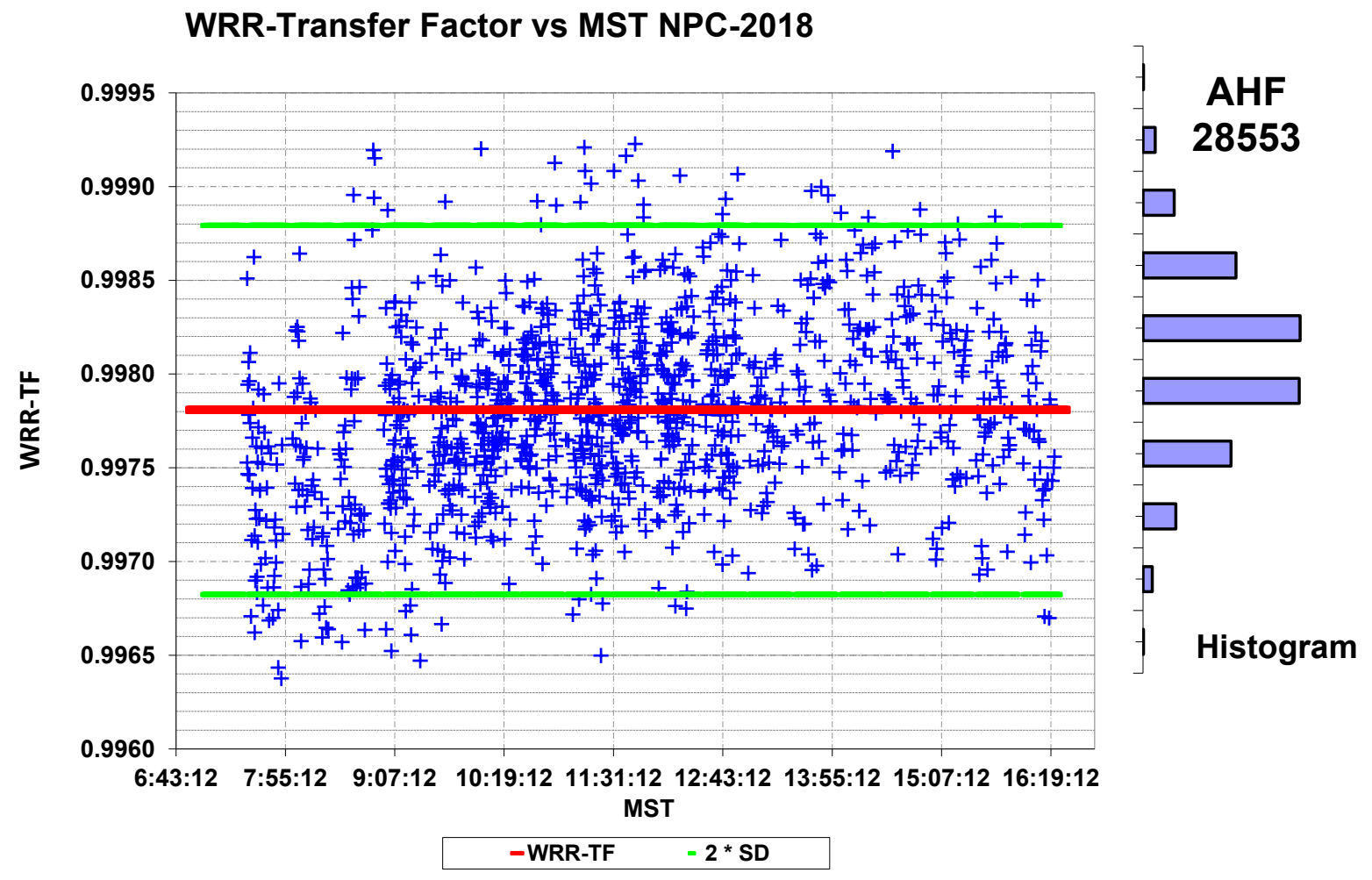

Figure 8. WRR-Transfer Factor vs. MST NPC-2018 for AHF28553

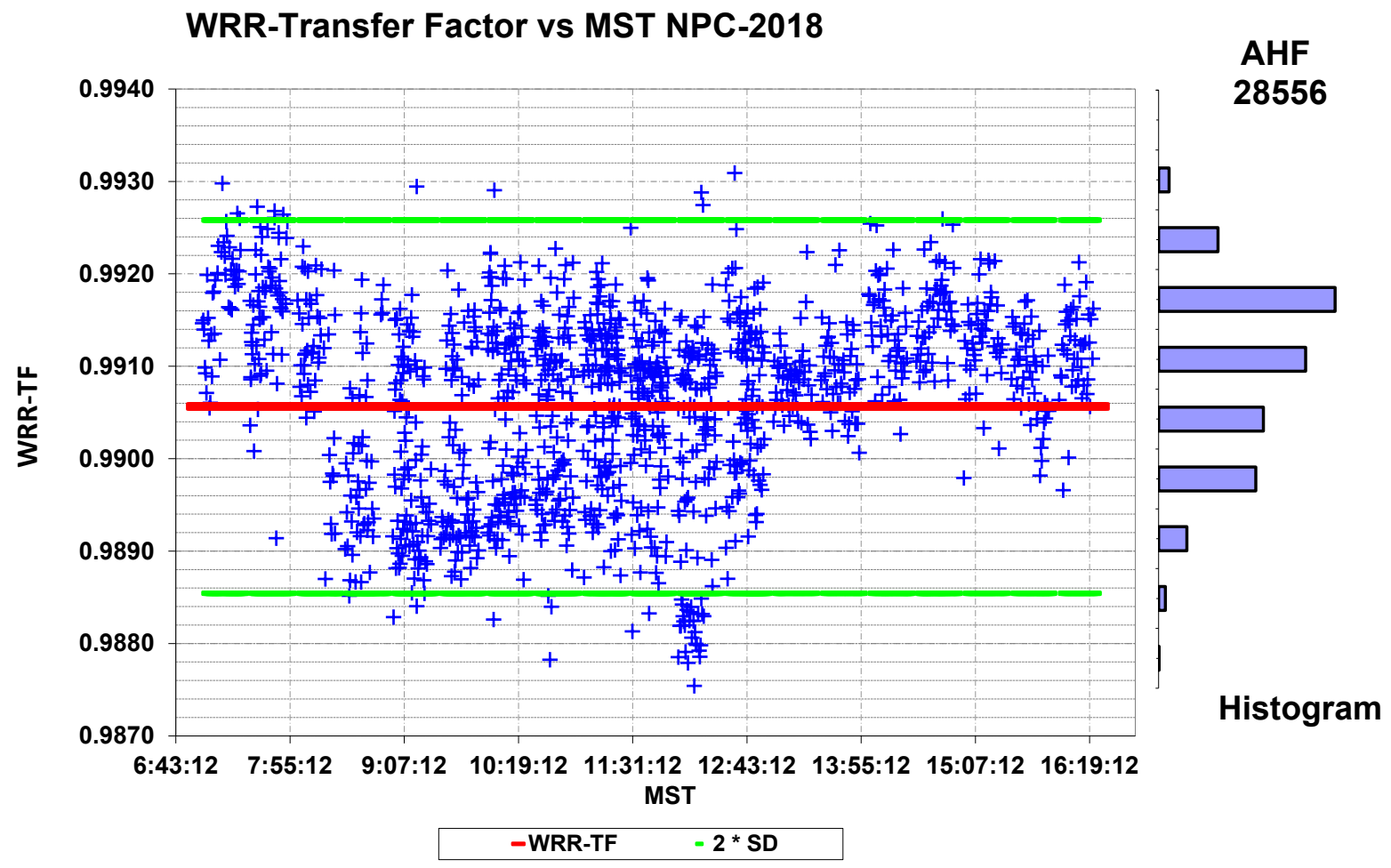

Figure 9. WRR-Transfer Factor vs. MST NPC-2018 for AHF 28556 
WRR-Transfer Factor vs MST NPC-2018

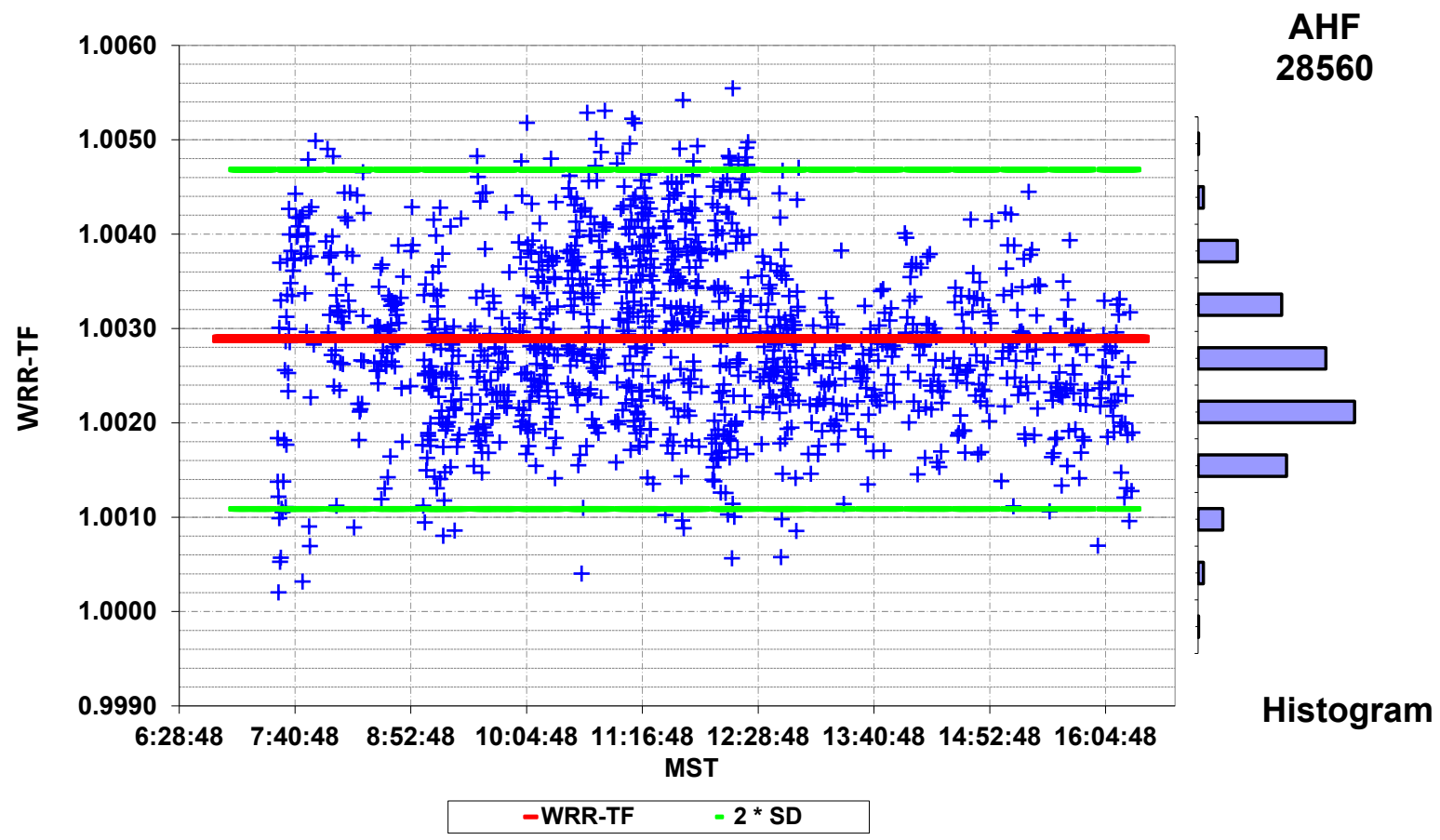

Figure 10. WRR-Transfer Factor vs. MST NPC-2018 for AHF 28560

WRR-Transfer Factor vs MST NPC-2018

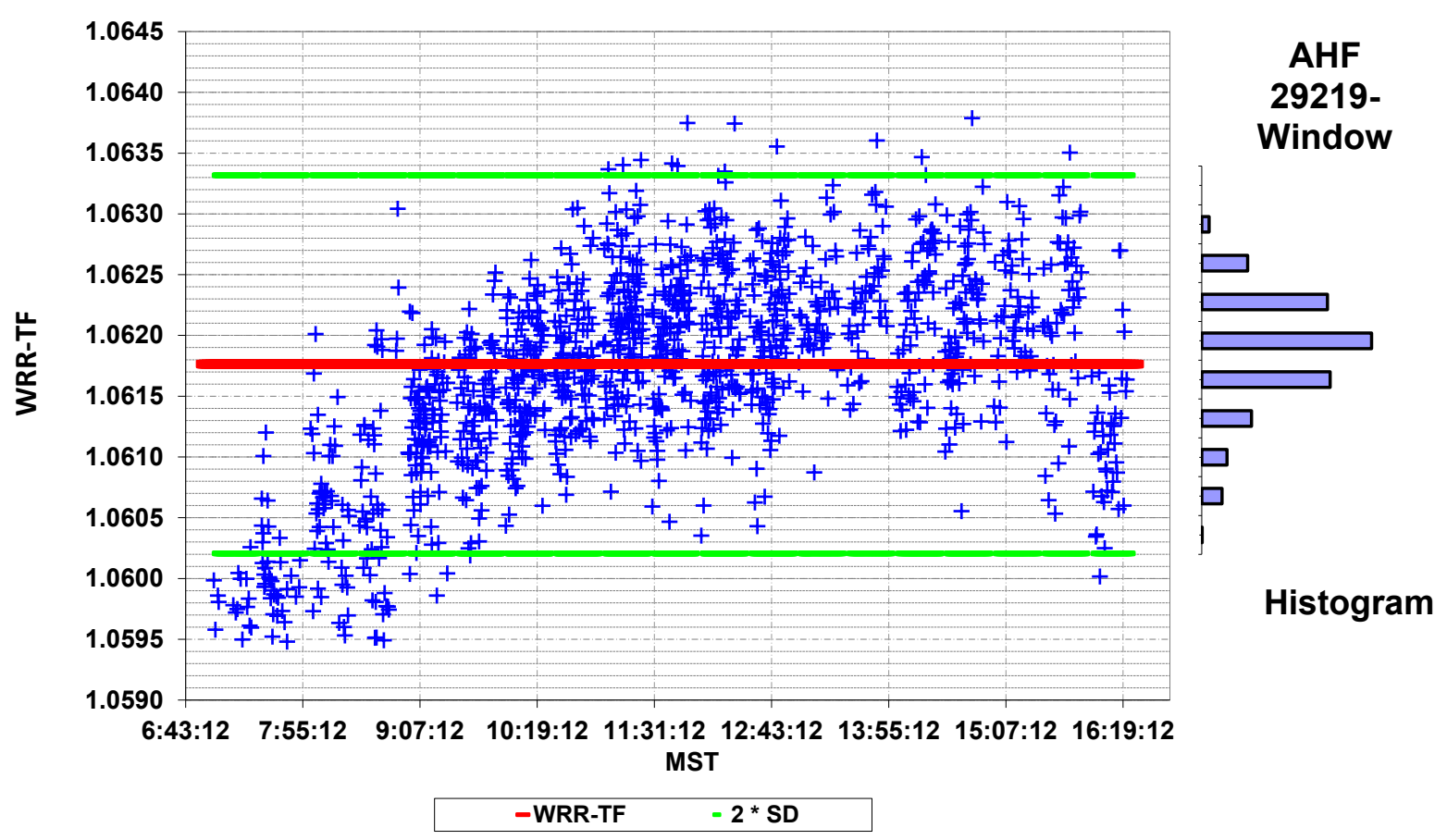

Figure 11. WRR-Transfer Factor vs. MST NPC-2018 for AHF 29219 - Windowed 
WRR-Transfer Factor vs MST NPC-2018

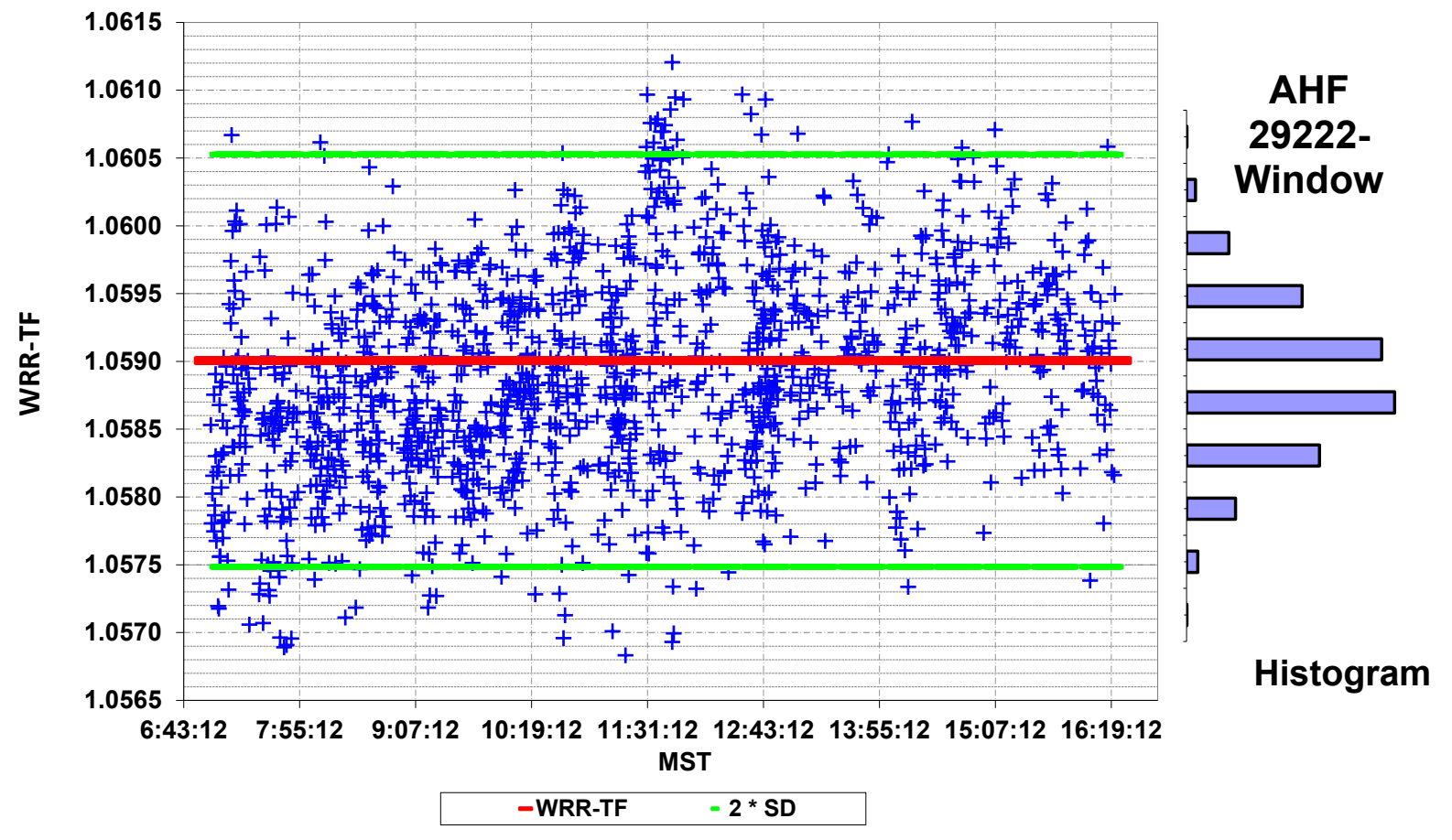

Figure 12. WRR-Transfer Factor vs. MST NPC-2018 for AHF 29222 - Windowed

WRR-Transfer Factor vs MST NPC-2018

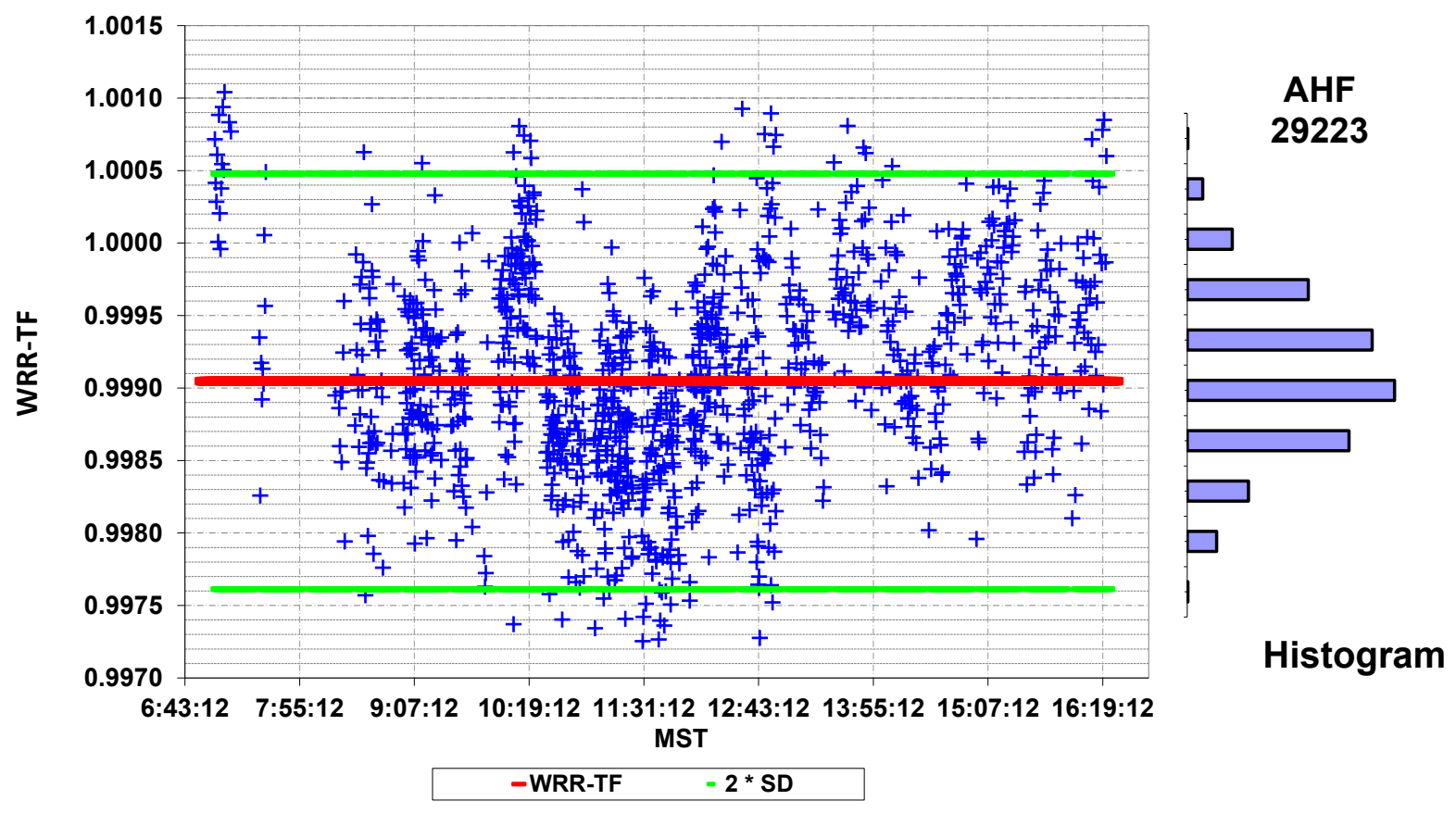

Figure 13. WRR-Transfer Factor vs. MST NPC-2018 for AHF 29223 
WRR-Transfer Factor vs MST NPC-2018

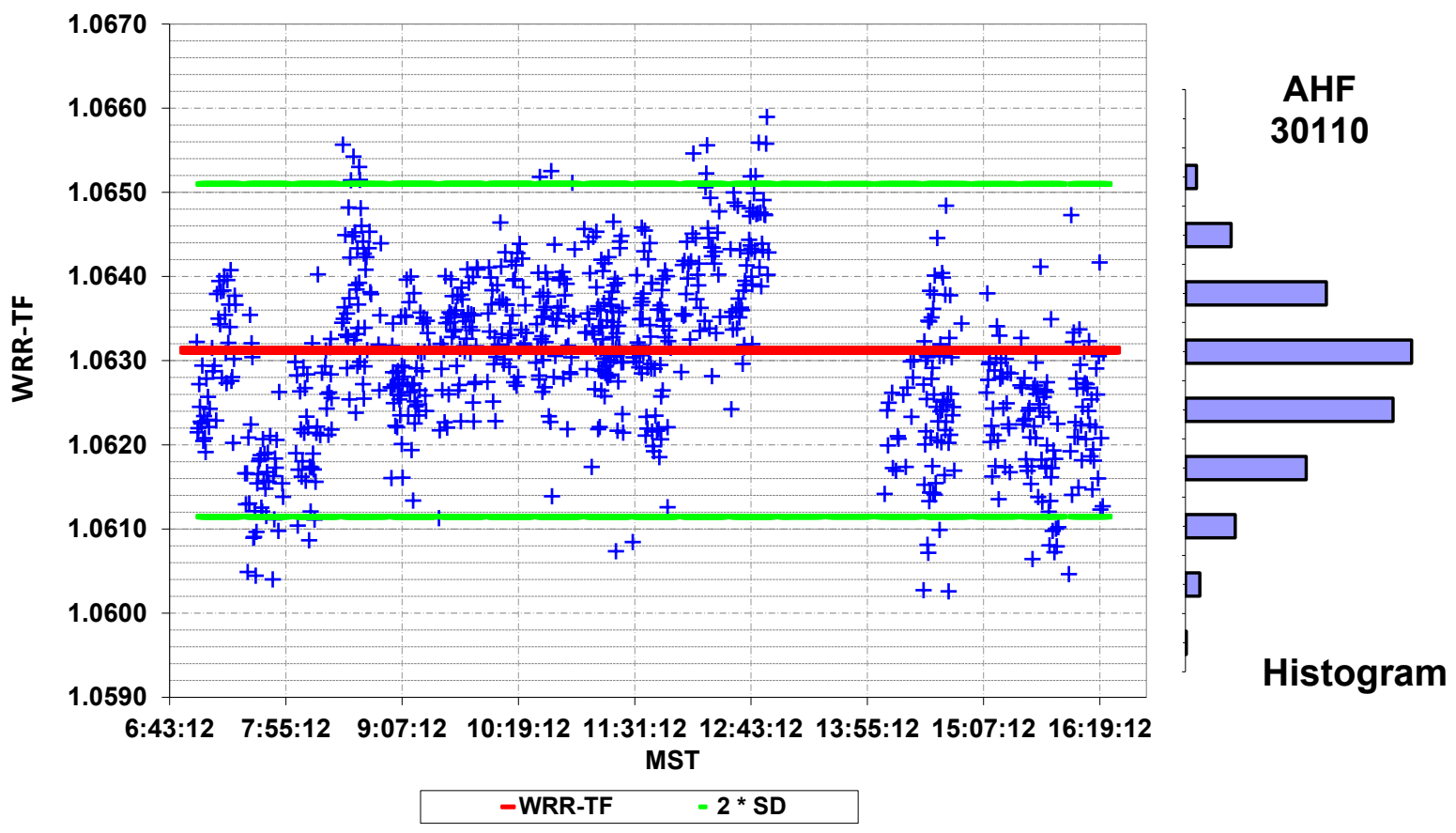

Figure 14. WRR-Transfer Factor vs. MST NPC-2018 for AHF 30110

WRR-Transfer Factor vs MST NPC-2018

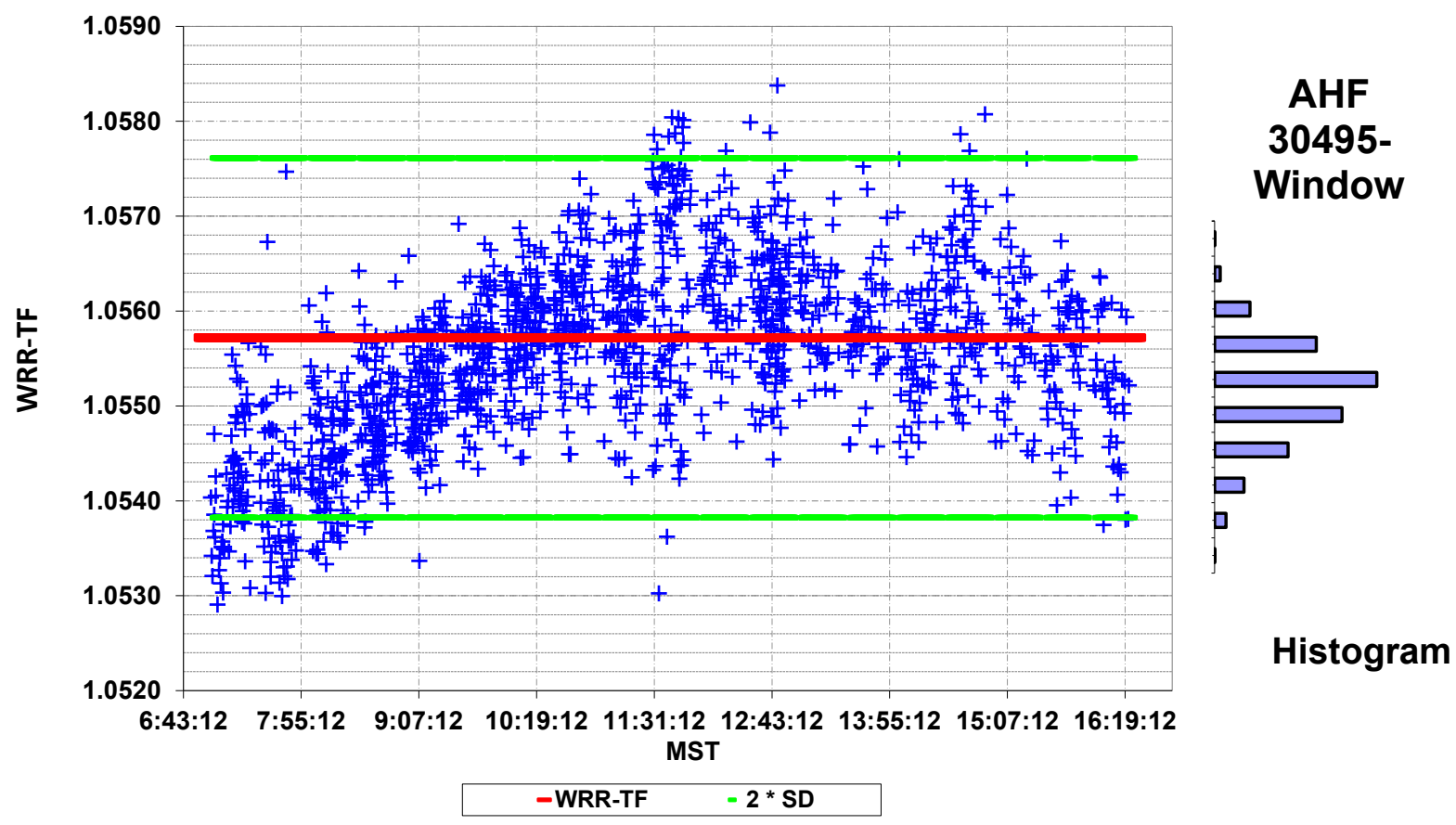

Figure 15. WRR-Transfer Factor vs. MST NPC-2018 for AHF 310495-Window 
WRR-Transfer Factor vs MST NPC-2018

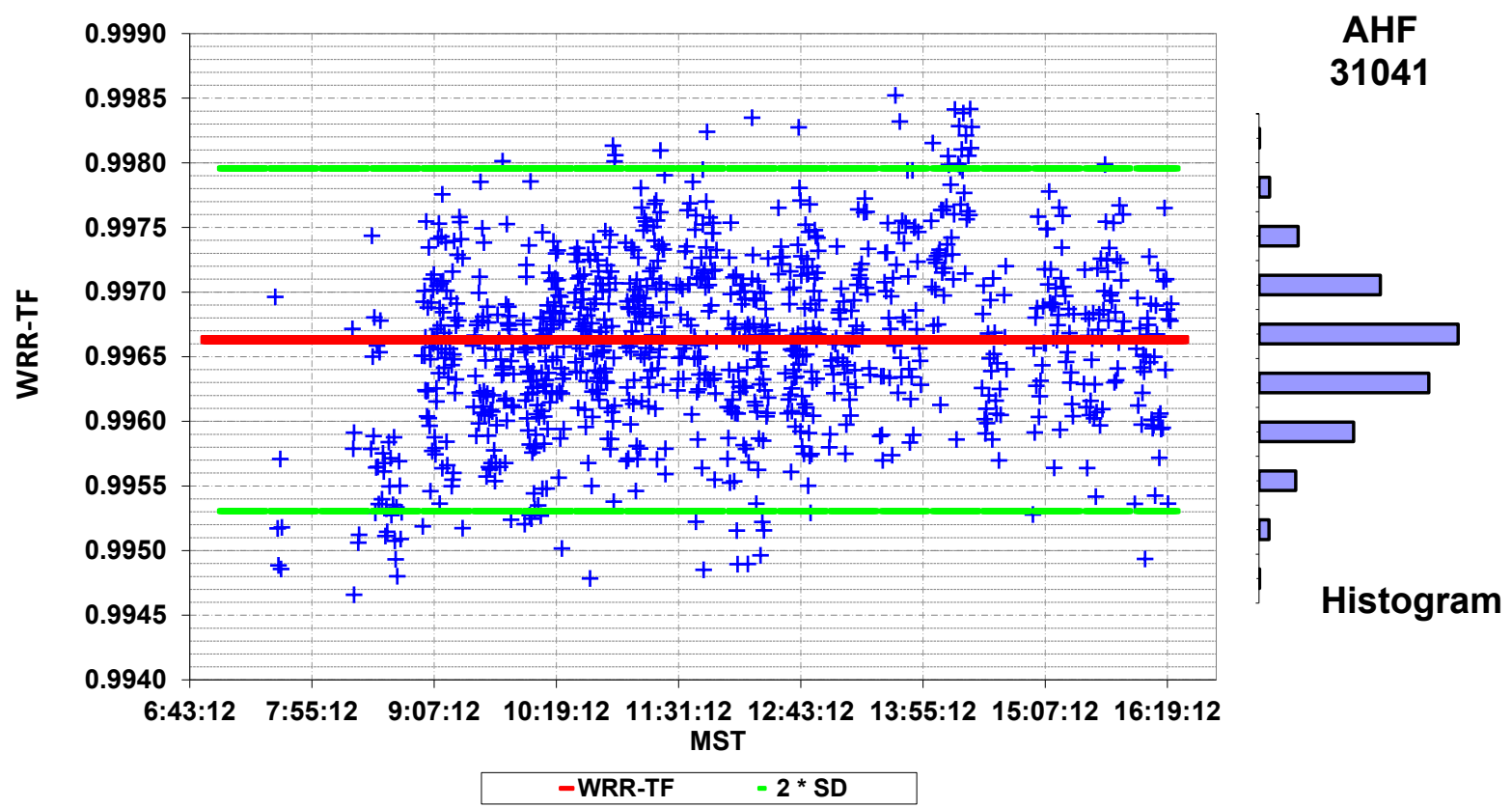

Figure 16. WRR-Transfer Factor vs. MST NPC-2018 for AHF 31041

WRR-Transfer Factor vs MST NPC-2018

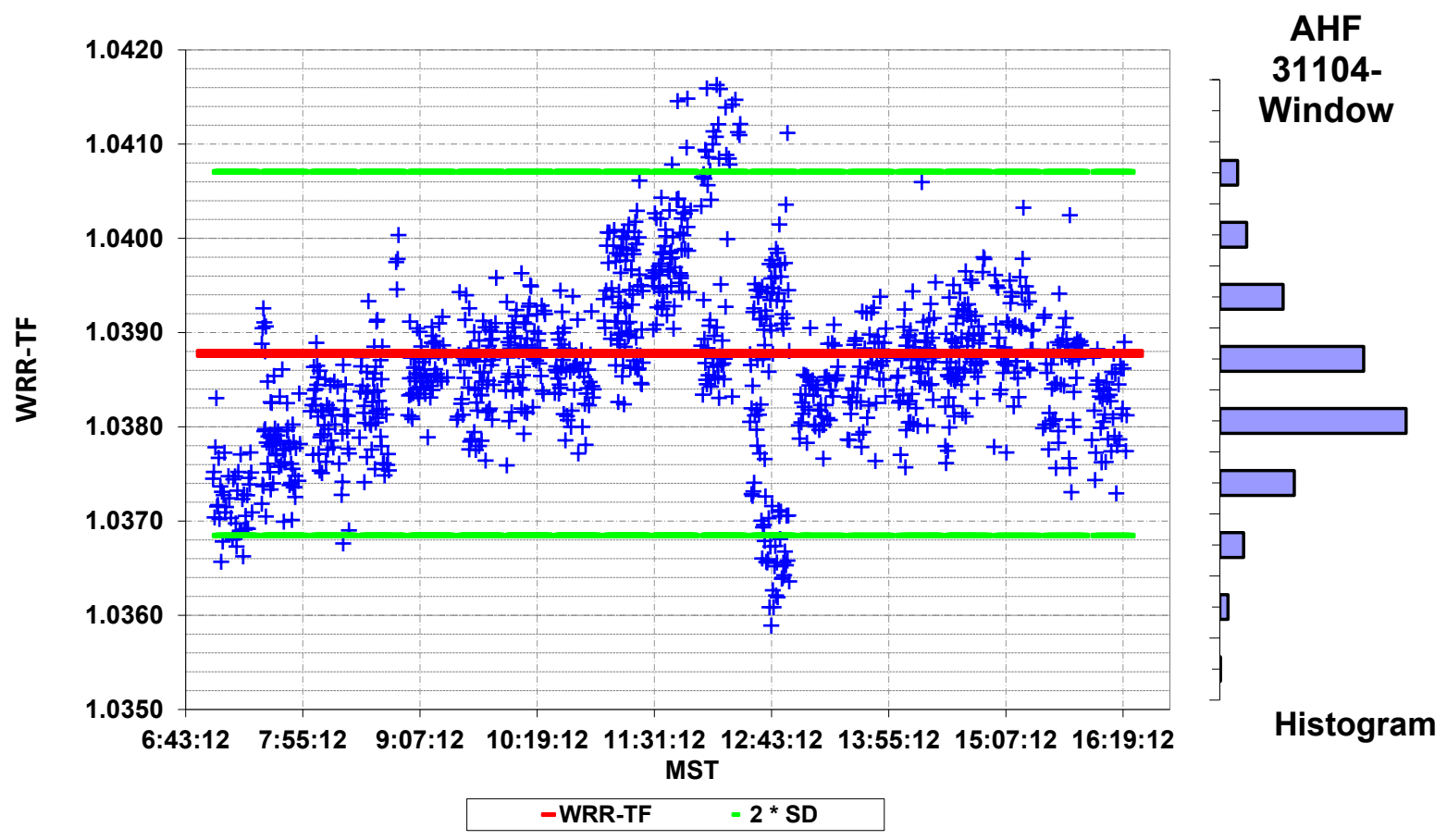

Figure 17. WRR-Transfer Factor vs. MST NPC-2018 for AHF 31104-Window 
WRR-Transfer Factor vs MST NPC-2018

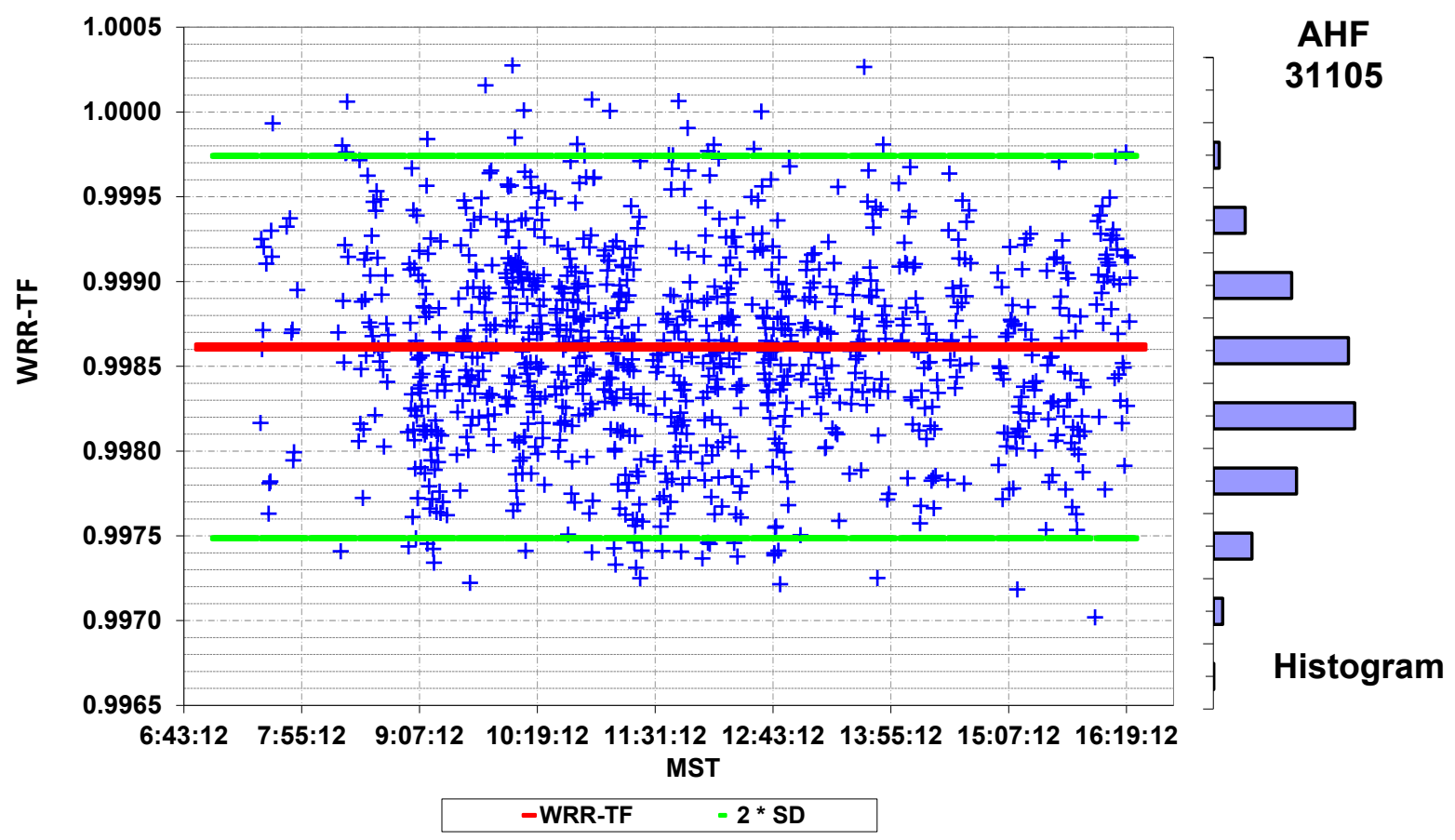

Figure 18. WRR-Transfer Factor vs. MST NPC-2018 for AHF 31105

WRR-Transfer Factor vs MST NPC-2018

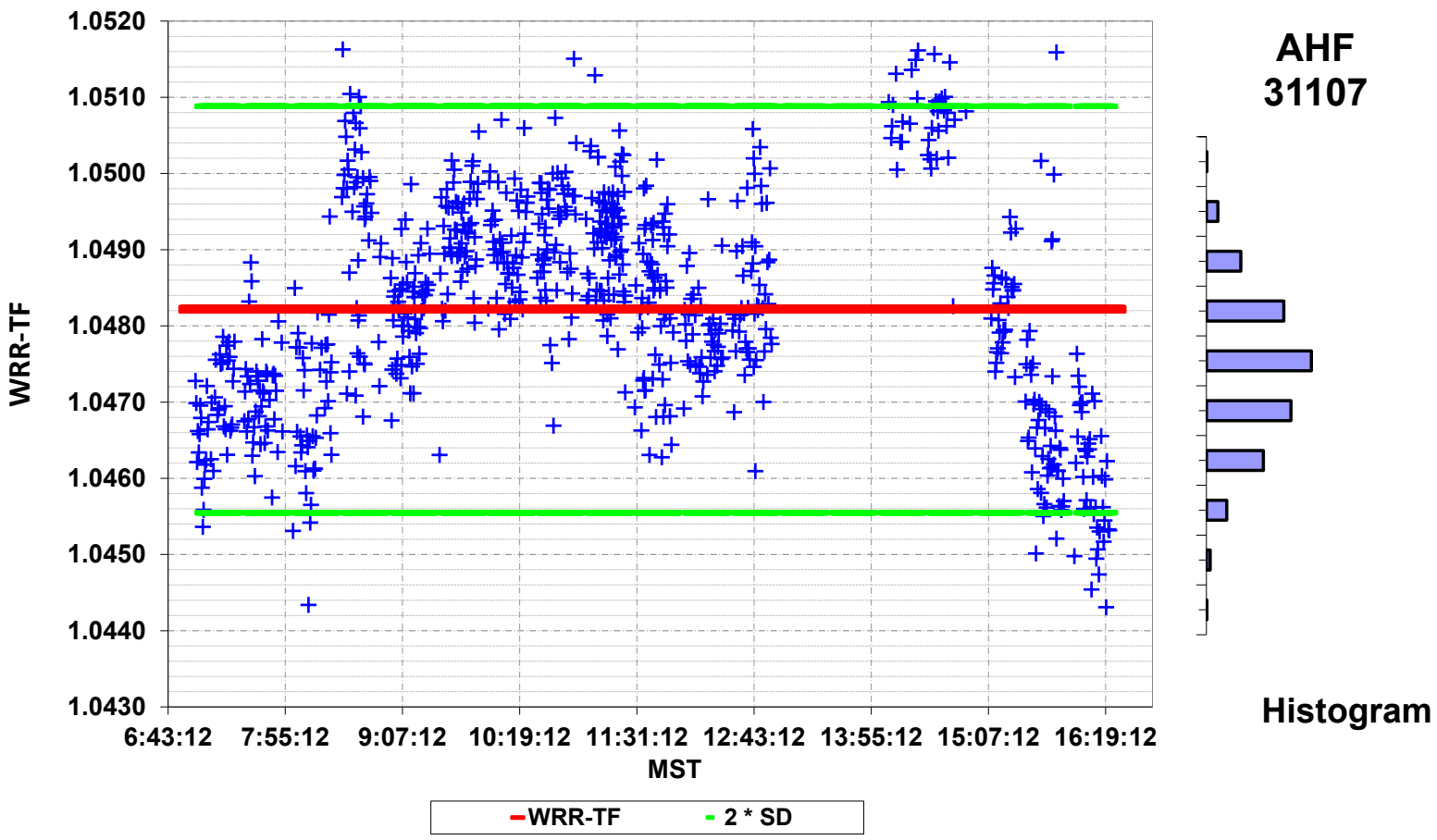

Figure 19. WRR-Transfer Factor vs. MST NPC-2018 for AHF 31107 
WRR-Transfer Factor vs MST NPC-2018

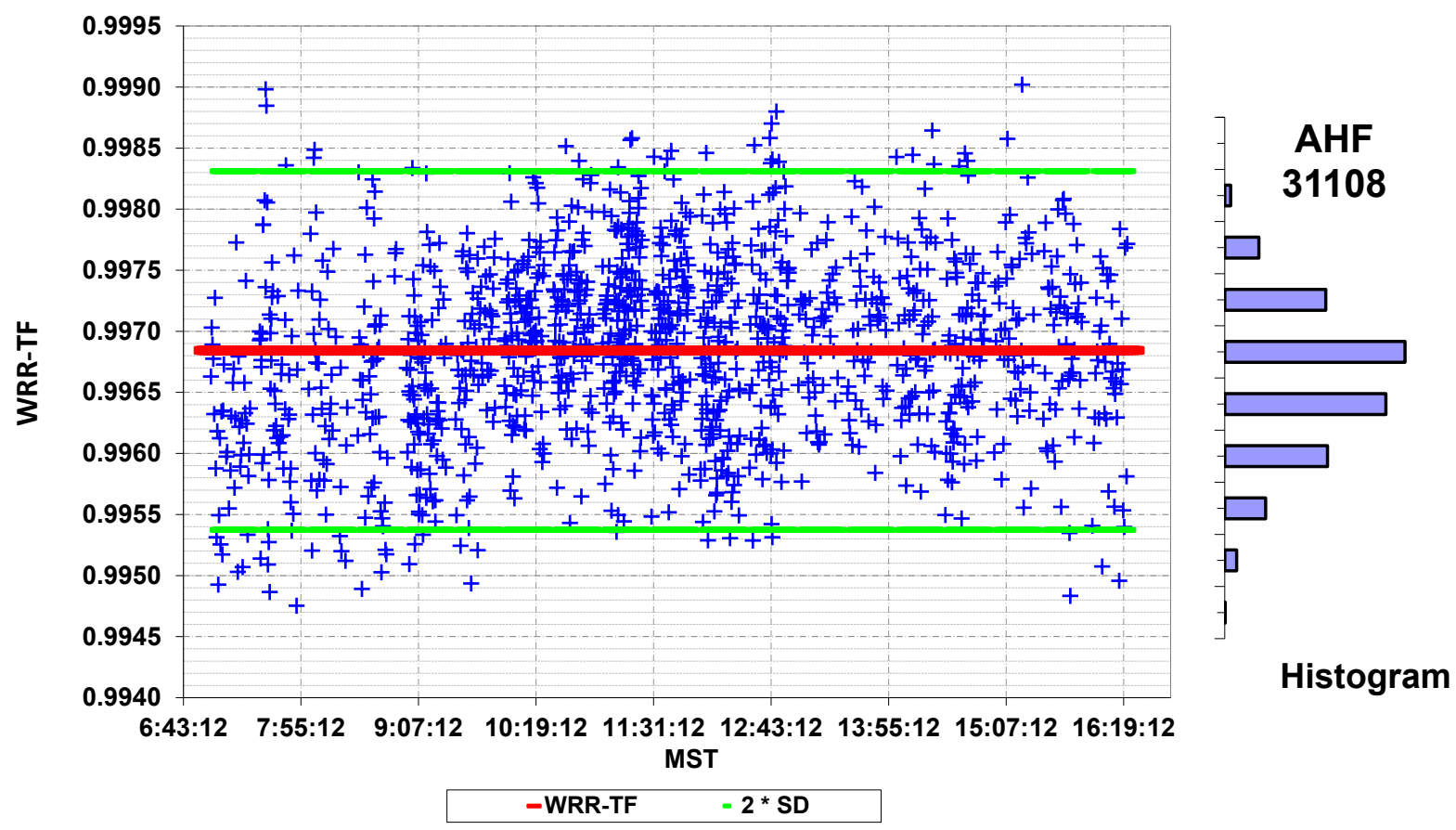

Figure 20. WRR-Transfer Factor vs. MST NPC-2018 for AHF 31108

WRR-Transfer Factor vs MST NPC-2018

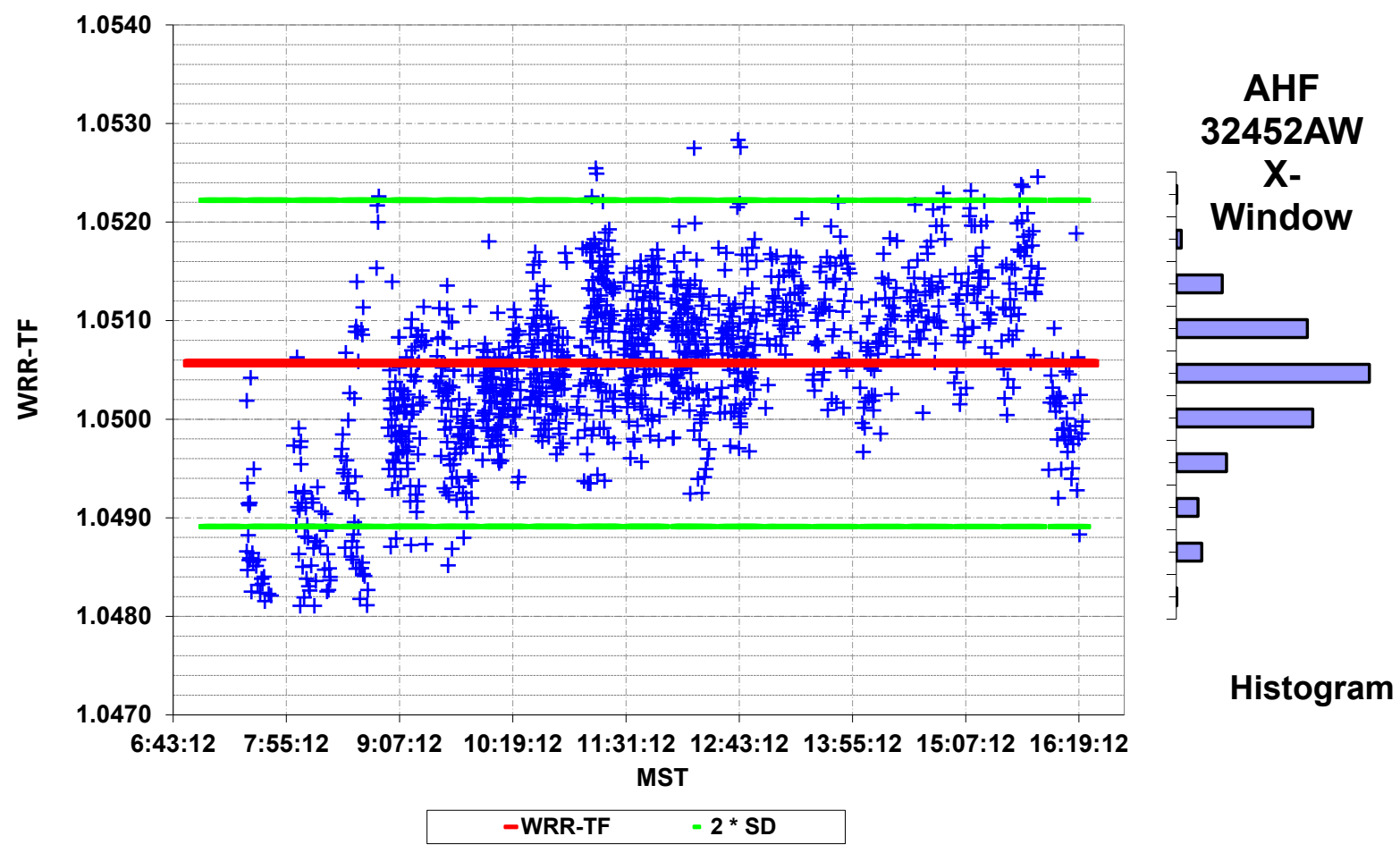

Figure 21. WRR-Transfer Factor vs. MST NPC-2018 for AHF 32452AWX-Window 


\section{WRR-Transfer Factor vs MST NPC-2018}

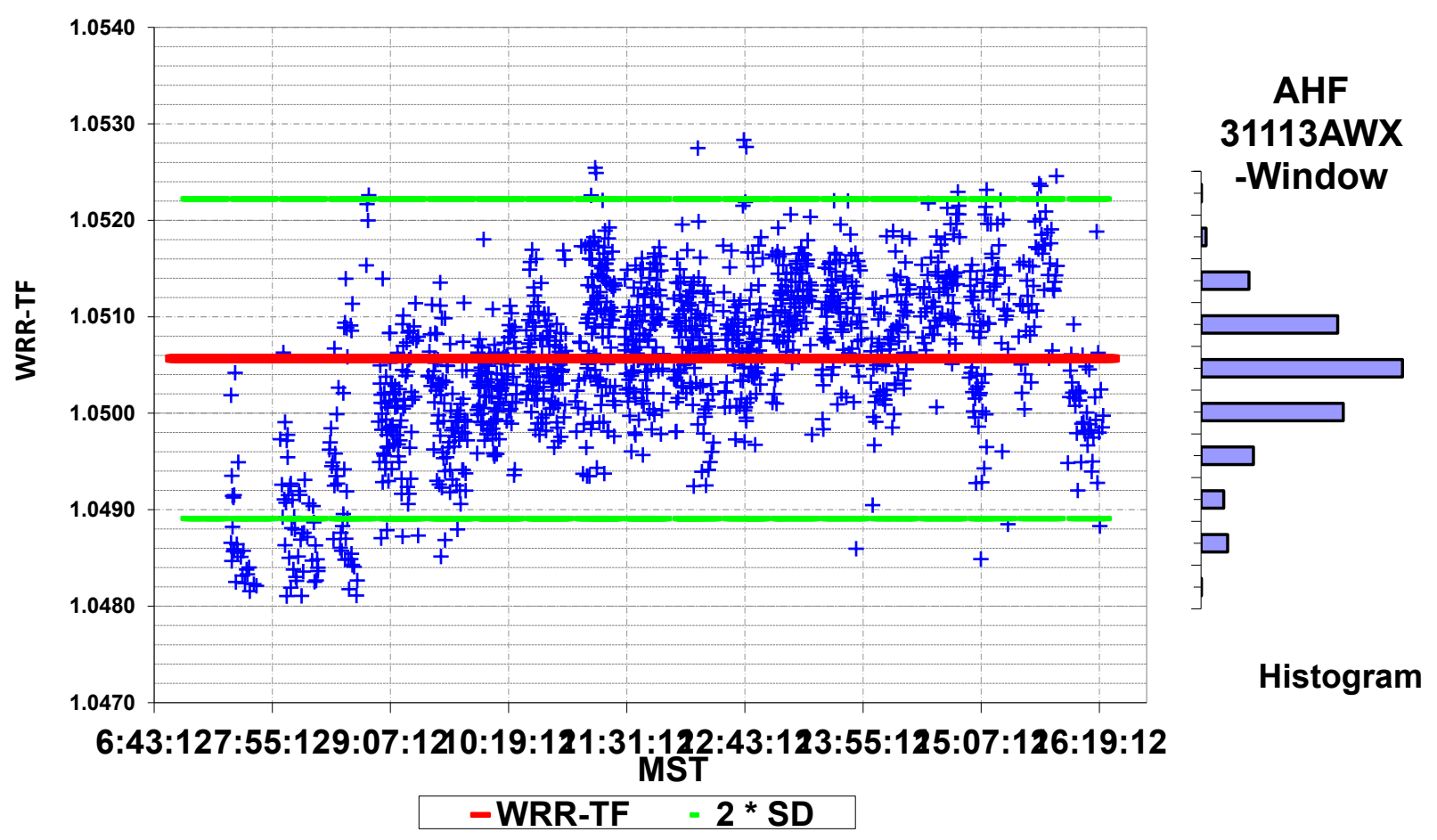

Figure 22. WRR-Transfer Factor vs. MST NPC-2018 for AHF 31113AWX-Window

WRR-Transfer Factor vs MST NPC-2018

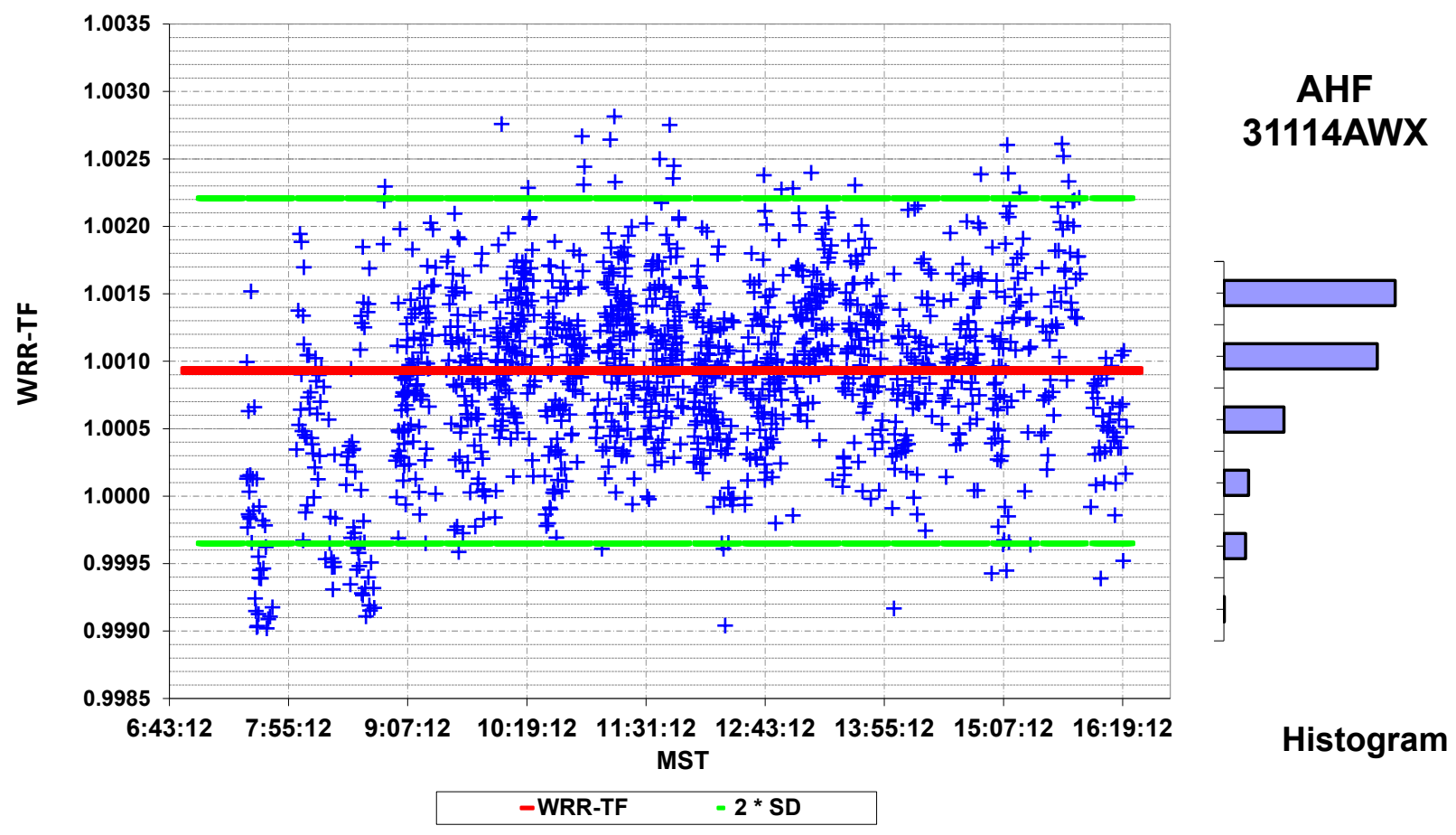

Figure 23. WRR-Transfer Factor vs. MST NPC-2018 for AHF 31114AWX 
WRR-Transfer Factor vs MST NPC-2018

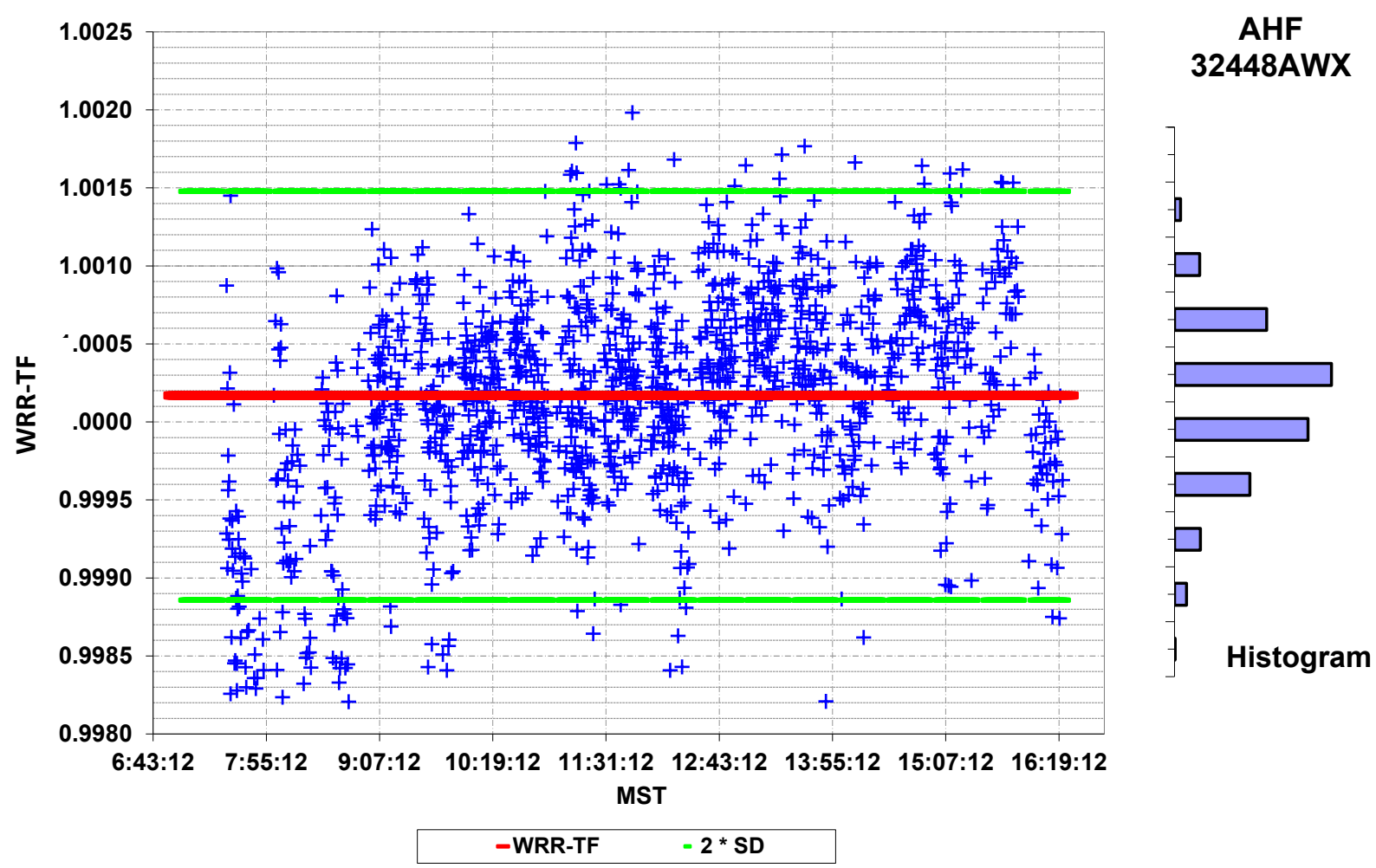

Figure 24. WRR-Transfer Factor vs. MST NPC-2018 for AHF 32448AWX

WRR-Transfer Factor vs MST NPC-2018

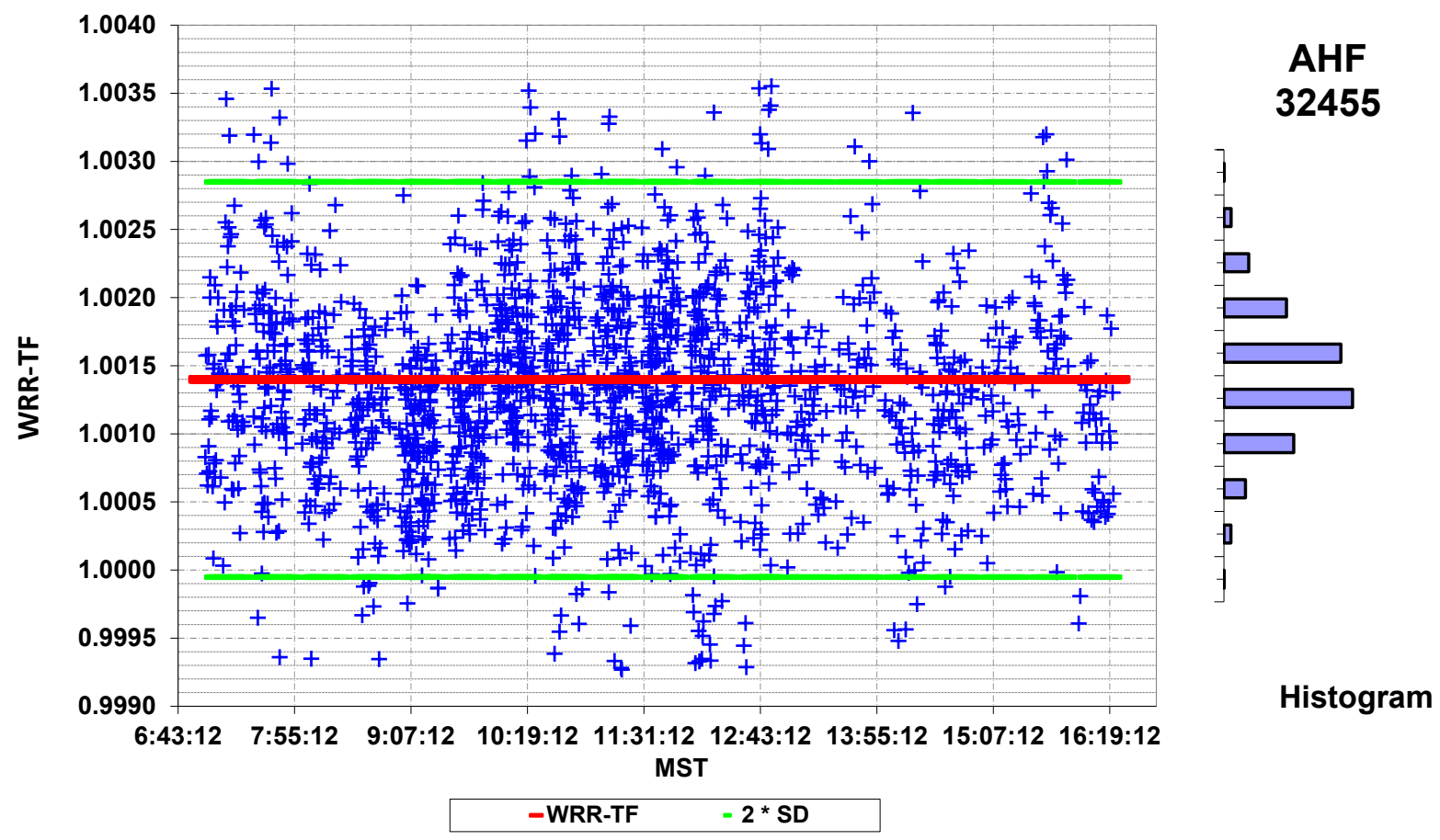

Figure 25. WRR-Transfer Factor vs. MST NPC-2018 for AHF 32455 
WRR-Transfer Factor vs MST NPC-2018
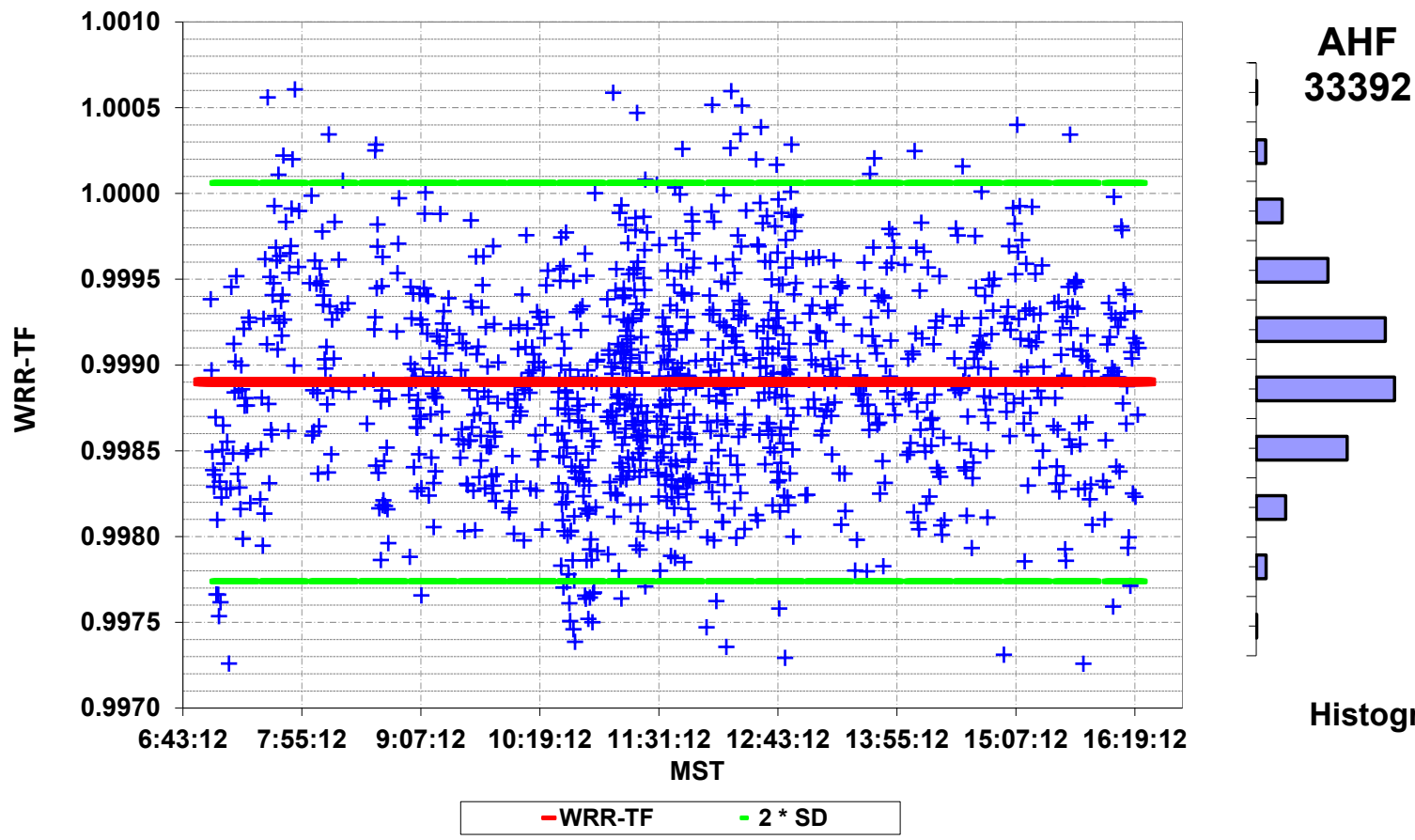

Histogram

Figure 26. WRR-Transfer Factor vs. MST NPC-2018 for AHF 33392

WRR-Transfer Factor vs MST NPC-2018

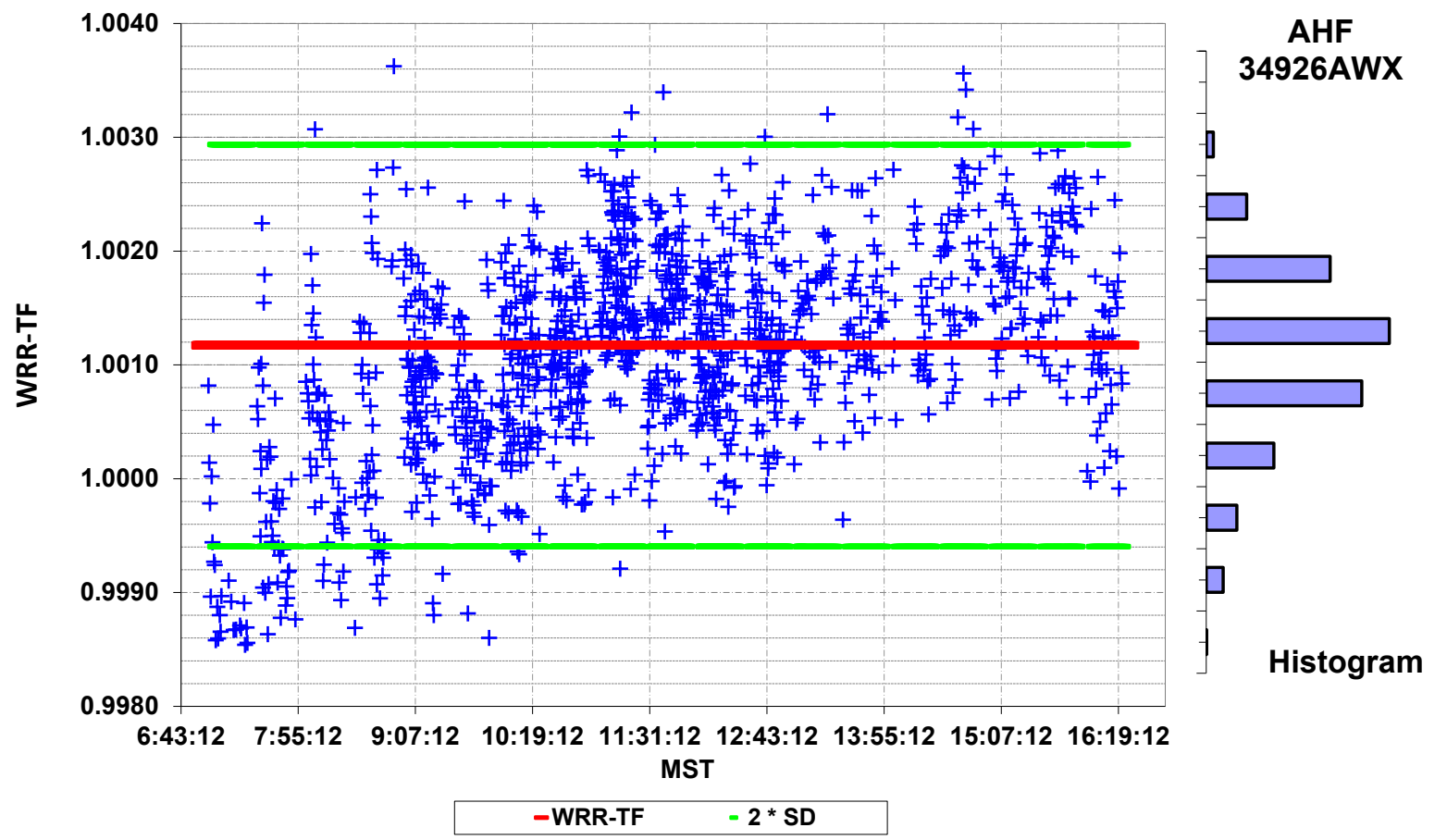

Figure 27. WRR-Transfer Factor vs. MST NPC-2018 for AHF 34926AWX 
WRR-Transfer Factor vs MST NPC-2018

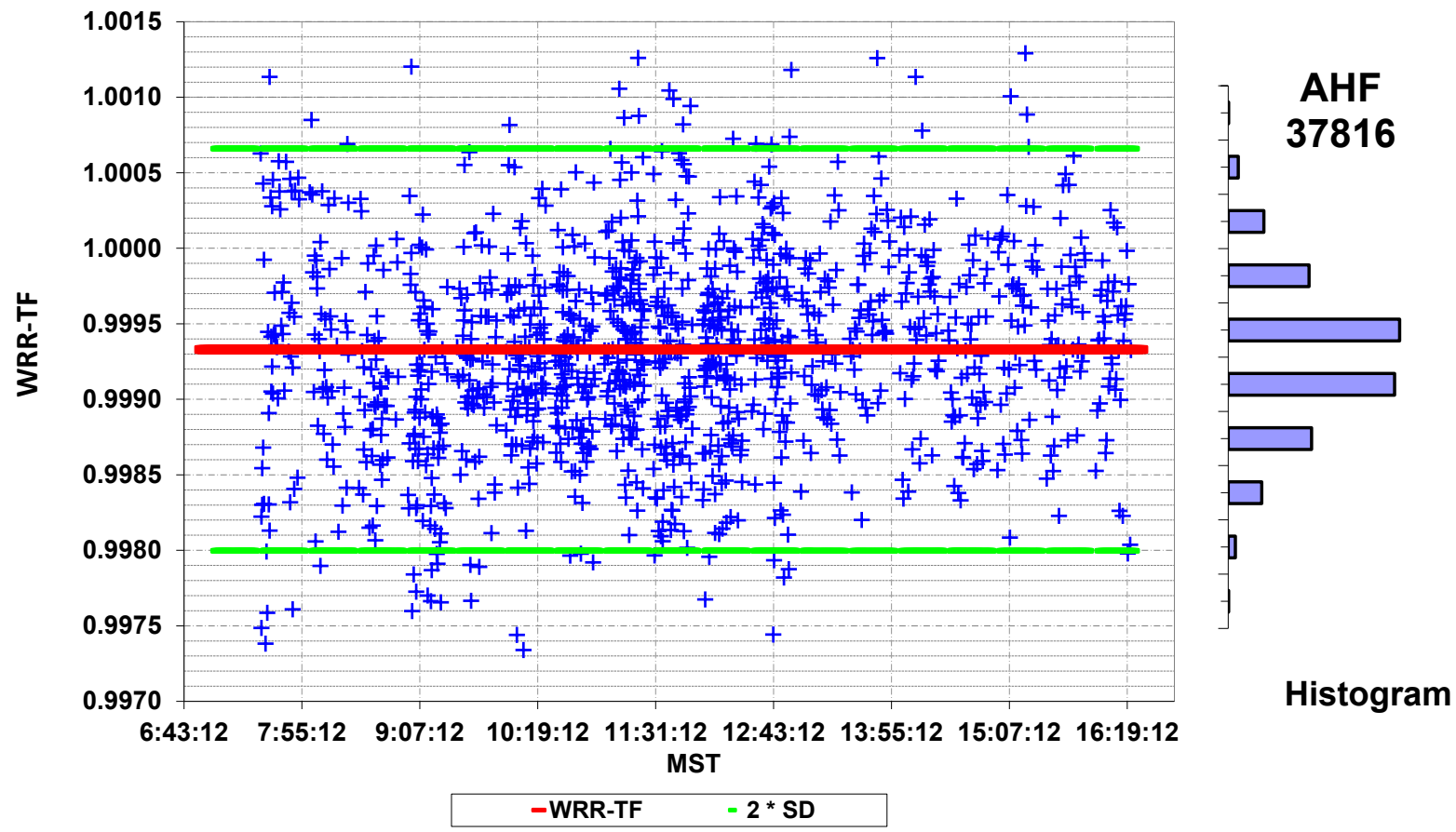

Figure 28. WRR-Transfer Factor vs. MST NPC-2018 for AHF 37816

WRR-Transfer Factor vs MST NPC-2018

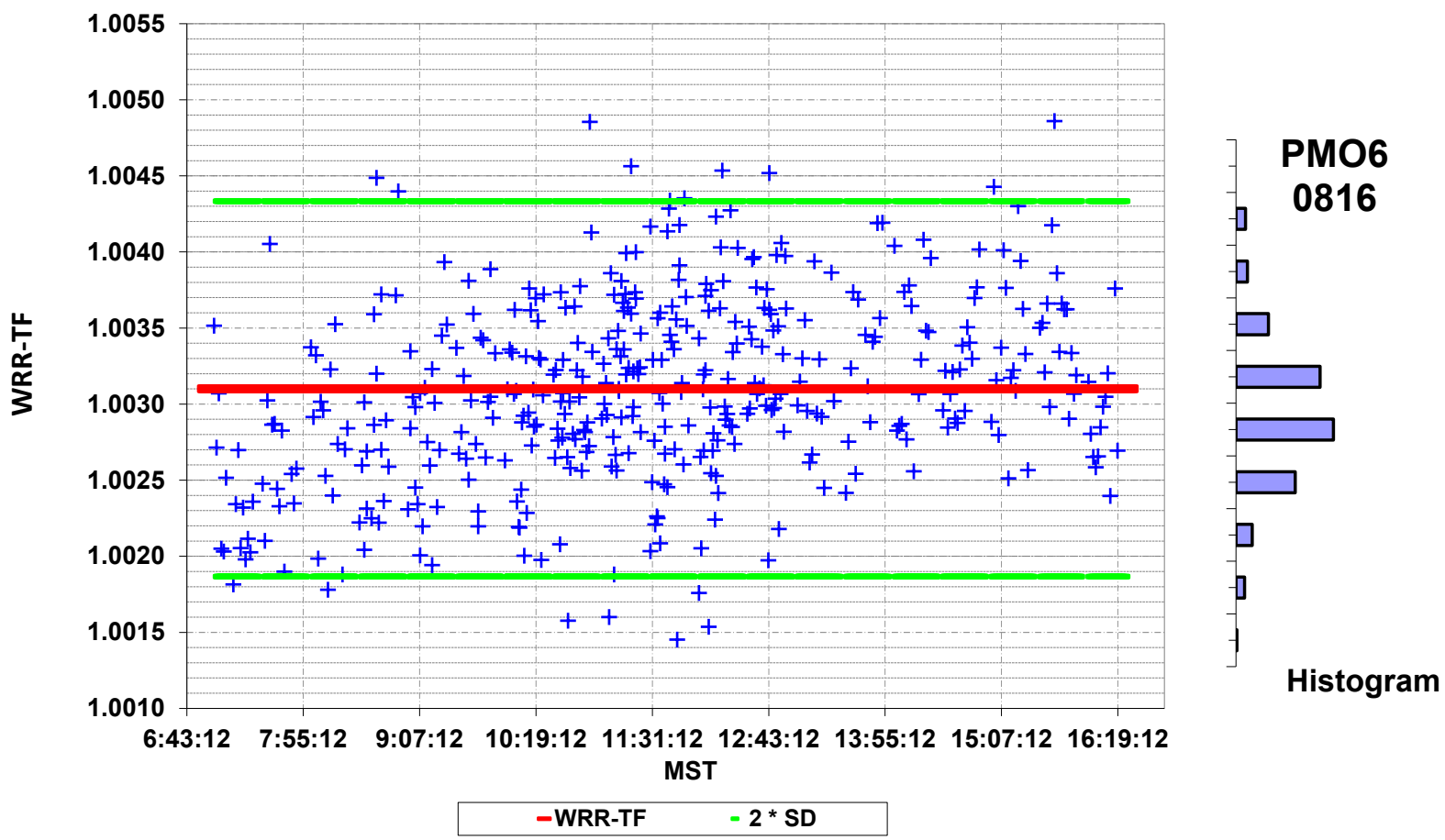

Figure 29. WRR-Transfer Factor vs. MST NPC-2018 for PMO6 0816 
WRR-Transfer Factor vs MST NPC-2018

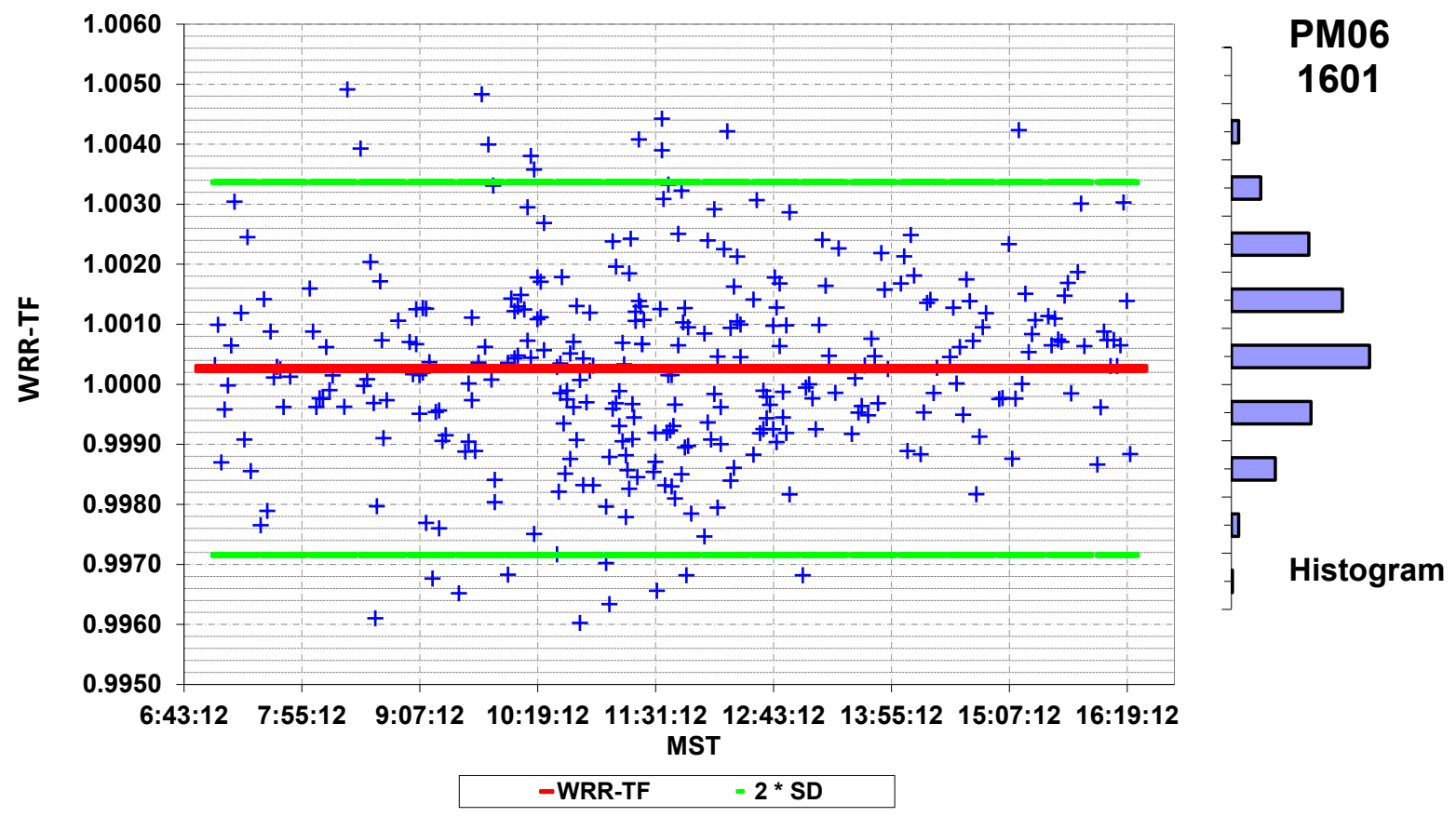

Figure 30. WRR-Transfer Factor vs. MST NPC-2018 for PMO6 1601

\section{WRR-Transfer Factor vs MST NPC-2018}

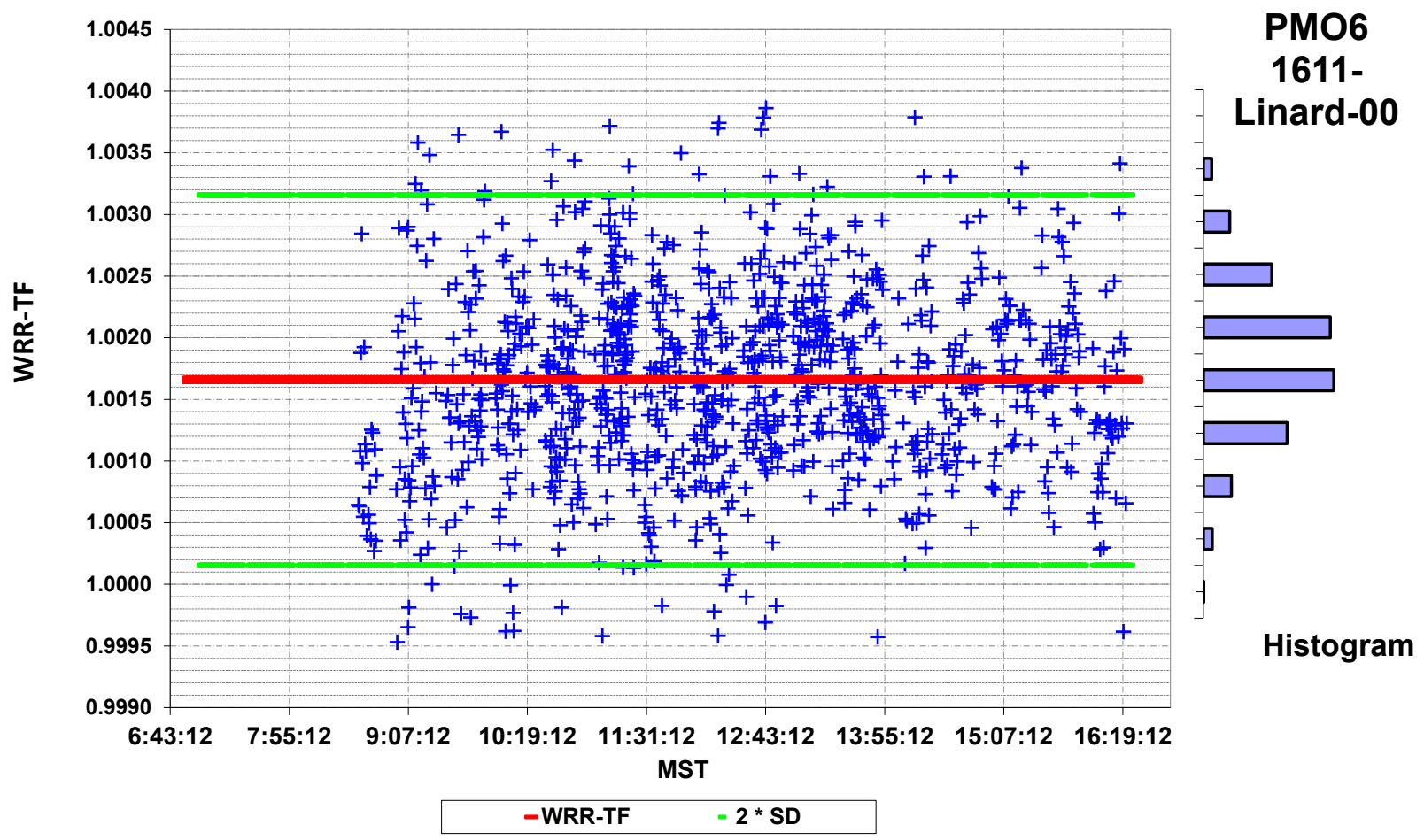

Figure 31. WRR-Transfer Factor vs. MST NPC-2018 for PMO6 1611-Linard-00 
WRR-Transfer Factor vs MST NPC-2018

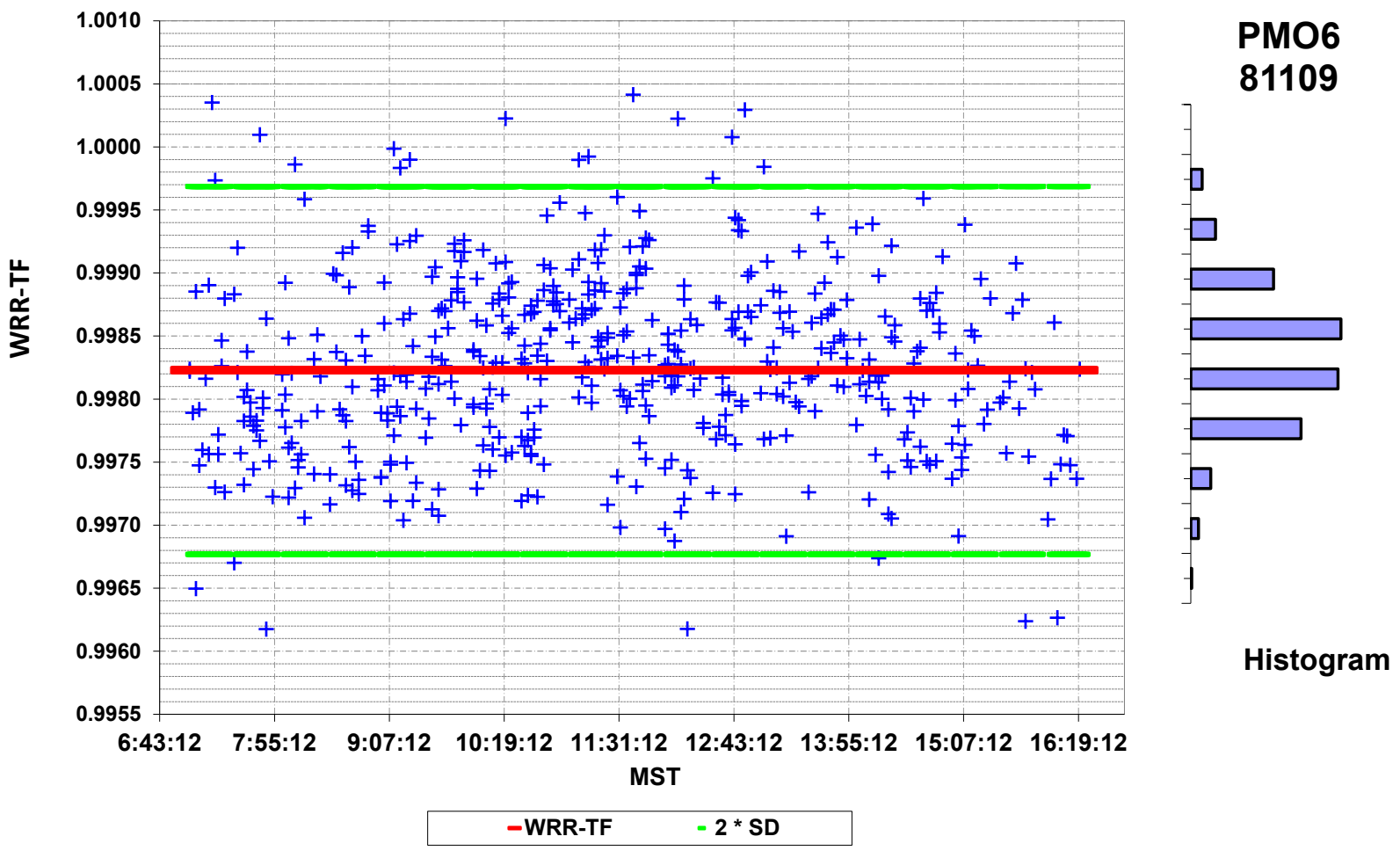

Figure 32. WRR-Transfer Factor vs. MST NPC-2018 for PMO6 81109

WRR-Transfer Factor vs MST NPC-2018

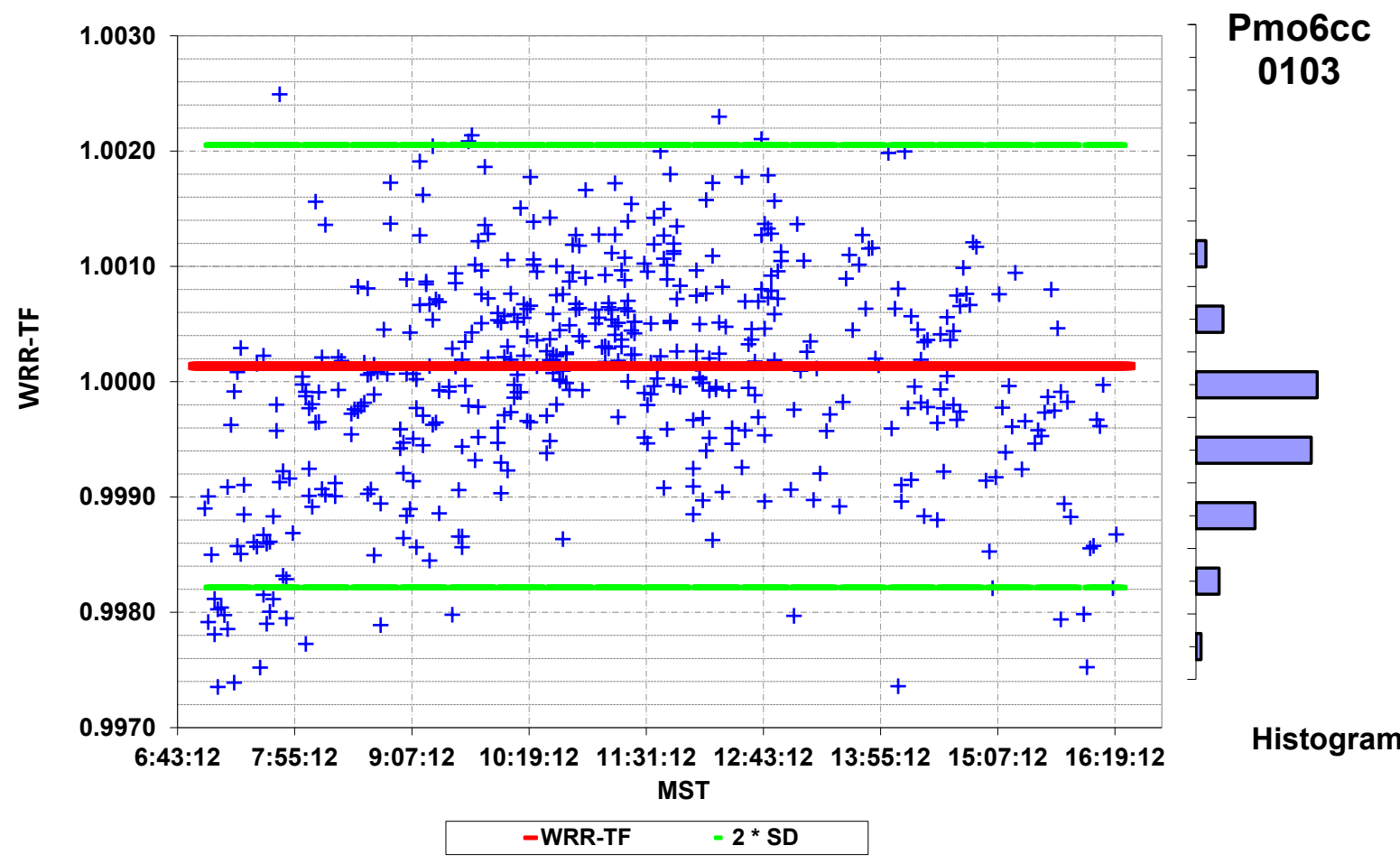

Figure 33. WRR-Transfer Factor vs. MST NPC-2018 for PMO6cc 0103 
WRR-Transfer Factor vs MST NPC-2018

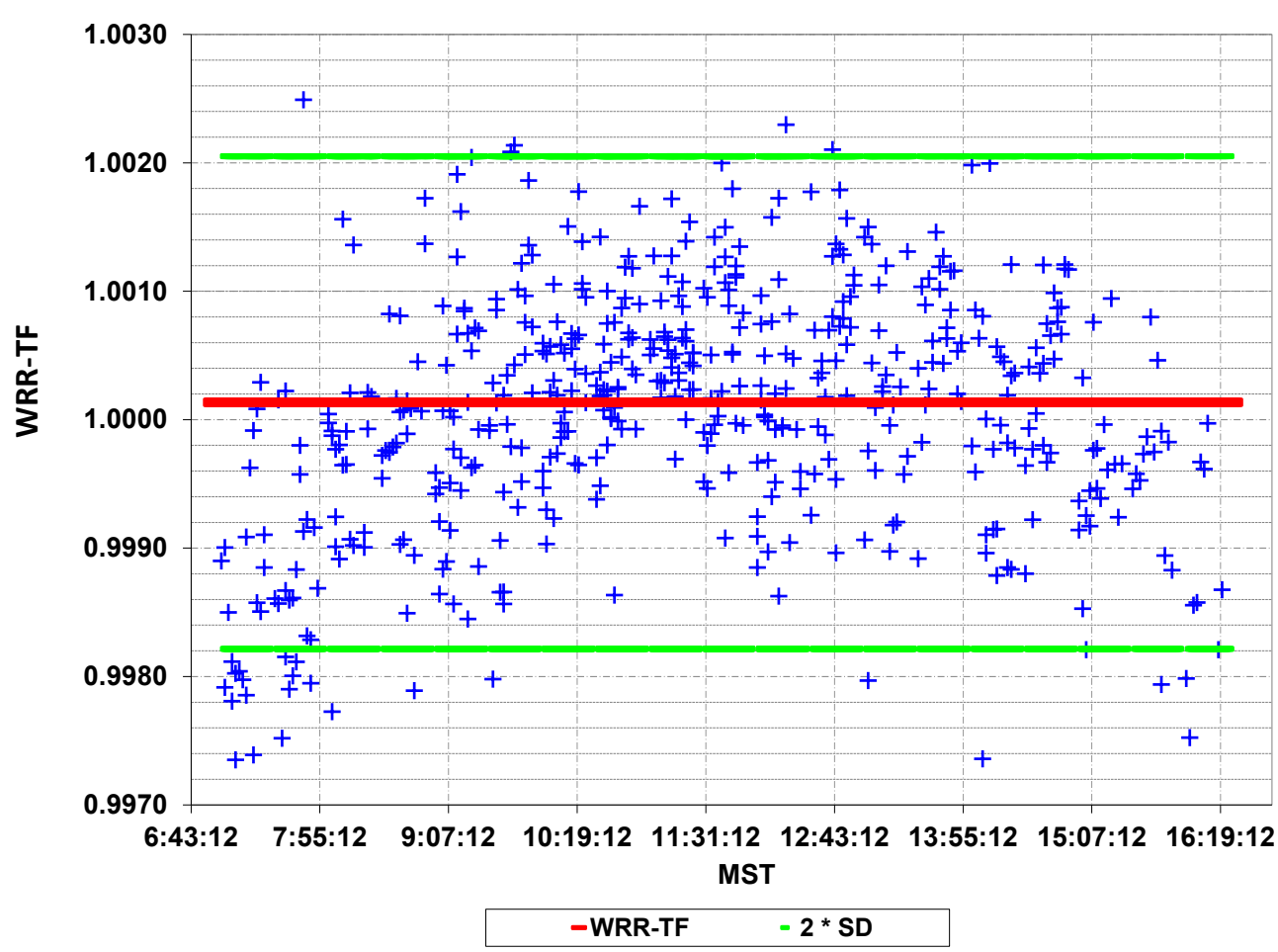

PMO6

911204

Figure 34. WRR-Transfer Factor vs. MST NPC-2018 for PMO6 911204

WRR-Transfer Factor vs MST NPC-2018

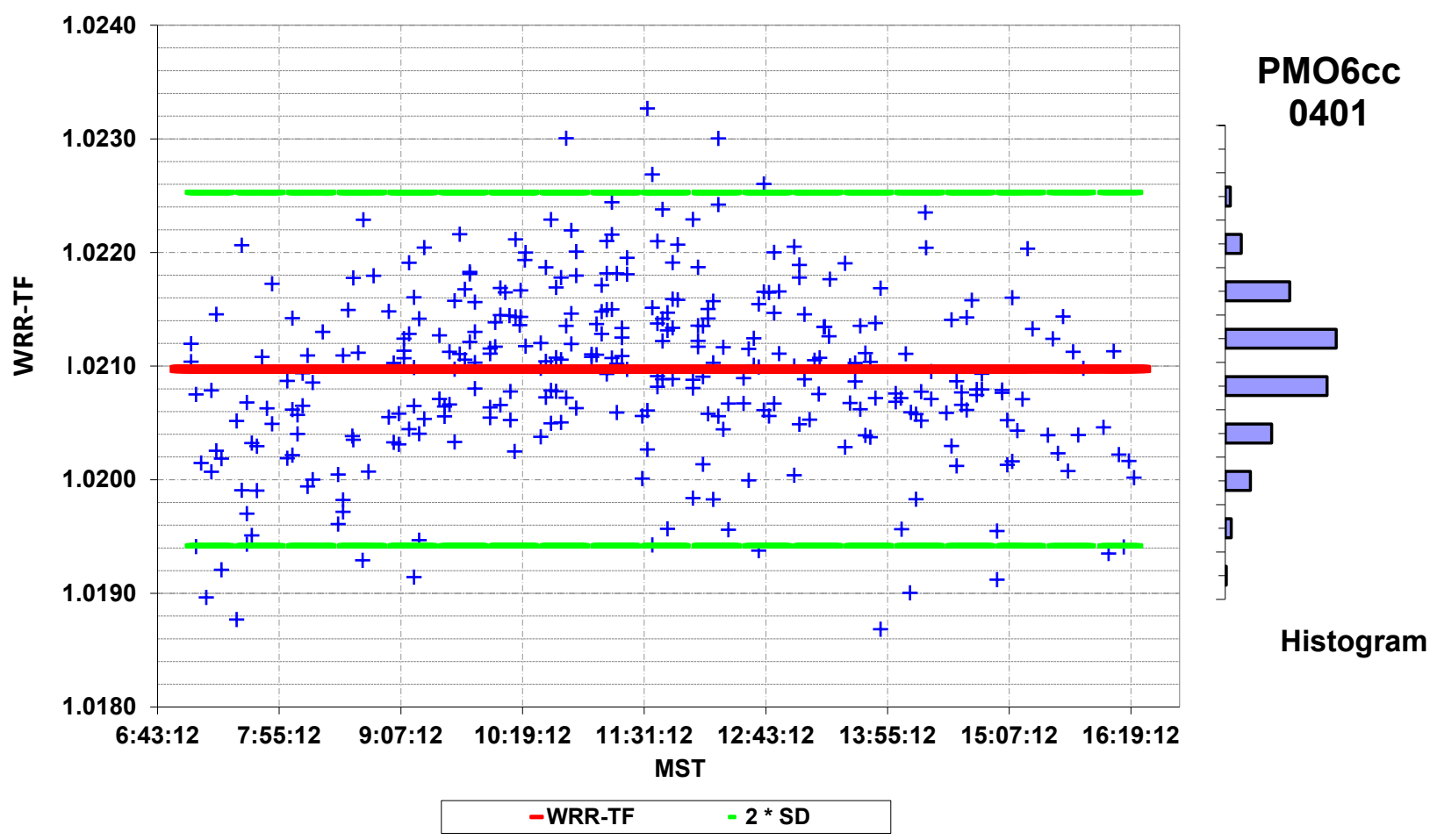

Figure 35. WRR-Transfer Factor vs. MST NPC-2018 for PMO6cc 0401 
WRR-Transfer Factor vs MST NPC-2018

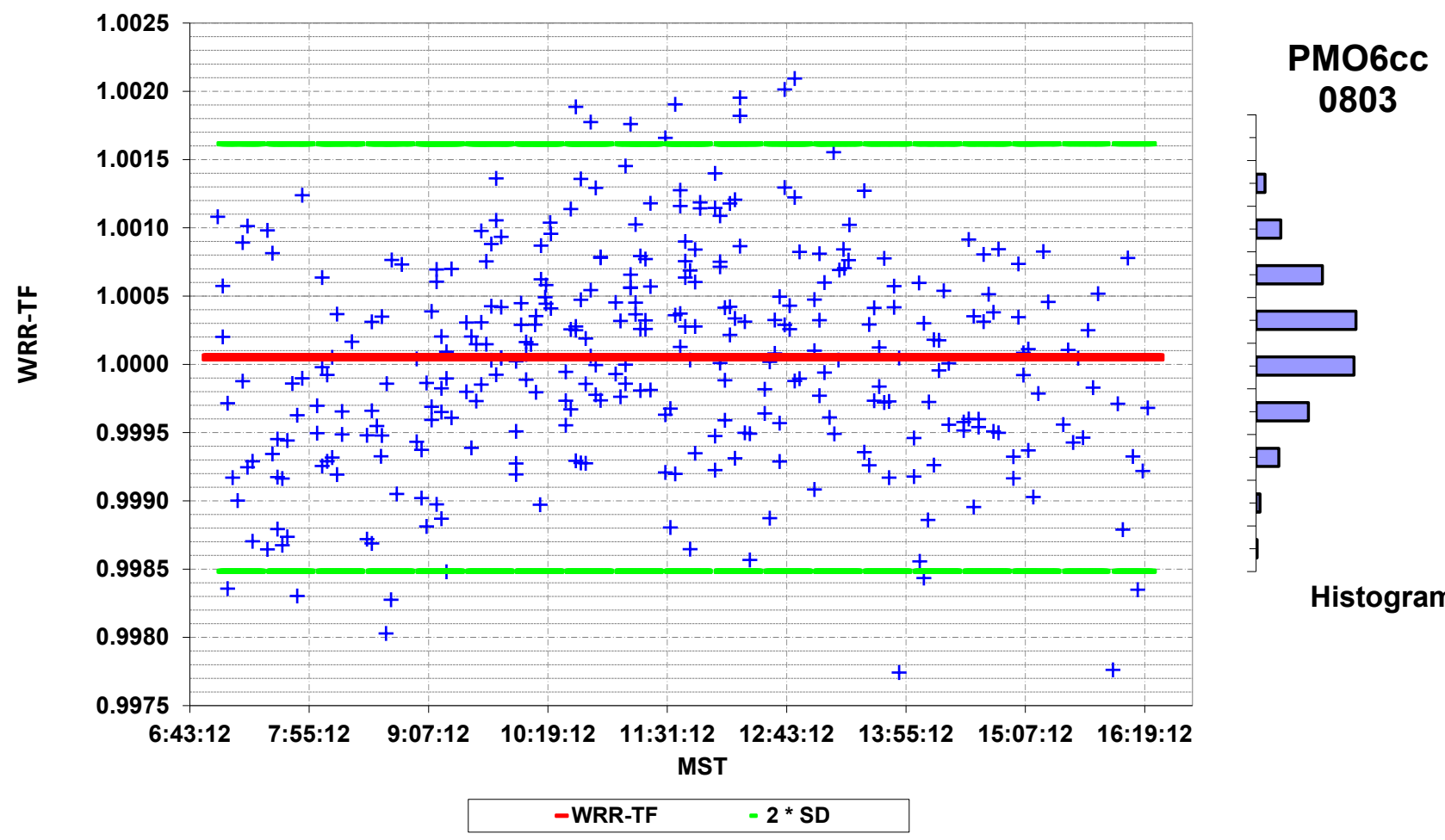

Figure 36. WRR-Transfer Factor vs. MST NPC-2018 for PMO6cc 0803

WRR-Transfer Factor vs MST NPC-2018

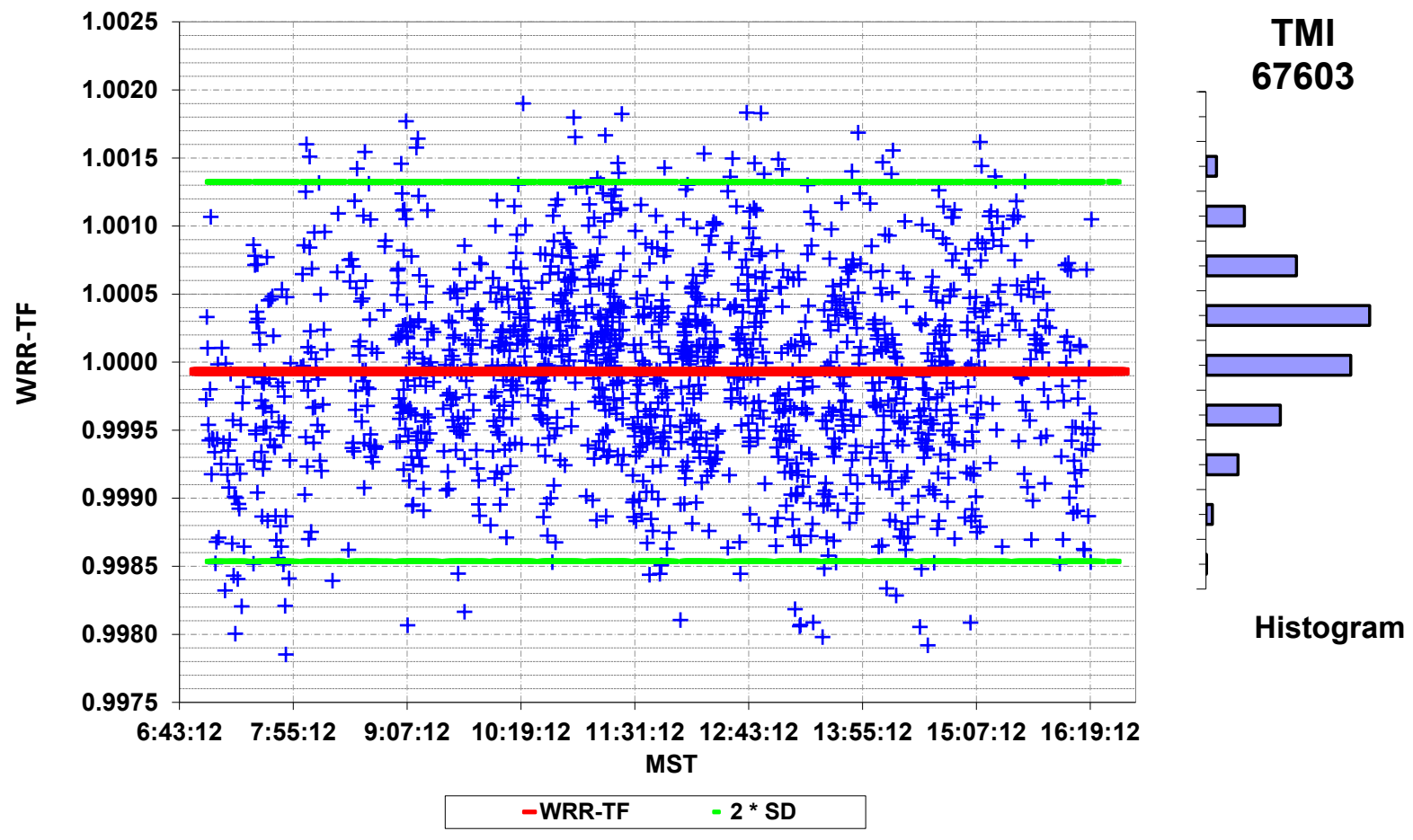

Figure 37. WRR-Transfer Factor vs. MST NPC-2018 for TMI 67603 
WRR-Transfer Factor vs MST NPC-2018

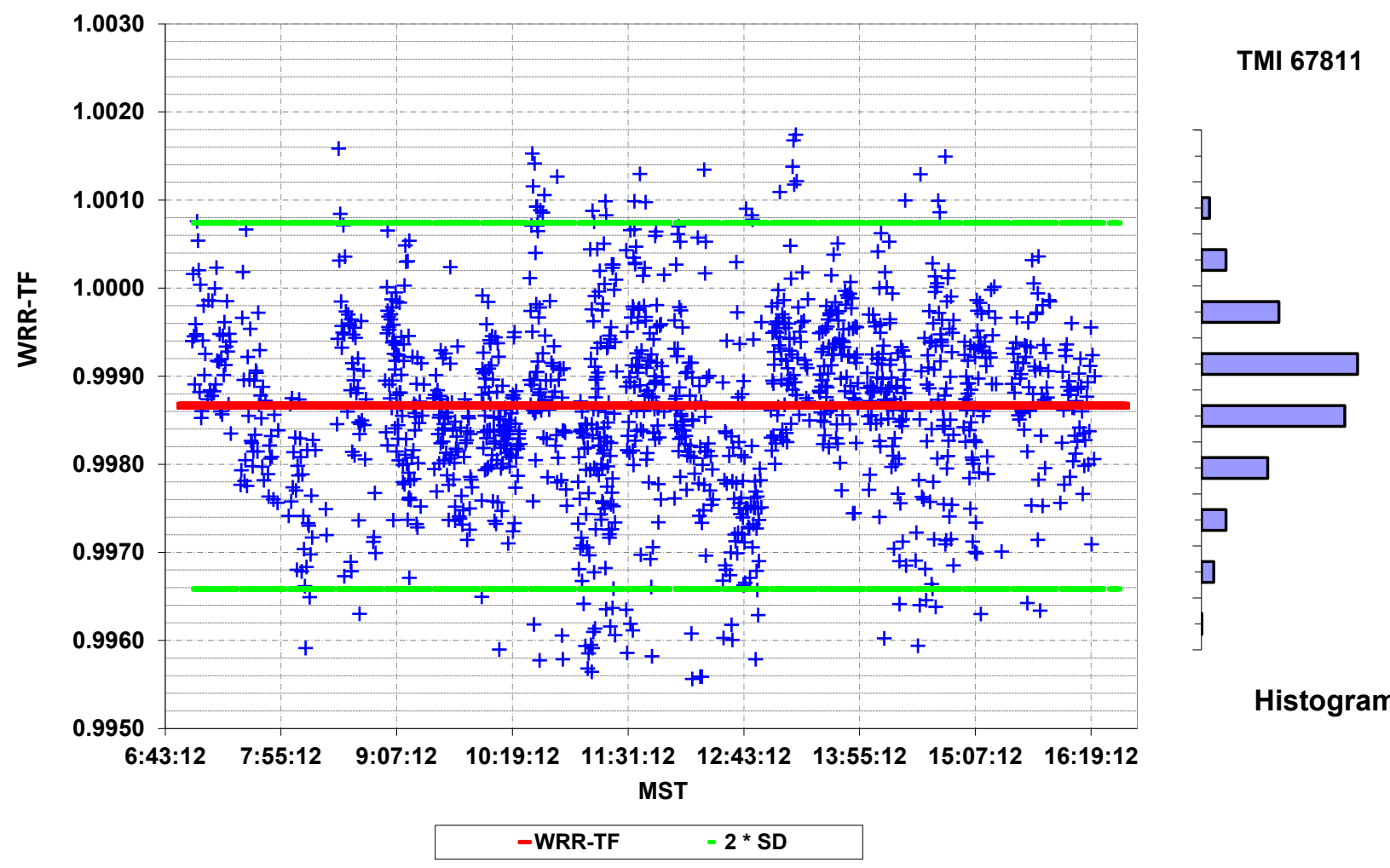

Figure 38. WRR-Transfer Factor vs. MST NPC-2018 for TMI 67811

\section{WRR-Transfer Factor vs MST NPC-2018}

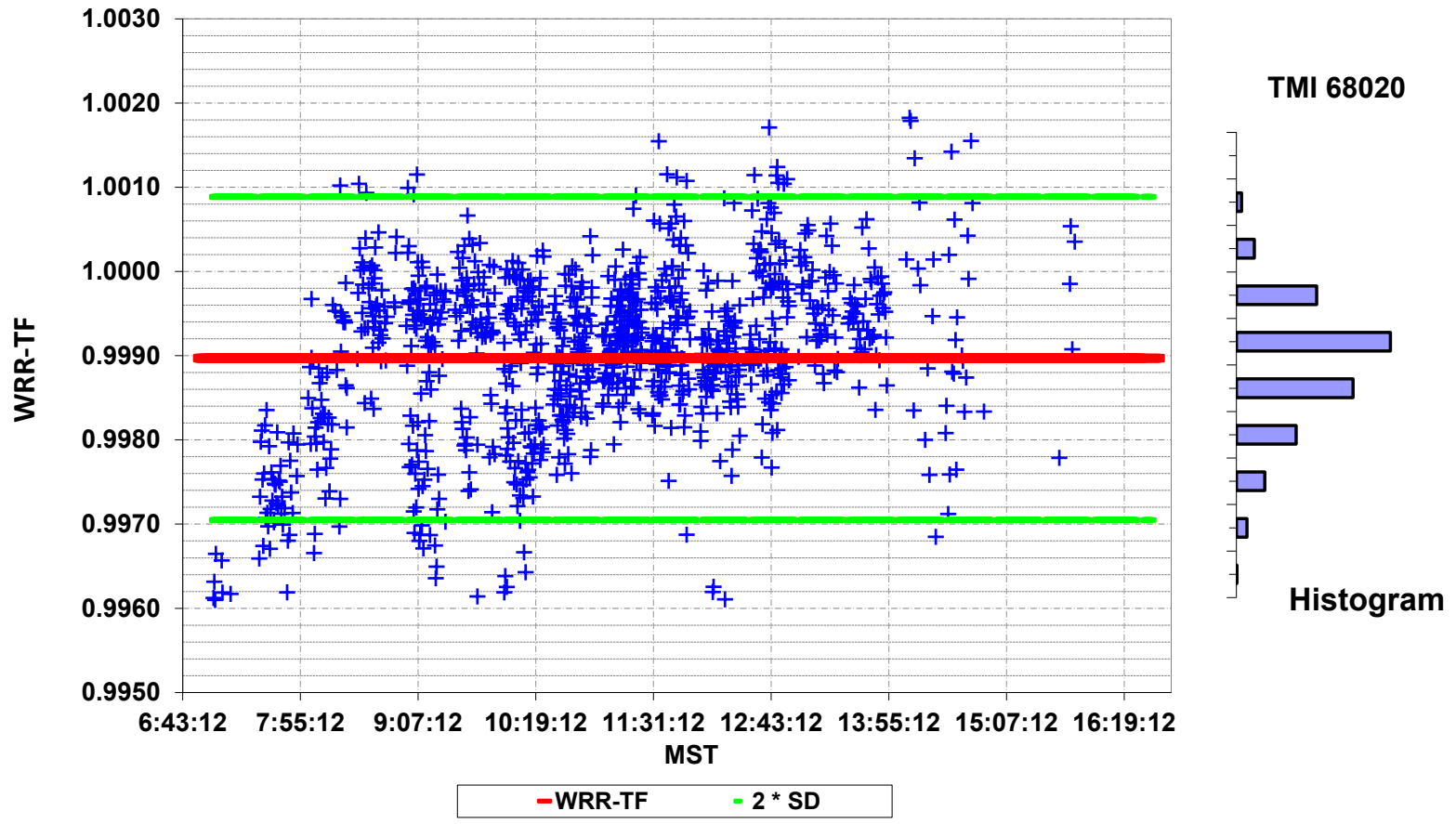

Figure 39. WRR-Transfer Factor vs. MST NPC-2018 for TMI 68020 
WRR-Transfer Factor vs MST NPC-2018

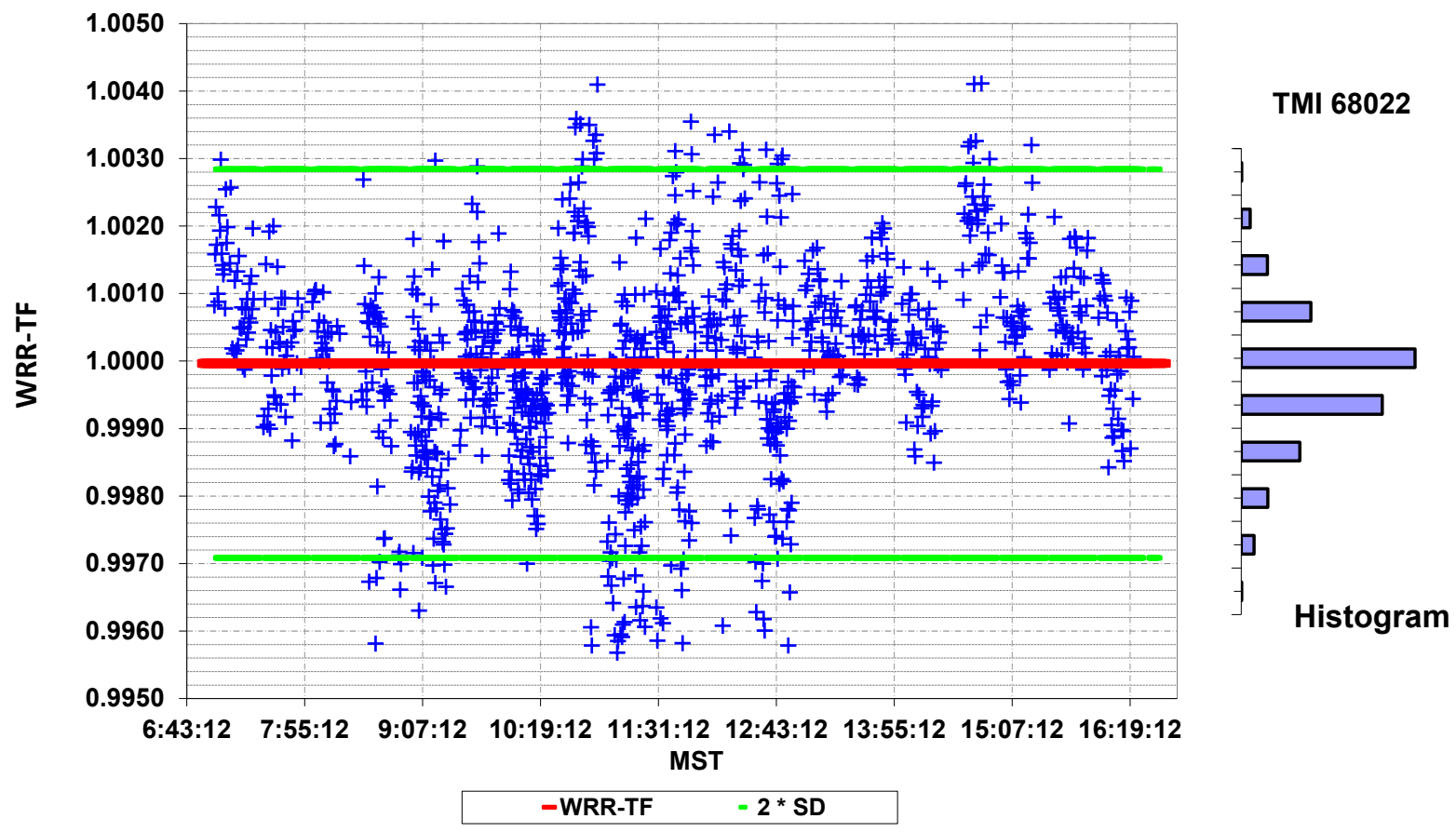

Figure 40. WRR-Transfer Factor vs. MST NPC-2018 for TMI 68022

WRR-Transfer Factor vs MST NPC-2018

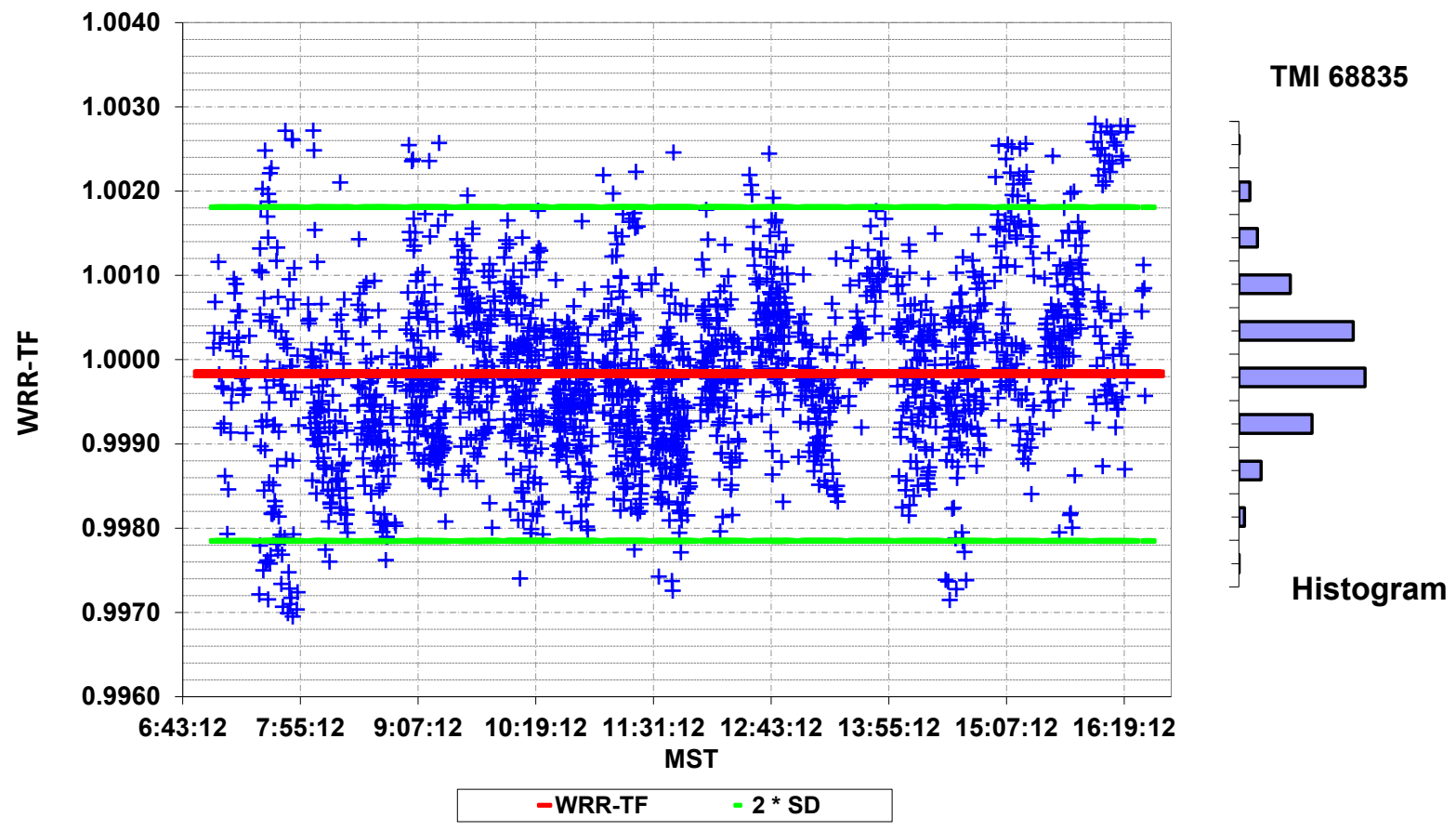

Figure 41. WRR-Transfer Factor vs. MST NPC-2018 for TMI 68835

\subsection{Recommendations}

As a result of these comparisons, it is suggested that participants observe the following measurement practices: 
- For the purpose of pyrheliometer comparisons, such as NPC-2018, it is recommended that the user apply only the manufacturer's calibration factor, not the WRR-TF or the new calibration factor, to report his or her absolute cavity radiometer's irradiance readings. This eliminates the possibility of compounding WRR factors from previous comparisons.

- For data collection in the field, the manufacturer's calibration factor should be used to calculate the cavity responsivity. Each irradiance reading should then be multiplied by the appropriate WRR-TF to provide homogeneity of solar radiation measurements that are traceable to the WRR. This approach is recommended to realize the benefits of participating in the NPC. 


\section{Ancillary Data}

The environmental conditions (i.e., temperature, relative humidity, barometric pressure, wind speed, precipitable water vapor, and spectral data) were measured during the comparisons using the meteorological station at SRRL. Additional information, including data and graphical summaries, can be found at the Measurements and Instrumentation Data Center: www.nrel.gov/midc/srrl bms.

Time-series plots and other graphical presentations of these data collected during the pyrheliometer comparisons are presented in Appendix B. 


\section{References}

Finsterle, W. (2018). WMO International Pyrheliometer Comparison, IPC-XII, 28 September - 16 October 2015: Final Report. WMO IOM Report No. 124. Davos, Switzerland; 98 pp.

Fröhlich, C. (1991). "History of Solar Radiometry and the World Radiometric Reference." Metrologia, (28:3); pp. 111-115.

Reda, I. (1996). Calibration of a Solar Absolute Cavity Radiometer with Traceability to the World Radiometric Reference. NREL/TP-463-20619. Golden, CO: The National Renewable Energy Laboratory. Accessed April 9, 2013: www.nrel.gov/docs/legosti/fy96/20619.pdf

Reda, I.; Myers, D.; Stoffel, T. (December 2008). "Uncertainty Estimate for the Outdoor Calibration of Solar Pyranometers: A Metrologist Perspective." Measure (NCSLI Journal of Measurement Science) (3:4); pp. 58-66. NREL/JA-581-41370.

Romero, J. (1995). Direct Solar Irradiance Measurements with Pyrheliometers: Instruments and Calibrations. IPC-VIII. Davos, Switzerland. 16 pp.

Romero, J.; Fox, N.P.; Fröhlich, C. (May 1996). "Improved Comparison of the World Radiometric Reference and the SI Radiometric Scale.” Metrologia (32:6); pp. 523-524.

WRC/PMOD (1996). International Pyrheliometer Comparison, IPC VIII, 25 September - 13 October 1995, Results and Symposium. Working Report No. 188. Davos Dorf, Switzerland: Swiss Meteorological Institute, Dorfstrasse 33, CH-7260; 115 pp. 


\section{Appendix A: List of Participants and Pyrheliometers}

\begin{tabular}{|c|c|c|c|}
\hline $\mathbf{S} / \mathbf{N}$ & Operator 1 & Operator 2 & Affiliation \\
\hline AHF 29223 & Adriana Gonzalez & & UNAM \\
\hline AHF 23734 & Afshin Andreas & Mike Dooraghi & $\begin{array}{l}\text { National Renewable Energy } \\
\text { Laboratory (NREL) } \\
\text { (Metrology, SePA, and Cell } \\
\text { \& Module Certification } \\
\text { Group) }\end{array}$ \\
\hline AHF 29219-Window & Afshin Andreas & Mike Dooraghi & $\begin{array}{l}\text { NREL } \\
\text { (Metrology, SePA, and Cell } \\
\text { \& Module Certification } \\
\text { Group) }\end{array}$ \\
\hline AHF 31104-Window & Afshin Andreas & Mike Dooraghi & $\begin{array}{l}\text { NREL } \\
\text { (Metrology, SePA, and Cell } \\
\text { \& Module Certification } \\
\text { Group) }\end{array}$ \\
\hline AHF 32452AWX-Window & Afshin Andreas & Mike Dooraghi & $\begin{array}{l}\text { NREL } \\
\text { (Metrology, SePA, and Cell } \\
\text { \& Module Certification } \\
\text { Group) }\end{array}$ \\
\hline PM06 1601 & Ajay Singh & Matt Perry & Campbell Scientific Inc. \\
\hline PMO6 0816 & Akiyama Akihito & Will Beuttell & EKO Instruments \\
\hline AHF 33392 & Anthony Bucholtz & & Naval Research Laboratory \\
\hline AHF 31108 & Bill Boyson & Charles Robinson & $\begin{array}{l}\text { Sandia National } \\
\text { Laboratories } \\
\text { (Photovoltaic Systems } \\
\text { Evaluation Lab) }\end{array}$ \\
\hline TMI 67603 & Bill Boyson & Charles Robinson & $\begin{array}{l}\text { Sandia National } \\
\text { Laboratories } \\
\text { (Photovoltaic Systems } \\
\text { Evaluation Lab) }\end{array}$ \\
\hline AHF 32455 & Christian Thomann & & PMOD/WRC \\
\hline PMO6cc 0401 & Christian Thomann & & PMOD/WRC \\
\hline PMO6cc 0803 & Christian Thomann & & PMOD/WRC \\
\hline AHF 29222-Window & Craig Webb & & $\begin{array}{l}\text { DOE Atmospheric } \\
\text { Radiation Measurement } \\
\text { (ARM) Program }\end{array}$ \\
\hline AHF 30495-Window & Craig Webb & & $\begin{array}{l}\text { DOE Atmospheric } \\
\text { Radiation Measurement } \\
\text { (ARM) Program }\end{array}$ \\
\hline AHF 28553 & Emiel Hall & Jim Wendell & NOAA/ESRL/GMD \\
\hline $\begin{array}{l}\text { S/N } \\
\text { AHF 31113AWX-Window }\end{array}$ & $\begin{array}{l}\text { Operator } 1 \\
\text { Emiel Hall }\end{array}$ & $\begin{array}{l}\text { Operator } 2 \\
\text { Jim Wendell }\end{array}$ & $\begin{array}{l}\text { Affiliation } \\
\text { NOAA/ESRL/GMD }\end{array}$ \\
\hline
\end{tabular}




\begin{tabular}{|c|c|c|c|}
\hline AHF 31114AWX & Emiel Hall & Jim Wendell & NOAA/ESRL/GMD \\
\hline AHF 32448AWX & Emiel Hall & Jim Wendell & NOAA/ESRL/GMD \\
\hline AHF 28560 & Erik Naranen & & $\begin{array}{l}\text { ISO-CAL North America, } \\
\text { LLC }\end{array}$ \\
\hline AHF 37816 & Erik Naranen & & $\begin{array}{l}\text { ISO-CAL North America, } \\
\text { LLC }\end{array}$ \\
\hline AHF 31041 & Fred Denn & & $\begin{array}{l}\text { Science Systems \& } \\
\text { Applications, Inc. }\end{array}$ \\
\hline AHF 31105 & Fred Denn & & $\begin{array}{l}\text { Science Systems \& } \\
\text { Applications, Inc. }\end{array}$ \\
\hline AHF28968 & Ibrahim Reda & Mike Dooraghi & $\begin{array}{l}\text { NREL } \\
\text { (Metrology and SePA) }\end{array}$ \\
\hline AHF29220 & Ibrahim Reda & Mike Dooraghi & $\begin{array}{l}\text { NREL } \\
\text { (Metrology and SePA) }\end{array}$ \\
\hline AHF30713 & Ibrahim Reda & Mike Dooraghi & $\begin{array}{l}\text { NREL } \\
\text { (Metrology and SePA) }\end{array}$ \\
\hline TMI68018 & Ibrahim Reda & Mike Dooraghi & $\begin{array}{l}\text { NREL } \\
\text { (Metrology and SePA) }\end{array}$ \\
\hline TMI 68020 & Jim Goza & Gian Mazzadi-Smith & Lockheed Martin \\
\hline AHF 28486 & Jose Balenzategui & & CIEMAT \\
\hline AHF 34926AWX & Josh Peterson & & SRML University of Oregon \\
\hline PMO6 1611-Linard-00 & Markus Suter & & Davos Instruments \\
\hline AFH 30110 & Mohammed Al Harbi & & $\begin{array}{l}\text { King Abdullah City for } \\
\text { Atomic and Renewable } \\
\text { Energy (KACARE) }\end{array}$ \\
\hline AHF 31107 & Mohammed Al Harbi & & $\begin{array}{l}\text { King Abdullah City for } \\
\text { Atomic and Renewable } \\
\text { Energy (KACARE) }\end{array}$ \\
\hline AHF 17142 & Patrick Smith & & $\begin{array}{l}\text { Atlas Material Testing } \\
\text { Technology, LLC }\end{array}$ \\
\hline AHF 28556 & Patrick Smith & & $\begin{array}{l}\text { Atlas Material Testing } \\
\text { Technology, LLC }\end{array}$ \\
\hline TMI 67811 & Tim Moss & Alan Nelson & $\begin{array}{l}\text { Sandia National Labs } \\
\text { (Concentrating Solar } \\
\text { Energy) }\end{array}$ \\
\hline
\end{tabular}




\begin{tabular}{|c|c|c|c|}
\hline $\begin{array}{l}\text { S/N } \\
\text { TMI } 68022\end{array}$ & $\begin{array}{l}\text { Operator } 1 \\
\text { Tim Moss }\end{array}$ & $\begin{array}{l}\text { Operator } 2 \\
\text { Alan Nelson }\end{array}$ & $\begin{array}{l}\text { Affiliation } \\
\text { Sandia National Labs } \\
\text { (Concentrating Solar } \\
\text { Energy) }\end{array}$ \\
\hline AHF 14915 & Tom Kirk & & EPPLEY LAB \\
\hline Pmo6cc 0103 & Victor Cassella & Joop Mes & Kipp \& Zonen USA, Inc \\
\hline AHF 0000 & Wim Zaaiman & & $\begin{array}{l}\text { European Commission } \\
\text { Directorate General JRC }\end{array}$ \\
\hline PMO6 81109 & Wim Zaaiman & & $\begin{array}{l}\text { European Commission } \\
\text { Directorate General JRC }\end{array}$ \\
\hline PMO6 911204 & Wim Zaaiman & & $\begin{array}{l}\text { European Commission } \\
\text { Directorate General JRC }\end{array}$ \\
\hline TMI 68835 & Wim Zaaiman & & $\begin{array}{l}\text { European Commission } \\
\text { Directorate General JRC }\end{array}$ \\
\hline
\end{tabular}




\section{Appendix B: Ancillary Data Summaries}

The measurement performance of an absolute cavity can be affected by several environmental parameters. Potentially relevant meteorological data collected during the NPC are presented in this appendix. The BMS has been in continuous operation at the SRRL since 1981. BMS data are recorded as 1-minute averages of 3-second samples for each instrument. (Additional information about SRRL and the BMS can be found at the Measurement and Instrumentation Data Center: http://www.nrel.gov/midc/srrl bms/).

Time-series plots and other graphical presentations of these data acquired during the NPC-2018 measurements are presented here. 

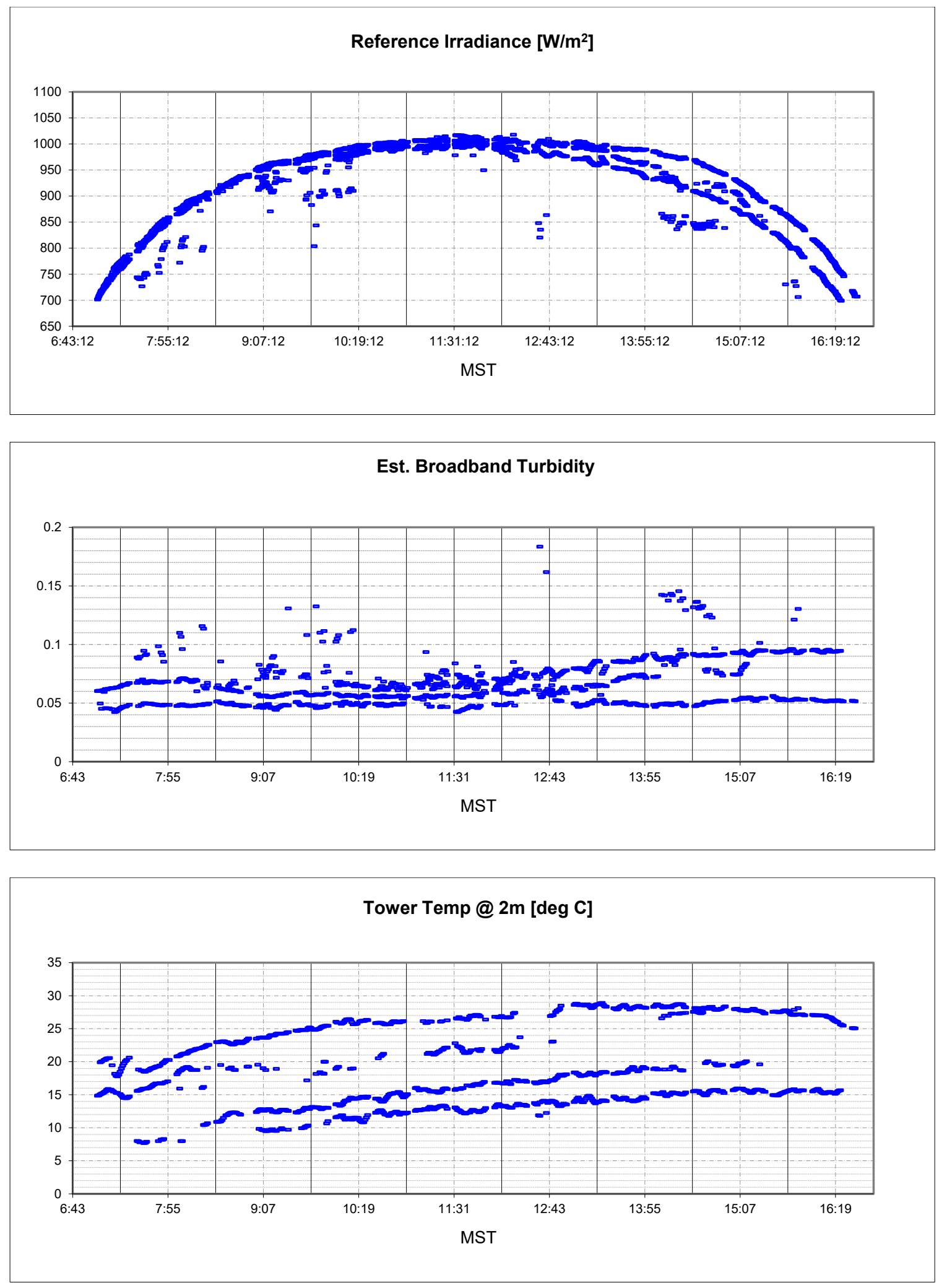
Tower RH @ 2m [\%]
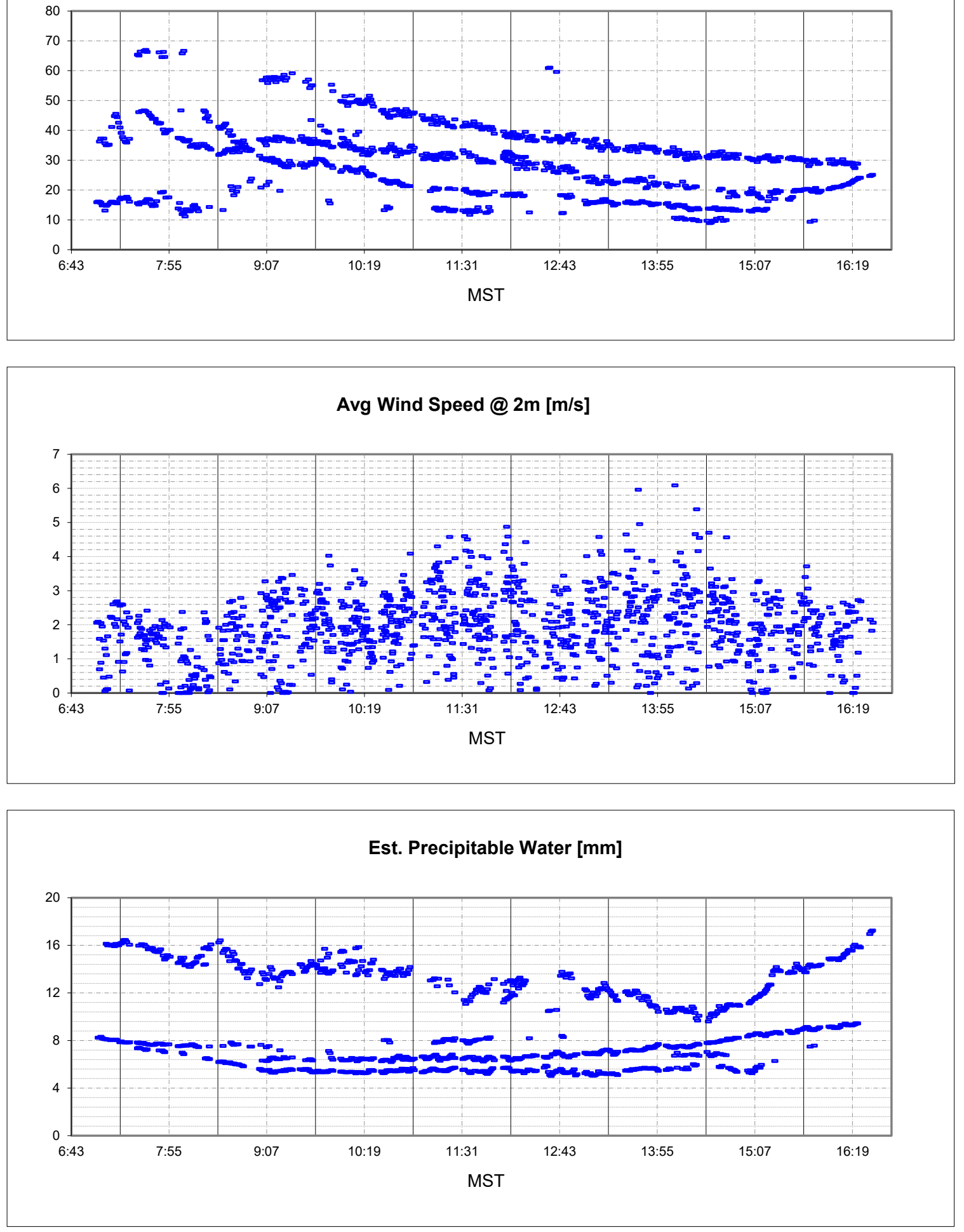

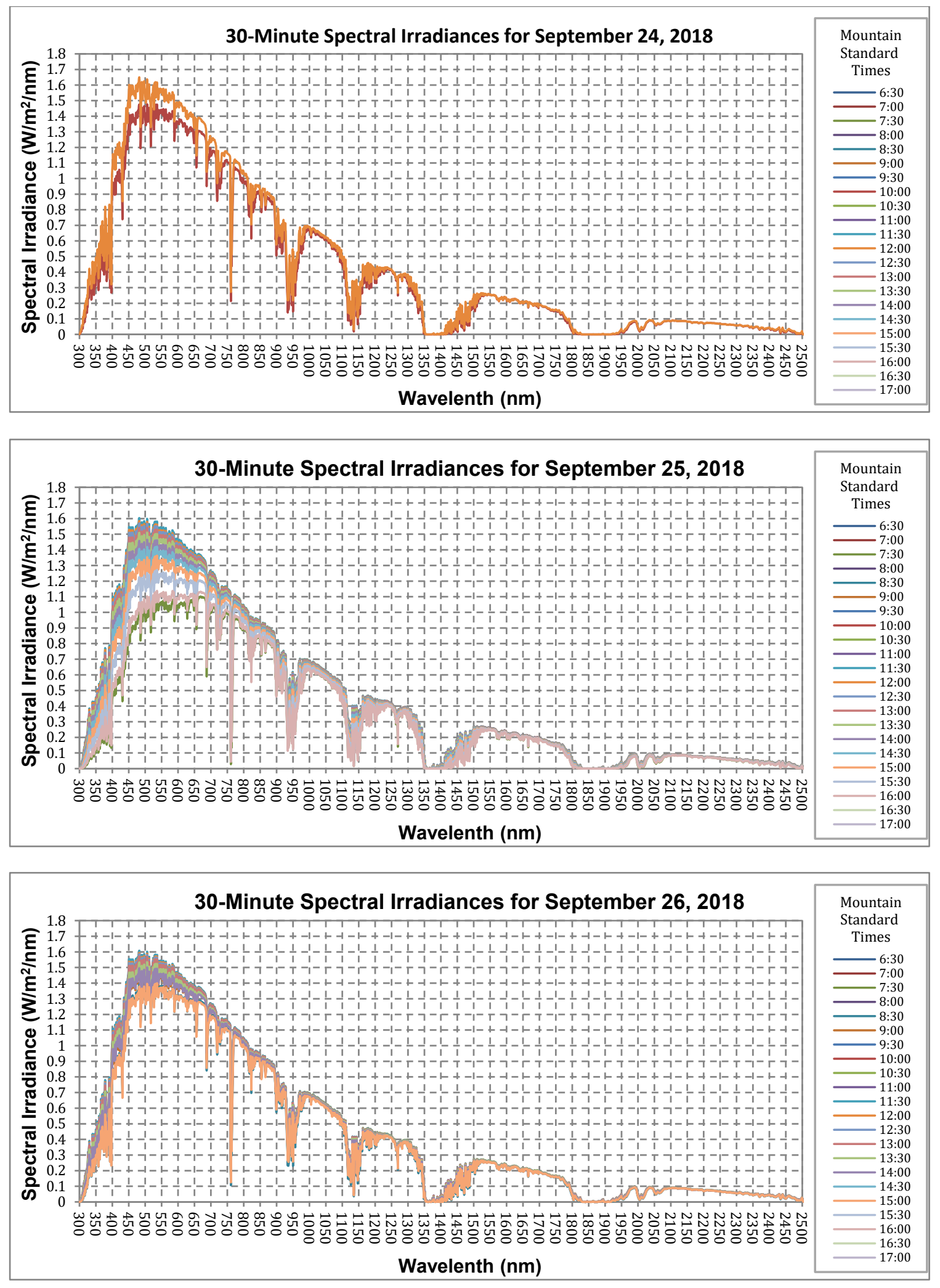

This report is available at no cost from the National Renewable Energy Laboratory (NREL) at www.nrel.gov/publications. 

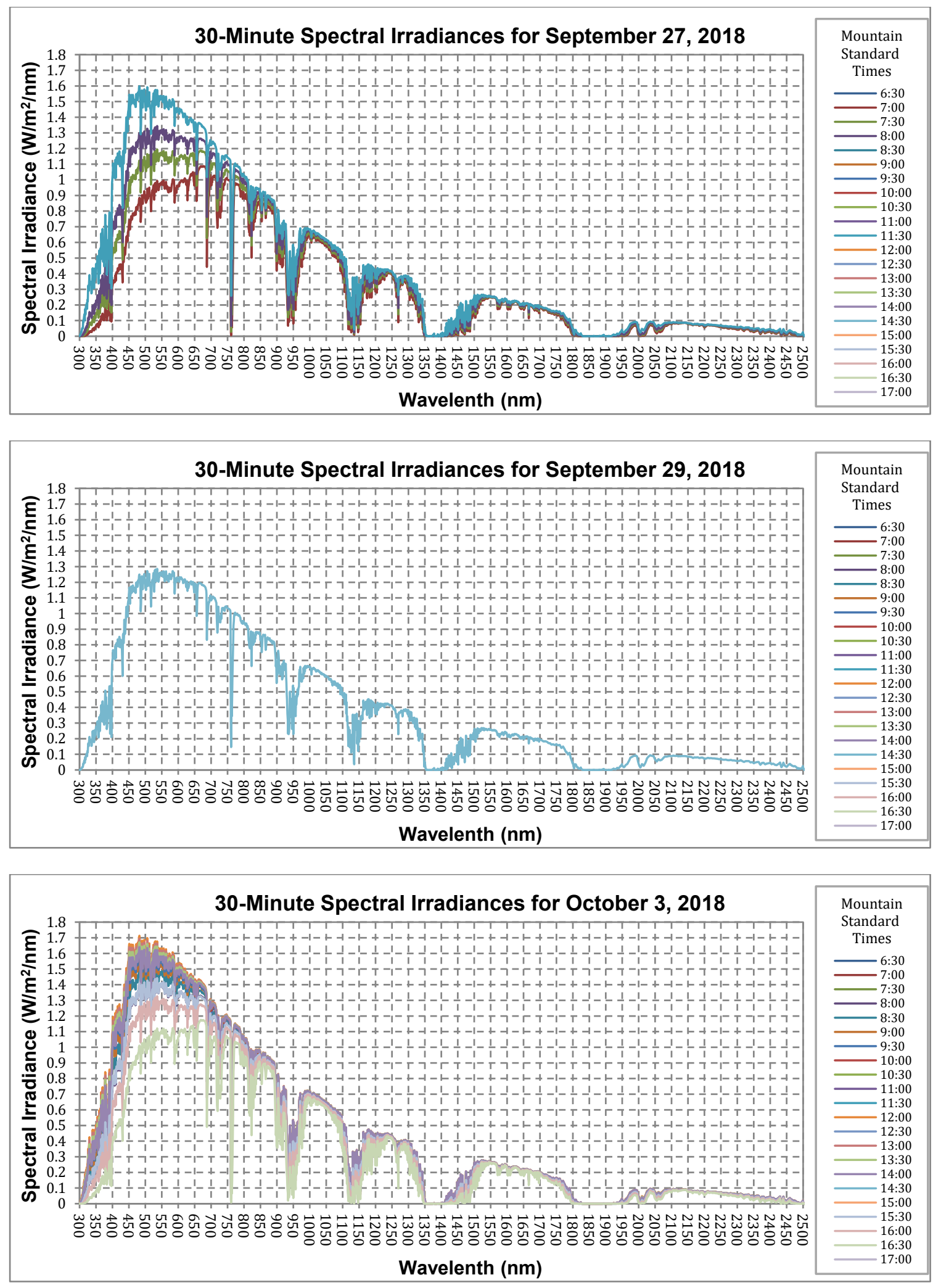

This report is available at no cost from the National Renewable Energy Laboratory (NREL) at www.nrel.gov/publications. 